Aus dem Department für Nutztierwissenschaften

- Abteilung Produktionssysteme der Nutztiere der Georg-August-Universität Göttingen

Fakultät für Agrarwissenschaften

\title{
Untersuchungen zum Einfluss melktechnischer Parameter auf die Zitzenkondition von Milchkühen
}

\author{
Dissertation \\ zur Erlangung des Doktorgrades \\ der Fakultät für Agrarwissenschaften \\ der Georg-August-Universität Göttingen
}

vorgelegt von

Michael Hubal

geboren in Bremen

Göttingen, Dezember 2010 
D 7

Referent:

Prof. Dr. Dr. M. Gauly

Korreferent:

Prof. Dr. D. Ordolff

Tag der mündlichen Prüfung:

17. Februar 2011 


\section{Inhaltsverzeichnis}

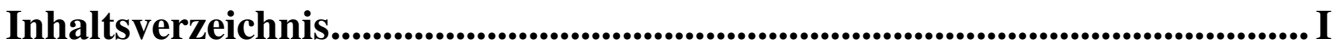

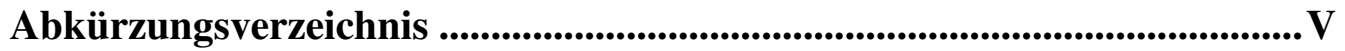

Tabellenverzeichnis.................................................................................. VIII

Abbildungsverzeichnis........................................................................................

1. Einleitung und Zielsetzung .............................................................

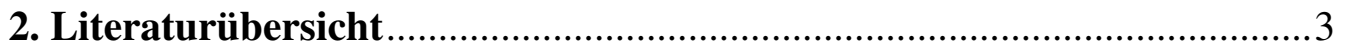

2.1 Zitzenkondition und Zitzenkonditionsstörungen ............................... 3

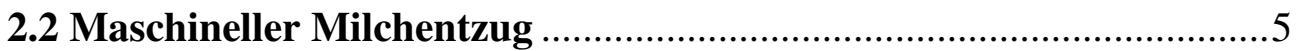

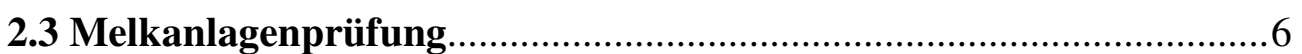

2.4 Melktechnische Parameter ................................................................ 9

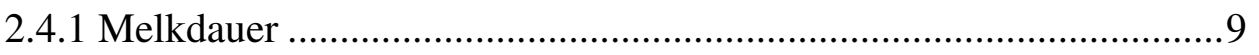

2.4.2 Blindmelken und Abnahmeschwelle ..............................................9

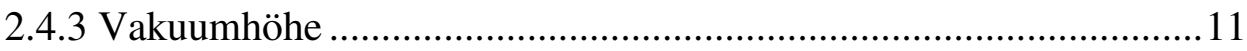

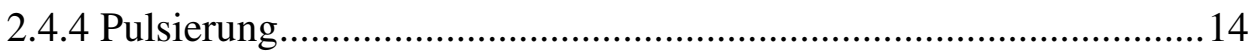

2.4.5 Überdruckapplikation.................................................................. 17

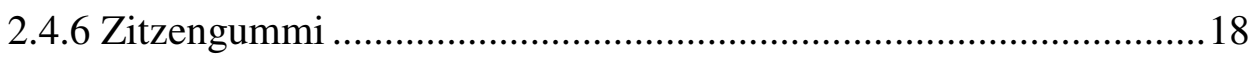

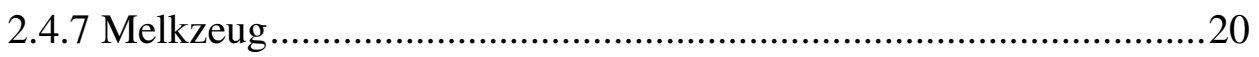

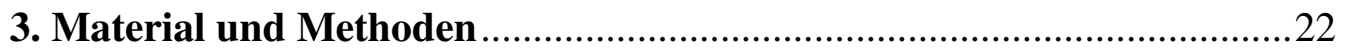

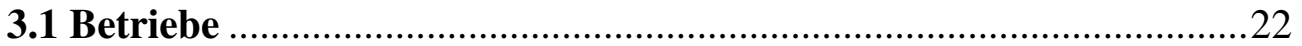

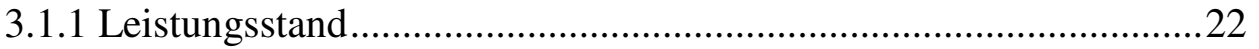

3.1.2 Technischer Zustand der Melkanlagen ...........................................22

3.1.3 Melktechnik der Betriebe ..............................................................23

3.1.4 Melkarbeit in den Betrieben.......................................................26

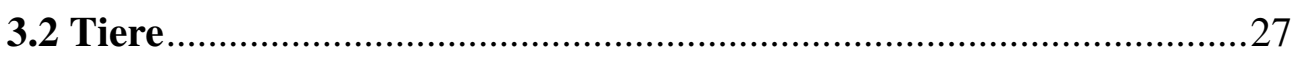

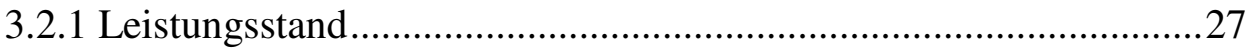

3.2.2 Laktationszahl und Laktationstag ..............................................22

3.2.3 Eutergesundheitszustand der ausgewählten Tiere.........................27 


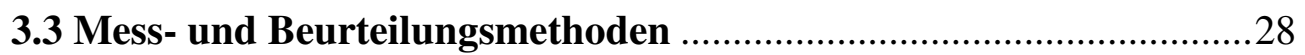

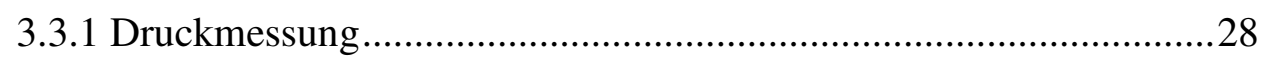

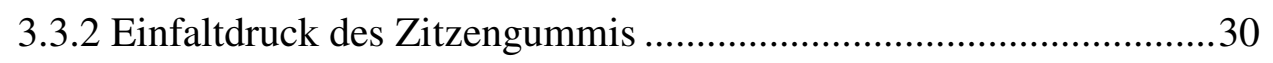

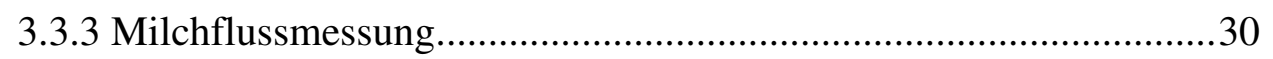

3.3.4 Zitzengewebefestigkeit (Zitzendicke) ..........................................31

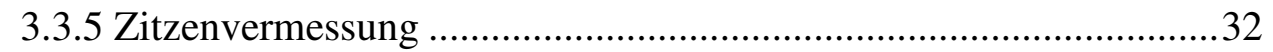

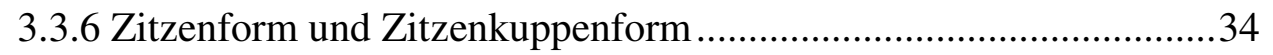

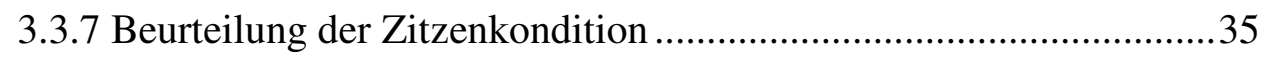

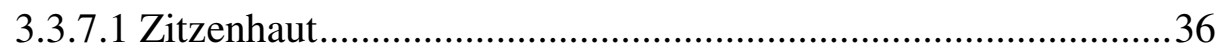

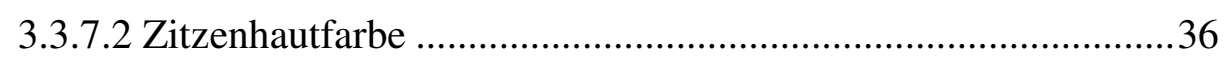

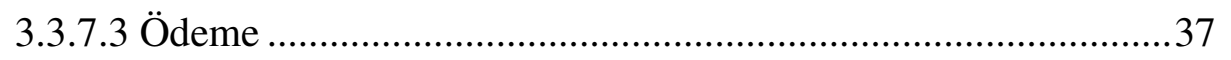

3.3.7.4 Hyperkeratosen ................................................................ 38

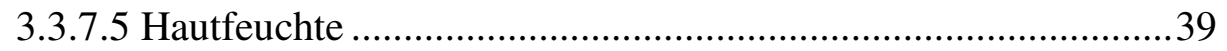

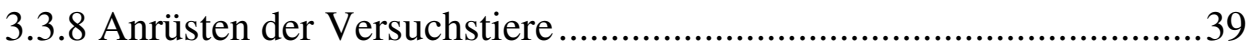

3.3.9 Bestimmung des Ausmelkgrades ..................................................39

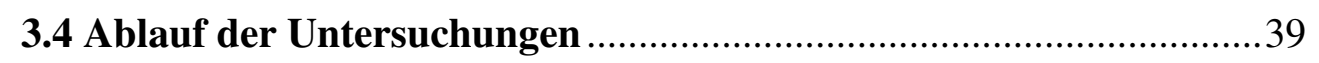

3.5 Mathematisch-statistische Auswertung der

Untersuchungsergebnisse ..........................................................4 41

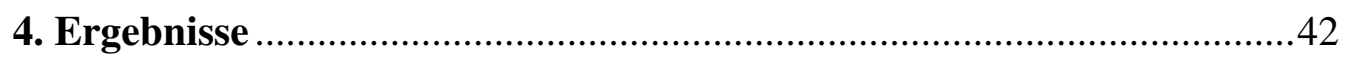

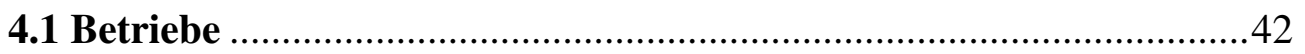

4.1.1 Fabrikate und Melkzeuge ...........................................................42

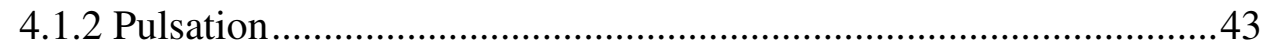

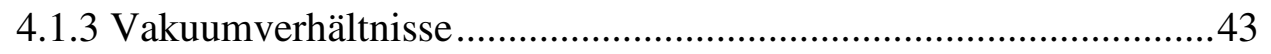

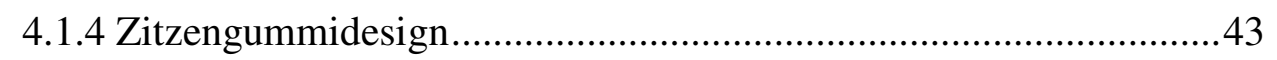

4.2 Tiere

4.2.1 Eutergesundheit und Leistung....................................................45

4.2.2 Milchflussparameter.............................................................. 46

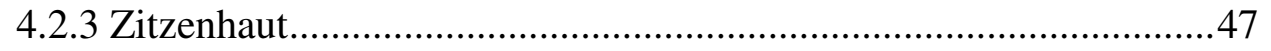

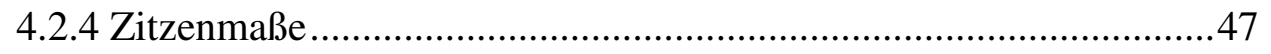


4.2.5 Zitzenform und Zitzenkuppenform ............................................48

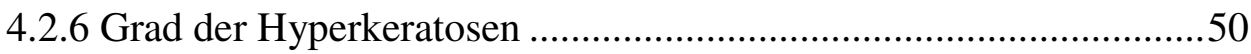

4.2.7 Zitzengewebefestigkeit (Zitzendicke) ...........................................50

4.2.8 Ödematisierung an der Zitzenbasis und Kongestion

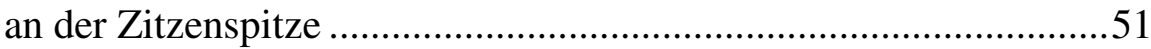

4.3 Einfluss der untersuchten Merkmale auf die Zitzenkondition

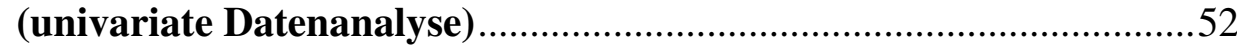

4.3.1 Grad der Hyperkeratosen .........................................................52

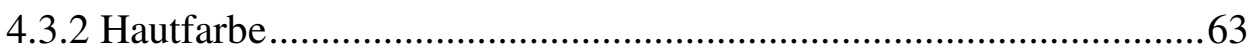

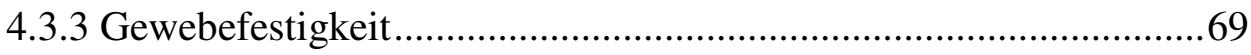

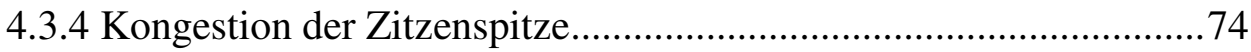

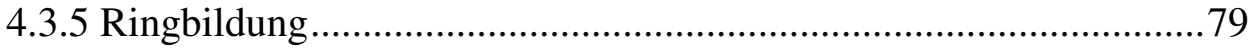

4.4 Einfluss der untersuchten Merkmale auf die Zitzenkondition

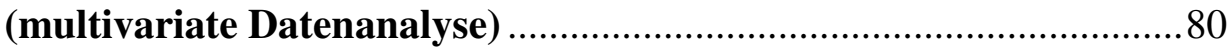

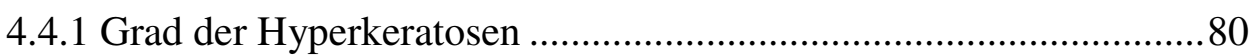

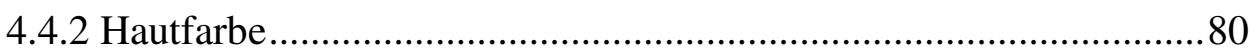

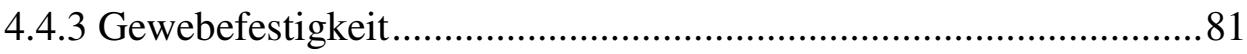

4.4.4 Kongestion der Zitzenspitze .......................................................8 81

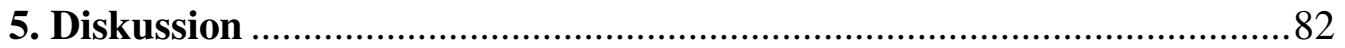

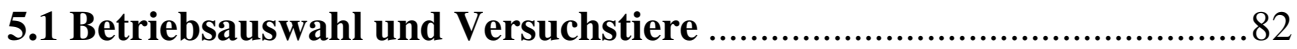

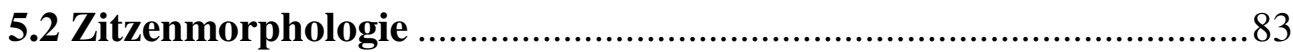

5.3 Einflüsse der melktechnischen Variablen .........................................8 84

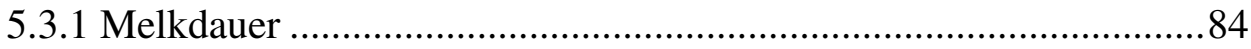

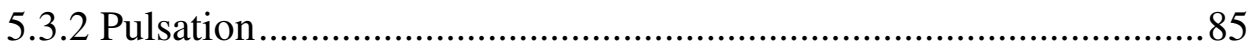

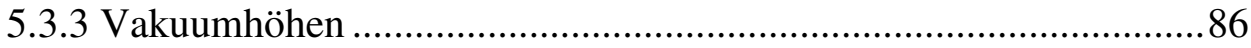

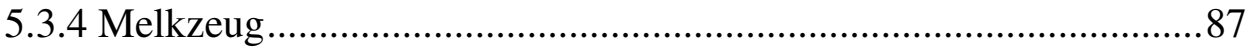

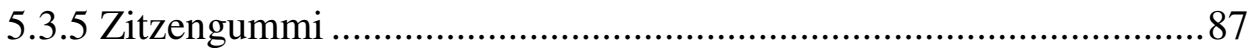

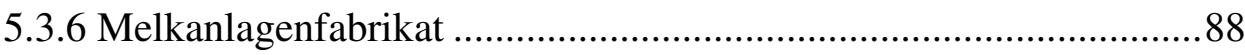

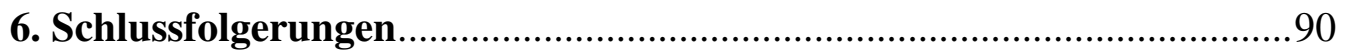




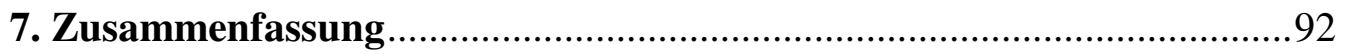

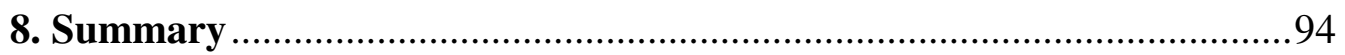

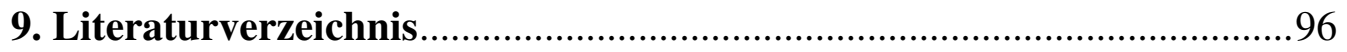

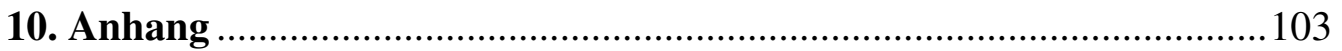




\section{Abkürzungsverzeichnis}

\begin{tabular}{|c|c|}
\hline$\%$ & Prozent \\
\hline Abb. & Abbildung \\
\hline $\mathrm{cm}$ & Centimeter \\
\hline CutiVor & Messwert des modifizierten Kutimeters vor dem Melken \\
\hline CutiNach & Messwert des modifizierten Kutimeters nach dem Melken \\
\hline CutDiff\% & $\begin{array}{l}\text { Differenz der Messwerte des modifizierten Kutimeters } \\
\text { vor und nach dem Melken in } \%\end{array}$ \\
\hline DIN & Deutsches Institut für Normung \\
\hline DMKMS & Durchmesser kurzer Milchschlauch \\
\hline DMLMS & Durchmesser langer Milchschlauch \\
\hline $\mathrm{EDkPa}$ & Einfaltdruckdifferenz in KiloPascal \\
\hline $\mathrm{g}$ & Gramm \\
\hline GHKHL & Grad der Hyperkeratose hintere linke Zitze \\
\hline GHKHR & Grad der Hyperkeratose hintere rechte Zitze \\
\hline GHKVL & Grad der Hyperkeratose vordere linke Zitze \\
\hline GHKVR & Grad der Hyperkeratose vordere rechte Zitze \\
\hline HautFarb & Farbe der Zitzenhaut nach dem Melken \\
\hline HautFeu & Feuchte der Zitzenhaut nach dem Melken \\
\hline HautText & Hauttextur \\
\hline HMF & Höchster Milchfluss \\
\hline ISO & International Organisation for Standardization \\
\hline ICAR & International Committee for Animal Recording \\
\hline $\mathrm{k}$ & kilo \\
\hline Kong & Kongestion \\
\hline Kopf & Durchmesser Kopflochöffnung des Zitzengummis \\
\hline KopfVak & Vakuum im Zitzengummikopfraum \\
\hline KMS & Kurzer Milchschlauch \\
\hline KMSMax & Maximales Vakuum im kurzen Milchschlauch während \\
\hline eines & Melkzyklus \\
\hline KMSMin & $\begin{array}{l}\text { Minimales Vakuum im kurzen Milchschlauch während } \\
\text { eines Melkzyklus }\end{array}$ \\
\hline
\end{tabular}


L

LAKTAG

LE

LKV

LMS

LWK

MGG

$\min$

MLP

$\mathrm{mm}$

ms

MZtyp

pa

PA

Prate

RB

SCC

Schaft

SD

t400

Minute

tAB

tAN

tMGG

tPL

VDKMS

während

ZFHL

ZFHR

ZFVL

ZFVR

ZitzDick

ZitzLaen
Liter

Laktationstage

Lufteinbruch

Landeskontrollverband

Langer Milchschlauch

Landwirtschaftskammer

Gesamtgemelk

Minute

Milchleistungsprüfung

Millimeter

Millisekunde

Melkzeugtyp

Pascal

Pulsationsart (Alternierend oder Simultan)

Pulsrate (Zyklen je Minute)

Ringbildung an der Zitzenbasis

Somatischer Zellgehalt

Durchmesser des Zitzengummischaftes

Standardabweichung

Zeit in Minuten zwischen Milchfluss 400 Gramm je und 200 Gramm je Minute am Ende des Melkvorgangs

Dauer der Abstiegsphase in Minuten

Dauer der Anstiegsphase in Minuten

Dauer der gesamten Melkung in Minuten

Dauer der Plateauphase in Minuten

Fluktuation des Vakuums im kurzen Milchschlauch

des höchsten Milchflusses

Zitzenform hintere linke Zitze

Zitzenform hintere rechte Zitze

Zitzenform vordere linke Zitze

Zitzenform vordere rechte Zitze

Zitzendicke

Zitzenlänge 
ZKFHL

Zitzenkuppenform hintere linke Zitze

ZKFHR

Zitzenkuppenform hintere rechte Zitze

ZKFVL

Zitzenkuppenform vordere linke Zitze

ZKFVR

Zitzenkuppenform vordere rechte Zitze 


\section{Tabellenverzeichnis}

Tabelle 1: Häufigkeit der Melkanlagenfabrikate und verwendete Melkzeuge .... 42

Tabelle 2: Pulsationscharakteristika der untersuchten Betriebe.......................... 43

Tabelle 3: Vakuumverhältnisse im Melkzeug während des Melkens................. 44

Tabelle 4: Zitzengummimaße und Einfaltdruckdifferenz ............................... 45

Tabelle 5: Zellgehalte und Gemelksmengen der untersuchten Tiere ................... 46

Tabelle 6: Milchflussparameter der untersuchten Tiere ..................................... 46

Tabelle 7: Zitzenhautbeschaffenheit vor und nach dem Melken ........................ 47

Tabelle 8: Zitzenmaße der hinteren linken Zitzen ........................................... 47

Tabelle 9: Häufigkeit der Zitzenformen ....................................................... 48

Tabelle 10:Häufigkeit der Zitzenkuppenformen ................................................ 49

Tabelle 11:Verteilung der Hyperkeratosenstufen nach Eutervierteln ................... 50

Tabelle 12:Gewebefestigkeit der Zitzen in cm Kutimeterwert ............................. 51

Tabelle 13:Durchschnittliche Melkdauer und durchschnittliche Melkdauer mit geringem Milchfluss nach Hyperkeratoseklassen der Tiere ......... 53

Tabelle 14:Dauer der Pulsationsphasen nach Hyperkeratoseklassen der Tiere .... 54

Tabelle 15:Bewertung der Hyperkeratosen nach Pulsationsarten und Vierteln.... 55

Tabelle 16:Bewertung der Hyperkeratosen nach Vakuumverhältnissen .............. 56

Tabelle 17:Bewertung der Hyperkeratosen nach Melkzeug- und Zitzengummi-

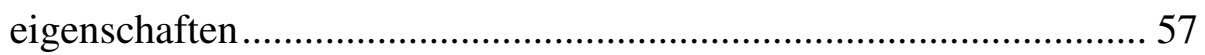

Tabelle 18:Bewertung der Hyperkeratosen nach Melkzeugtyp .......................... 58

Tabelle 19:Bewertung der Hyperkeratosen nach Melkanlagenfabrikat................ 59

Tabelle 20:Bewertung der Hyperkeratosen nach Zitzenmaßen ............................6 60

Tabelle 21:Bewertung der Hyperkeratosen nach Zitzenlänge in Gruppen ............ 60

Tabelle 22:Bewertung der Hyperkeratosen nach Zitzenformen .......................... 61

Tabelle 23:Bewertung der Hyperkeratosen nach Zitzenkuppenformen................ 62

Tabelle 24:Durchschnittliche Melkdauer und durchschnittliche Melkdauer mit geringem Milchfluss in den Hautfarbenklassen nach dem Melken .... 63

Tabelle 25:Dauer der Pulsationsphasen in den Hautfarbenklassen....................... 64

Tabelle 26:Anteil der Zitzen in den Hautfarbenklassen nach Pulsationsart ......... 64 
Tabelle 27:Mittlere Vakuumhöhen in den Hautfarbenklassen der Zitzen

Tabelle 28:Mittlere Werte der Melkzeug- und Zitzengummidaten in den

Hautfarbenklassen der Zitzen. 66

Tabelle 29:Anteil der Hautfarbenklassen der Zitzen nach Melkzeugtyp..... 67

Tabelle 30:Anteil der Hautfarbenklassen der Zitzen nach Melkanlagenfabrikat.. 68

Tabelle 31:Maße der Zitzen in den Hautfarbenklassen. 68

Tabelle 32:Melkdauer, Abstiegsdauer und Melkdauer mit geringem Milchfluss und Gewebefestigkeitsveränderung der Zitzen nach dem Melken 69

Tabelle 33:Dauer der Pulsationsphasen und Gewebefestigkeitsänderung............ 70

Tabelle 34:Anteil der Gewebefestigkeitsveränderungen nach Pulsationsart ........ 70

Tabelle 35:Mittlere Vakuumhöhen und Gewebefestigkeitsveränderung.............. 71

Tabelle 36:Werte der Melkzeug- und Zitzengummidaten und

Gewebefestigkeitsveränderung 72

Tabelle 37:Zitzenmaße und Gewebefestigkeitsveränderung 73

Tabelle 38:Melkdauer, Abstiegsdauer und Melkdauer mit geringem Milchfluss

in Bezug zu vorhandener Kongestion der Zitzenspitze. 74

Tabelle 39:Dauer der Pulsationsphasen und das Auftreten von Kongestionen .... 75

Tabelle 40:Anteil der Kongestionen nach Pulsationsart ..................................... 75

Tabelle 41:Vakuumhöhen und Kongestionen der Zitzenspitze .......................... 76

Tabelle 42:Werte der Melkzeug- und Zitzengummidaten und das Auftreten

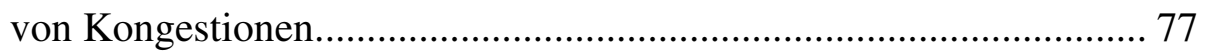

Tabelle 43:Zitzenmaße und das Auftreten von Kongestionen ............................. 78

Tabelle 44:Mittlere Werte der Zitzengummidaten und das Auftreten von Ringbildung an der Zitzenbasis 79

Tabelle 45:Ergebnisse der binären logistischen Regression für das Auftreten von Kongestionen anhand von melktechnischen und morphologischen Variablen 


\section{Abbildungsverzeichnis}

Abbildung 1: Aufbau einer Melkanlage (LWK Niedersachsen, 2006).............. 6

Abbildung 2: Stellung des Zitzengummis in den Melkphasen

(verändert nach DeLaval, 2008)

Abbildung 3: Darstellung des Vakuums im Pulsraum

(aus DIN/ISO 3918/2010)

Abbildung 4: Zitzengummibegriffe und Maße (nach DIN/ISO 3918/2010) .... 25

Abbildung 5: Die Messstellen im Melkzeug ................................................... 29

Abbildung 6: Messnadel im kurzen Milchschlauch (Schema)......................... 29

Abbildung 7: Zitzengummikopf mit eingeführtem Tubus ............................... 29

Abbildung 8: Beispiel eines Milchabgabeprofils

(Aus: Bedienungsanleitung LactoCorder ${ }^{\circledR}$ )

Abbildung 9: Cutimeter zur Messung der Gewebefestigkeit

(Nach Hamann und Mein, 1988).............................................. 32

Abbildung 10: Messlehre zur Zitzenvermessung ............................................ 33

Abbildung 11: Einsatz der Messlehre zur Zitzenvermessung ............................ 33

Abbildung 12: Zitzenformen nach Grunert (1990) ........................................... 34

Abbildung 13: Zitzenkuppenformen nach Grunert (1990)................................ 35

Abbildung 14: Stufen der Zitzenhautkondition............................................... 36

Abbildung 15: Zitzen mit Ringwulst an der Basis ............................................ 37

Abbildung 16: Einteilung der Hyperkeratosen

(verändert nach Mein et al., 2001) ............................................. 38

Anhang

A1 DIN/ISO Protokoll Niedersachsen nach DIN/ISO 6690/1998.. 103

A2 Rückseite Protokoll Niedersachsen nach DIN/ISO 6690/1998 104

A3 Druckmessgerät Bilgery MT 52 ......................................... 105

A4 Datenerhebungsprotokoll Betriebs- und Melkanlagendaten ..... 106

A5 Datenerhebungsprotokoll Kuhdaten....................................... 107

A6 Datenerhebungsprotokoll Bewertungsschemen ....................... 108 


\section{Einleitung und Zielsetzung}

Neben der Melkarbeit und den Haltungsbedingungen nehmen melktechnische Variablen Einfluss auf die Zitzenkondition von Milchkühen. Da eine unzureichende Zitzenkondition mit Störungen der Eutergesundheit in Verbindung gebracht wird (Hamann, 1988b), sollten die technischen Variablen so gewählt werden, dass möglichst nur geringe melkabhängige Störungen der Zitzenkondition auftreten. Durch die komplexe Interaktion der melktechnischen Variablen ist eine Verbesserung der Zitzenkondition durch eine Optimierung der Einstellung nicht einfach zu erreichen.

Bei der Entstehung der Faktorenkrankheit Mastitis kann dem maschinellen Milchentzug eine zentrale Bedeutung zukommen. Dieser soll schonend, vollständig und zügig ablaufen, um Risiken für die Mastitisentstehung zu vermeiden. Es werden verschiedene Mechanismen diskutiert, die im Zusammenhang mit dem Zweiraummelkbechersystem Einfluss auf die Neuinfektionsrate eines Betriebes nehmen können. Direkte Einflüsse, wie zum Beispiel durch massive Druckdifferenzen entstehende Impacts, die Erreger über den Zitzenkanal in die Zitzenzisterne transportieren, bewirken eine Zunahme der Zitzenkontamination mit potentiell euterpathogenen Mikroorganismen. Dieses Risiko des Zweiraummelkbechers kann mittels melkhygienischer Maßnahmen deutlich reduziert werden.

Darüber hinaus können maschinelle Melksysteme die lokalen Abwehrsysteme im Zitzenbereich nachhaltig schädigen, oder durch ein unvollständiges Ausmelken gute Wachstumsvoraussetzungen für Mastitiserreger schaffen und so indirekten Einfluss auf die Neuinfektionsrate nehmen.

Mein et al. (2004) nehmen an, dass die Melkmaschine zu 10\% direkt - durch den Transport von Bakterien, Kreuz-Kontamination sowie die oben beschriebenen "impacts" - und zu weiteren $10 \%$ indirekt - durch Effekte auf die Gesundheit des Zitzenkanals, des Zitzengewebes und der Zitzenhaut - zur Entstehung von neuen Infektionen beiträgt. 
Eine Belastung der lokalen Abwehrsysteme kann sich durch Störungen der Zitzenkondition ausdrücken. Wenngleich in praxi eine Erkennung übermäßiger Störungen der Zitzenkondition häufig noch gelingt, fehlen aufgrund der Komplexität der Zusammenhänge klare Ableitungen zur Verbesserung des maschinellen Milchentzuges durch eine optimierte Anpassung der melktechnischen Variablen.

Die wissenschaftliche Literatur zum Zusammenhang von Melktechnik und Zitzenkondition von Milchkühen gibt einige Optimierungshinweise, zeigt aber gleichzeitig deutlich, dass eine systematische Optimierung der Zitzenkondition durch Anwendung klarer melktechnischer Vorgaben bislang nicht möglich ist. Dies lässt Raum für werbewirksame, ungeprüfte Hypothesen und verhindert eine kontinuierliche Verbesserung der Eutergesundheit durch optimierte Melkbedingungen. Aus diesem Grund sind Untersuchungen, die bestehendes Wissen integrieren und ergänzen sowie die komplexe Interaktion zwischen Zitzenkondition und Melktechnik darstellen, zwingend erforderlich.

Ziel der vorliegenden Arbeit ist es, den Einfluss verschiedener melktechnischer Variablen auf die Zitzenkondition von Milchkühen $\mathrm{zu}$ erfassen und $\mathrm{zu}$ bewerten, um der Entwicklung von Beratungsempfehlungen für die Praxis Vorschub zu leisten.

Dazu wurden Melk- und Zitzenkonditionsparameter von Milchkühen erfasst, die unterschiedlichen melktechnischen Einflüssen unterlagen. Die Variation und die Häufigkeit der unterschiedlichen Einflusskonstellationen bilden hierbei das tatsächliche Spektrum der in der norddeutschen Milchviehwirtschaft vorherrschenden Melktechnik ab. 


\section{Literaturübersicht}

\subsection{Zitzenkondition und Zitzenkonditionsstörungen}

Der beobachtbare und palpierbare Zustand der Zitze wird als „Zitzenkondition“ bezeichnet. Zitzen sollten nach Abnahme des Melkzeuges genauso aussehen wie vor dem Melken: rosafarben, glatt und trocken. Alle Anzeichen einer eingeschränkten Blutversorgung der Zitze sind unerwünscht und weisen auf ein erhöhtes Risiko für die Anheftung an und den Eintritt von Mastitiserregern in die Zitze hin. Mein et al. (2001) unterscheiden bei der Erfassung der Zitzenkondition Kurzzeitveränderungen (als Reaktion des Gewebes nach nur einer Melkzeit zu beobachten), Reaktionen, die innerhalb weniger Tage bis Wochen in Erscheinung treten und Langzeitveränderungen, deren Entwicklung zwei bis acht Wochen benötigt.

Wenn mehr als $20 \%$ aller Kühe eines Betriebes entsprechende Veränderungen aufweisen (bei Blutungen maximal $10 \%$ ), liegt ein Zitzenkonditionsproblem vor, das sowohl das eigentliche Melken nachteilig beeinflusst, als auch das Risiko für Euterentzündungen erheblich erhöht, da Mikroorganismen bessere Bedingungen zur Anheftung finden. In solch einem Fall sollte eine Ursachenforschung durchgeführt werden (Krömker, 2006). Eine diesbezügliche Kontrolle durch Adspektion und Palpation sollte bei mindestens $10 \%$ der Tiere einer Herde bzw. bei mindestens 10 Tieren durchgeführt werden, um aussagekräftige Informationen über den Einfluss des maschinellen Melkens auf die Zitzenkondition zu erhalten (Krömker und Hamann 1997). Dabei sollte bei der Tierauswahl berücksichtigt werden, dass die stärksten chronischen Zitzenkonditionsstörungen zwischen dem 100. und 200. Laktationstag auftreten.

Akute Veränderungen, die im Rahmen solcher Untersuchungen gefunden werden und als Mastitis fördernd angesprochen werden müssen, sind z.B. palpierbare Ödeme an Zitzenschaft und -kuppe (normal oder fest), Petechien und Farbabweichungen, eingeteilt in normal, gerötet und blau sowie 
palpierbare Ringbildungen an der Zitzenbasis, die allerdings auch chronisch manifestiert als so genannter Ringwulst auftreten können. Weiterhin können Läsionen und kleine Wunden als Folge der maschinellen Milchgewinnung vorkommen.

Zur Feststellung von Kongestionen kann die Dicke des Zitzengewebes mit Hilfe eines modifizierten Kutimeters durch Doppelmessung vor und nach dem Milchentzug bestimmt werden (Hamann, 1988a). Diese Parameter werden innerhalb etwa einer Minute nach Abnahme des Melkzeuges erfasst.

Als Langzeitveränderungen sind vor allem Hyperkeratosen anzusehen, die in Folge wiederkehrender, länger andauernder mechanischer Belastung und damit einhergehender Minderdurchblutung bzw. mangelnder Sauerstoffversorgung entstehen. Sie werden von Mein et al. (2001) in N (no ring), S (smooth, slightly rough), R (rough) und VR (very rough) eingeteilt. Diese Einteilung eignet sich nach Meinung der Autoren vor allem für Untersuchungen im Feld.

Für wissenschaftliche Untersuchungen dagegen empfehlen sie den Einteilungsschlüssel nach Neijenhuis et al. (2000). Diese unterteilen Hyperkeratosen in fünf Klassen $(\mathrm{N}=$ normal, $\mathrm{A}=$ slight, $\mathrm{B}=$ moderate, $\mathrm{C}=$ thick, $\mathrm{D}=$ extreme) und bewerten sie zusätzlich noch als weich (1) oder rau (2).

Fühlbare Verhärtungen der Zitzenspitze sind ebenfalls Zeichen einer chronischen Gewebsschädigung.

Die hier genannten Erscheinungsbilder der Zitzenkondition werden unter anderem von morphologischen (Seykora und McDaniel, 1985) und auch von melktechnischen Parametern beeinflusst. Dies wurde für einzelne melktechnische Parameter bereits in der Vergangenheit beschrieben (siehe ab 4.1). 


\subsection{Maschineller Milchentzug}

Beim maschinellen Milchentzug wird die Kraft eines applizierten Vakuums zur Überwindung des Zitzenkanalwiderstandes genutzt. Dazu werden heute üblicherweise Melkeinheiten verwendet. Als Melkeinheit wird ein Satz von Bauteilen bezeichnet, der aus dem Melkzeug, dem Pulsator, dem langen Milchschlauch und dem langen Pulsschlauch besteht (DIN/ISO3918). Das Melkzeug für Kühe besteht aus vier Zweiraummelkbechern mit je einem kurzen Milchschlauch, einem kurzen Pulsschlauch und dem Sammelstück (DIN/ISO 3918). Ein in die Melkbecherhülse eingezogener Zitzengummi bildet mit dieser den Zweiraummelkbecher. Im Zitzengummiinnenraum besteht kontinuierlich ein Unterdruck, während im Pulsraum - dem Raum zwischen Melkbecherhülse und Zitzengummi - zyklisch ein Wechsel zwischen Unterdruck (Betriebsvakuum) und atmosphärischem Druck vollzogen wird. Durch diesen periodischen Druckwechsel wird eine Bewegung des Zitzengummis erreicht, welches sich abwechselnd öffnet und schließt (Hamann et al., 2001). Die Öffnungs- und Offenphase wird als Saugphase bezeichnet, die Schließ- und Geschlossenphase als Druckphase. Findet dieser Druckwechsel auf allen vier Melkbechern gleichzeitig statt, spricht man von simultaner Pulsation (Gleichtakt), bei der alternierenden Pulsation (Wechseltakt) befinden sich jeweils zwei von vier Melkbechern wechselweise in der Saug- beziehungsweise Druckphase.

Die Melkeinheit ist über den langen Milchschlauch mit der Milchleitung verbunden. Diese wird von der Vakuumpumpe über eine Vakuumleitung und den Milchabscheider, welcher die Milch zyklisch aus dem Vakuumbereich ausschleust, evakuiert. Die Stabilität des Unterdrucks im Vakuum- und Milchsystem wird über eine Regeleinheit gesteuert. Diese Regeleinheit kann aus einem gesteuerten Lufteinlass oder aus der Steuerung der Förderleistung der Vakuumpumpe bestehen. Die Evakuierung der Pulsatoren wird über eine separate Leitung gewährleistet, die von der Hauptluftleitung abzweigt (LWK Niedersachsen, 2006). 


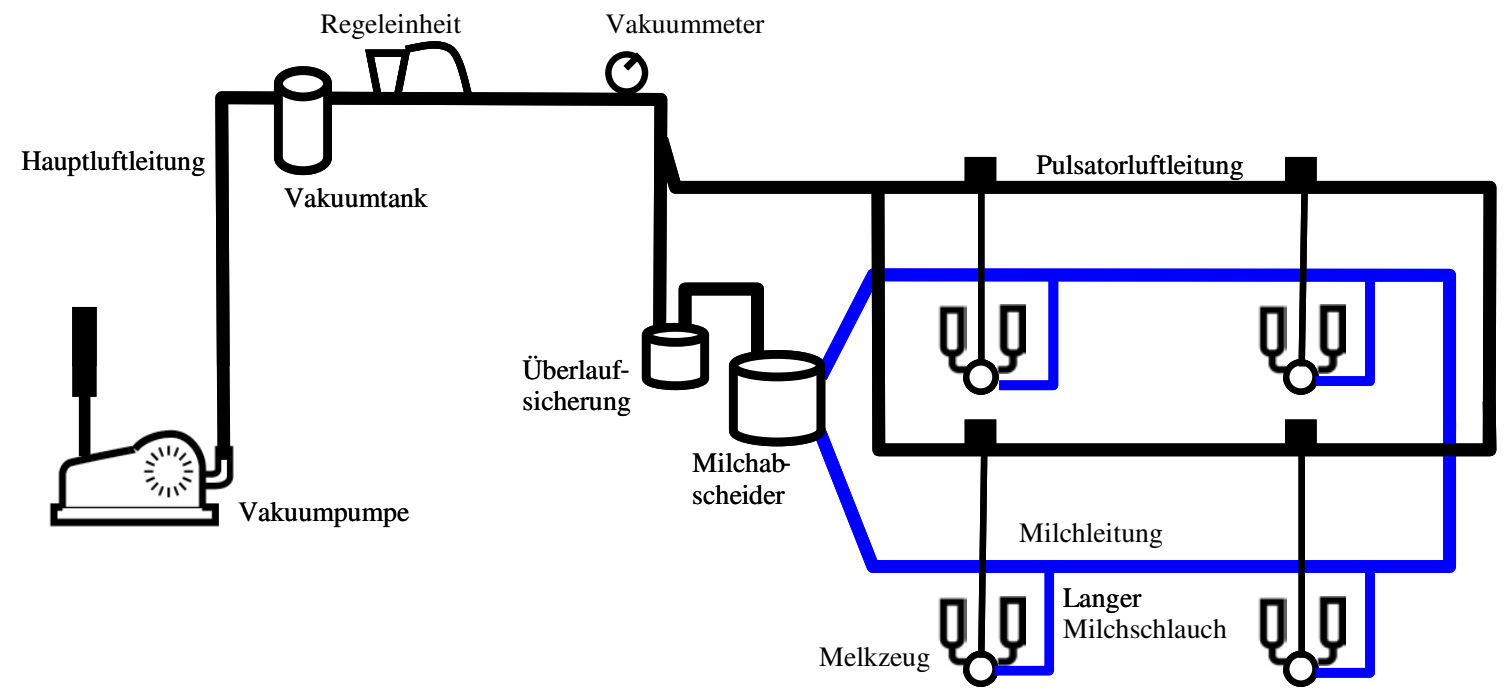

Abbildung 1: Aufbau einer Melkanlage (LWK Niedersachsen, 2006)

\subsection{Melkanlagenprüfung}

Die Arbeitsweise und Funktion einer Melkanlage unterliegt Mindestanforderungen, die im Rahmen von Prüfungen mittels Messung kontrolliert werden. Die Überprüfung nach technischem Regelwerk, den DIN ISO Normen, gilt für alle Melkanlagen verbindlich. Für alle seit dem Frühjahr 2010 neu installierten Melkanlagen gelten die von der Internationalen Organisation für Normung erstellten und von den nationalen Organisationen anerkannten Normen. Vor diesem Zeitpunkt installierte Melkanlagen wurden nach der DIN/ISO von 1998 bewertet, die im Wesentlichen der jetzt gültigen Norm entspricht (Hubal, 2005).

Hält eine Melkanlage der DIN ISO Prüfung nicht stand, ist dies als Hinweis auf ein erhöhtes Risiko für die Entstehung von Eutergesundheitsproblemen zu werten (Hubal, 2005). 
Bei der Überprüfung einer Melkanlage werden verschiedene Daten erfasst und in ein Datenblatt übertragen. Dieses Datenblatt - das DIN/ISO Protokoll umfasst folgende anlagenrelevanten Angaben:

- Fabrikat und Art der Melkanlage

- Anzahl der Bedienungspersonen beim Melken

- Anzahl der Melkzeuge

- Länge und Durchmesser der Leitungen (beim Durchmesser: Ist- und Sollwerte)

- Art der Zusatzeinrichtungen, wie z.B. automatische Melkzeugabnahme

- Nenn-Betriebsvakuum, Reinigungsvakuum und atmosphärischer Luftdruck

Zudem werden Daten zu Vakuumhöhen und deren zulässigen sowie tatsächlichen Abweichungen erfasst. Die Daten geben Auskunft über die Funktion des Manometers, der Regeleinheit sowie der Auslegung der Vakuumleitungen (Hubal, 2005).

Mittels Luftdurchflussmessungen werden die Reservekapazität, der Regelverlust, die Leckluft der Regeleinheit sowie die Dichtigkeit der Melkund Vakuumleitungen überprüft. Der Reservedurchfluss lässt sich anhand von Tabellen für das Melken und Reinigen der Anlage bestimmen, der jeweils höhere Wert (Reservedurchfluss Melken oder Reinigen) ist ausschlaggebend. Anhand des Sollwertes kann der Anlagenbetreiber erkennen, ob seine Melkanlage den Anforderungen genügt. Der Regelverlust beschreibt den Zusammenhang zwischen der Dimensionierung der Hauptvakuumleitung und der daraus resultierenden Funktion der Regeleinheit, die auch vom Montageort abhängig ist. Bei Überschreitung des Grenzwertes ist die ordnungsgemäße Funktion der Vakuumregelung eingeschränkt. Die Leckluft der Regeleinheit gibt Auskunft über eine mögliche Verunreinigung oder Beschädigung des Regelventils (Hubal, 2005). 
Das Registrieren des Luftverbrauchs der Melkeinheiten - eine über die DIN/ISO hinausgehende Prüfung - erlaubt beim Vergleich mit den Herstellerangaben Rückschlüsse über evtl. Fehlfunktionen Luft verbrauchender Teile, wie z.B. der Pulsatoren (Hubal, 2005).

Durch Vergleich der Grenz- und Messwerte bei der Dichtigkeitsprüfung der Anlagenabschnitte Melksystem und Luftsystem lassen sich Undichtigkeiten aufdecken, die zu unnötigem Leistungsverlust und Eindringen von Schmutz in das Leitungssystem führen können (Hubal, 2005).

Abschließend wird die Leistung der Vakuumpumpe (Luftdurchfluss bei 50 $\mathrm{kPa}$ ) festgestellt. Diese kann mit der Herstellerangabe, sollte aber in jedem Fall mit dem tatsächlich erforderlichen Bedarf verglichen werden (Hubal, 2005).

Ein weiterer wesentlicher Teil der Anlagenüberprüfung besteht in der Messung der Pulsatoren. Diese wird in der Regel gesondert dokumentiert, da die Messergebnisse für das Protokoll zu umfangreich sind (Hubal, 2005). Die Funktion der Pulsatoren sowie eine typische Pulsgrafik sind in Kapitel 2.4.4 (Pulsierung) in Abbildung 2 und 3 dargestellt.

Das Protokoll erlaubt außerdem die Dokumentation einiger optionaler Messungen und kurzer Beratungsaussagen. Der den Abtransport der Milch bewirkende Lufteinlass am Melkzeug wird ebenso gemessen wie die Funktion des Absperrventils, das gewährleistet, dass das Melkzeug schonend vom Euter entfernt werden kann. Der Luftdurchfluss am langen Milchschlauch, der vom Hersteller melkanlagenspezifisch angegeben wird, ist für die Vakuumversorgung am Melkzeug und den Abtransport der Milch mit entscheidend. Punkte wie das Niedrigvakuum, der Schaltpunkt und die Verzögerungszeit sind Hersteller- und Anlagenspezifisch und sollten somit den Herstellerangaben entsprechen. Hier bestehen jedoch auch Einflussgrößen, die durch die Melkbarkeit der Herde bestimmt werden und mit einem gewissen Spielraum eine Einstellung erlauben (Hubal, 2005). 


\subsection{Melktechnische Parameter}

\subsubsection{Melkdauer}

Die Dauer der Einwirkung des Melkvakuums auf die Zitzen beeinflusst die Zitzenkondition. Thompson und Sieber (1980) wiesen nach, dass bei einer mittleren Melkzeit von unter 5 Minuten $20 \%$ der Zitzen einer Herde eine glatte, nicht herausgestülpte, geschlossene Öffnung aufweisen. Demgegenüber sank der Anteil der Zitzen mit einer derartigen Zitzenkondition bei einer mittleren Melkzeit von über 6 Minuten auf $10 \%$. Neijenhuis et al. (2000) ermittelten einen Korrelationskoeffizienten von $r=0,22(P=0,08)$ für die Beziehung zwischen der Melkzeughaftzeit (machine-on time) und der Rauhigkeit der Hyperkeratose. Reinemann et al. (2008) konnten aufzeigen, dass bei einer Melkdauer von unter 4,3 Minuten die Wahrscheinlichkeit zur Entstehung von Hyperkeratosen der Zitzenspitze, verglichen mit einer Melkdauer von über 5,3 Minuten, sinkt. Auch Reid und Johnson (2003) gehen von einer Verbesserung der Kondition der Zitzenhaut und der Zitzenkuppe durch eine Reduzierung der Melkdauer aus. Graff et al. (2007) empfehlen eine Melkzeughaftzeit von 6-8 Minuten. Hamann und Mein (1995) befürworten eine mittlere Melkgeschwindigkeit von mindestens $2 \mathrm{~kg} / \mathrm{min}$. für die ersten 10 $\mathrm{kg}$ eines Gemelks und von $5 \mathrm{~kg} / \mathrm{min}$. für das weitere Gemelk.

Um das Auftreten von Hyperkeratosen zu vermindern, empfehlen Mein et al. (2003b) die Reduzierung der Melkdauer. Die Autoren verweisen darauf, dass vor allem das Melken bei einem Milchfluss von unter $1 \mathrm{~kg} / \mathrm{min}$ sowie bei einem mittleren Sammelstückvakuum von über 42 bis $45 \mathrm{kPa}$, reduziert werden muss.

\subsubsection{Blindmelken und Abnahmeschwelle}

Die Dauerbelastung der Zitzen durch das anliegende Melkvakuum wird während der Milchabgabe durch die in das Melksystem eintretende Milch und 
die daraus entstehende Vakuumabsenkung gemindert. Wird nach dem Sistieren des Milchflusses der maschinelle Milchentzug nicht beendet und das Melkzeug von der Milchdrüse entfernt, liegt das Melkvakuum in voller Höhe an der Zitze an, so dass die mechanische Belastung in dieser Phase besonders hoch ist (Blindmelken).

Nach Grindal (1988) führt Blindmelken zu einer Schädigung des Epithels der Zitzenzisterne, da die Epithelien während des Kollabierens des Zitzengummis untereinander als Reibungsflächen dienen können. Durch das Blindmelken dringt das Vakuum in das Zitzenlumen vor, so dass in Verbindung mit der Pulsation Epithelschäden auftreten (Wendt, 2004). Nach Rasmussen (2004) sind mindestens 10 Pulszyklen notwendig, bis das Vakuum in der Zitzenzisterne der Pulsationskurve folgt. Die Dauer des Blindmelkens sollte optimalerweise unter 30 bis 40 Sekunden liegen (Graff et al., 2007). Hillerton et al. (2002) untersuchten die Zitzenkondition bei einer Abnahmeschwelle von $200 \mathrm{~g} / \mathrm{min}$ ohne Blindmelken und nach einer Dauer des Blindmelkens von 2 und 5 Minuten. Mit zunehmender Zeit des Blindmelkens nahm die Anzahl verfärbter und fester Zitzen signifikant zu. Zusätzlich wurde ein signifikanter Anstieg des Anteils an Zitzen mit palpierbaren Ringen festgestellt. Rasmussen (1993) untersuchte die Effekte der Abnahmeschwellen von 200 g/min und 400 g/min bei Einsatz einer automatischen Abnahmehilfe. Für die Hinterviertel erstlaktierender Tiere war nach acht Wochen und für ältere Tieren nach vier Wochen ein signifikanter Unterschied hinsichtlich des Grades der Hyperkeratosen festzustellen. Die höhere Abnahmeschwelle war mit einer herabgesetzten Melkdauer verbunden und führte $\mathrm{zu}$ einer reduzierten Zitzenkuppendicke erstlaktierender Kühe. Der Autor schlussfolgerte aus seinen Untersuchungen, dass die letzten 30 Sekunden des Melkens für die Entstehung von Hyperkeratosen entscheidend sind. Gleeson et al. (2002) stellten mit zunehmender Dauer des Blindmelkens von 0 Minuten, 5 Minuten und 8 Minuten bei einer Abnahmeschwelle von $200 \mathrm{~g} / \mathrm{min}$ keine signifikanten Effekte auf Zitzenkanallänge, Zitzendurchmesser, Zitzenwanddicke und Zitzenlänge fest. Ein signifikanter Unterschied bestand hinsichtlich der 
Änderung des Durchmessers der Zitzenzisterne zwischen den Zitzen, bei denen das Melkzeug an der Abnahmeschwelle entfernt wurde und den blindgemolkenen Zitzen. Die Abnahme des Melkzeuges an der Abnahmeschwelle führte $\mathrm{zu}$ einer Reduzierung des Durchmessers der Zitzenzisterne um 7,7 mm. Nach dem Blindmelken für 5 Minuten war eine Reduktion um 8,5 mm und nach 8minütigem Blindmelken eine Minderung um $8,8 \mathrm{~mm}$ zu beobachten. Der Vergleich der Zitzen, von denen das Melkzeug bei einer Abnahmeschwelle von $200 \mathrm{~g} / \mathrm{min}$ entfernt wurde und von für 5 Minuten blindgemolkenen Zitzen erbrachte einen signifikant niedrigeren Anteil an Zitzenkanalkeratin und einen signifikant höheren Anteil an Zitzenzisternenverletzungen nach dem Blindmelken (Gleeson et al., 2003).

Beobachtungen von Paulrud et al. (2005) zeigen, dass die Zunahme der Zitzenwanddicke eine Folge des Blindmelkens darstellt. Blindmelken über kurze bis mittellange Zeiträume geht mit verfärbten Zitzen, Ringen an der Zitzenbasis und einer Erhöhung der Festigkeit der Zitzen einher. Blindmelken über längere Zeiträume dagegen führt zur Bildung von Hyperkeratosen. Fällt die Milchmenge unter 0,9 kg/min., so verschlechtert sich die Zitzenkondition aufgrund der Bildung rauer oder sehr rauer Zitzenkuppen (Kirk, 2003).

\subsubsection{Vakuumhöhe}

Beim maschinellen Milchentzug entsteht die auf das Zitzengewebe einwirkende und damit die Zitzenkondition verändernde Kraft durch die Druckdifferenz zwischen anliegendem Vakuum und dem atmosphärischen Druck. Insofern kann die Krafteinwirkung durch die Wahl der Vakuumhöhe beeinflusst werden. Während grundsätzlich eine größere Kraft eine Maximierung der Milchentleerungsgeschwindigkeit und eine kräftigere Massage des Zitzengewebes bewirkt, so hat sie auch eine stärkere Gewebsbelastung zur Folge.

Ein überhöhtes Melkvakuum führt zu radialen Brüchen im Epithel und folglich zu einer sofortigen Verhornung der Zellen des Stratum granulosum (Williams 
und Mein 1985). Hamann und Mein (1988) untersuchten die Dicke der Zitzenspitze bei Anlagenvakua von $30 \mathrm{kPa}, 50 \mathrm{kPa}$ und $70 \mathrm{kPa}$ und einer Pulsrate von 60 Zyklen/min. Der Anteil der Saugphase lag bei $70 \%$. Die Zitzenspitzendicke nahm während des Melkens mit zunehmendem Vakuum im Mittel um $2 \%$ bei einem Vakuum von $30 \mathrm{kPa}$, um $8 \%$ bei einem Vakuum von $50 \mathrm{kPa}$ sowie um $21 \%$ bei einem Vakuum von $70 \mathrm{kPa} \mathrm{zu}$. Bei Verwendung eines pulsationslosen Systems lagen die mittleren Zunahmen mit 10\% für die Vakuumstufe von $30 \mathrm{kPa}$, mit $18 \%$ für $50 \mathrm{kPa}$ und mit $25 \%$ für $70 \mathrm{kPa}$ deutlich höher. Nach Hamann (1988b) führt ein höheres Vakuum zu einer stärkeren prozentualen Zunahme der Gewebefestigkeit für die untersuchten Vakuumstufen $30 \mathrm{kPa}, 50 \mathrm{kPa}$ und $70 \mathrm{kPa}$. Die Saugphase hatte einen Anteil von 71,5 \%. Mit Erhöhung der Pulszahl von 20 auf 40 und 60 verringert sich die prozentuale Gewebefestigkeit je Vakuumstufe. Die Unterschiede der prozentualen Gewebefestigkeitsänderung waren bei 30 und $50 \mathrm{kPa}$ signifikant. Ebendorff und Ziesack (1991) stellten, verglichen mit einem Vakuum von 50 $\mathrm{kPa}$, bei einem Vakuum von $45 \mathrm{kPa}$, einer Pulsrate von 60 Zyklen/min und einer Saugphase von 60 \% einen signifikant höheren Anteil von Kühen fest, die adspektorisch und palpatorisch ohne Befund waren. Während bei $45 \mathrm{kPa}$ Rötungen und Blaufärbungen nach der Melkzeugabnahme seltener zu beobachten waren, eine signifikant geringere Verhornung der Zitzenkanalmündung auftrat und mehr Zitzenkanäle nach der Melkzeugabnahme verschlossen waren, konnten beim Auftreten der Kongestionen keine Differenzen beobachtet werden. Der Anteil starker Hyperkeratosen war in beiden Versuchsgruppen gleich. Hamann und Mein (1990) beobachteten bei den Vakuumstufen $25 \mathrm{kPa}$ und $50 \mathrm{kPa}$ (60 Zyklen/min, Saugphase 70 \%) nach dem Melken bei niedrigem Vakuumlevel eine Abnahme der Zitzendicke um 5 $\%$ und eine Zunahme um 10-15 \% bei der hohen Vakuumstufe. Das pulsationslose System führte sogar zu Zunahmen um über $30 \%$. Hamann et al. (1993) konnten zeigen, dass nach dem Melken mit $40 \mathrm{kPa}$ die Zitzenspitze signifikant dicker war als bei einem Vakuum von $30 \mathrm{kPa}$. Auch nach dem Melken mit $50 \mathrm{kPa}$ war im Vergleich zu dem Melkvakuum von $40 \mathrm{kPa}$ ein 
signifikanter Unterschied der Dicke der Zitzenspitze festzustellen. Die Zitze war bei den höheren Vakua (50 kPa bzw. $40 \mathrm{kPa}$ ) nach dem Melken im Mittel ebenfalls dicker als bei den niedrigen Vakua (40 kPa bzw. $30 \mathrm{kPa}$ ). Nach dem Melken mit einem Vakuum von $53 \mathrm{kPa}$ konnte eine größere Öffnung des Zitzenkanals beobachtet werden als bei einem Vakuum von $43 \mathrm{kPa}$ (Mellinger 1988; aus Geidel und Graff 2001). Rasmussen und Madsen (2000) stellten bei einer hoch verlegten Anlage (60 Zyklen/min, Pulsverhältnis 60:40) eine Abnahme der Zitzendicke um 1 bis $2 \%$ bei einem Vakuum von $38 \mathrm{kPa}$ in der Milchleitung fest, während bei $48 \mathrm{kPa}$ eine Zunahme der Zitzendicke um 1 bis $3 \% \mathrm{zu}$ verzeichnen war. Für eine tief verlegte Anlage konnten eine Abnahme um über $2 \%$ bei $32 \mathrm{kPa}$ und bei $42 \mathrm{kPa}$ eine Zunahme um 1 bis $2 \%$ erfasst werden; die Unterschiede waren nicht signifikant. Eine Vakuumstufe von 44 $\mathrm{kPa}$ bei einer Dauer der b-Phase (Vakuumphase) von $322 \mathrm{~ms}$ führte zu einer Zunahme der Dicke der Zitzenwand um $25 \%$. Bei $47 \mathrm{kPa}$ sowie $50 \mathrm{kPa}$ und einer Länge der b-Phase von $\geq 500 \mathrm{~ms}$ nahm die Dicke der Zitzenwand sogar um $35 \%$ zu (Reinemann et al., 2008).

Untersuchungen von Ryšánek et al. (2001) zu Folge korrelierte ein übermäßiges Vakuum signifikant mit dem Auftreten von Hyperkeratosen vor allem bei simultaner Pulsation. Nach Neijenhuis et al. (2004) führt eine Reduzierung des Melkvakuums von $50 \mathrm{kPa}$ auf $40 \mathrm{kPa}$ zu einem verringerten Risiko für die Entstehung schwerer Hyperkeratosen. Lacy-Hulbert et al. (1996) konnten jedoch weder bei einem Melkvakuum von $45 \mathrm{kPa}$ noch von $50 \mathrm{kPa}$ signifikante Effekte auf die entfernte Keratinmenge ermitteln, obwohl sich die Milchflussraten um $17 \%$ unterschieden. Die Reduzierung des Systemvakuums führt zu einer Verlängerung der Melkdauer, die wiederum negative Effekte auf die Kondition der Zitzenkuppe zur Folge hat (Reid und Johnson, 2003). Neijenhuis et al. (2000) stellten fest, dass eine längere Melkdauer (machine-on time) mit einer erhöhten Wahrscheinlichkeit für das Auftreten rauer Callusringe verbunden ist. Nach Hamann et al. (1993) ist das Melken mit Vakua von $30 \mathrm{kPa}$ oder niedriger nicht empfehlenswert; Vakuumapplikationen von 16-22 kPa führen Untersuchungen von Geidel und Graff (2001) zufolge zu 
keiner Kontraktion des Gewebes mehr. Um Läsionen der Zitzenenden zu reduzieren, empfehlen Ortega et al. (2008) eine Differenz zwischen dem Vakuum im Sammelstück und dem Einfaltdruck des Zitzengummis (collapse force) im Bereich von 26 bis $27 \mathrm{kPa}$.

\subsubsection{Pulsierung}

Die Vakuumapplikation führt zur vermehrten Ansammlung von Gewebeflüssigkeit in der Zitzenspitze (Mein und Williams 1984). Dieser vermehrten Flüssigkeitsansammlung im Gewebe wird durch massierendes, zyklisches Öffnen und Schließen des Zitzengummis entgegen gewirkt (Pulsierung, Abb. 3). Dies geschieht durch das zyklische Evakuieren und Belüften des Zwischenraumes zwischen Zitzengummi und Zitzenbecherhülse (Pulsraum, Abb.2). Wenn eine effektive Pulsierung nicht gelingt, können maschinelle Melksysteme die lokalen Abwehrsysteme im Zitzenbereich nachhaltig schädigen. Trotz optimaler Pulsierung, die neben morphologischen Eigenschaften (Zitzenlänge, Zitzendurchmesser) von technischen Parametern der Melkanlage (Zitzengummityp, Vakuumversorgung, PulsationsCharakteristik) beeinflusst wird, kann die dauerhafte Integrität des Zitzengewebes nur dadurch sichergestellt werden, dass die Anwendung des Vakuums zeitlich begrenzt erfolgt.

Bei der Pulsierung darf das höchste Vakuum im Pulsraum in der Vakuumphase nicht mehr als $2 \mathrm{kPa}$ unter dem Betriebsvakuum und das niedrigste Vakuum in der Druckphase nicht mehr als $4 \mathrm{kPa}$ über dem Umgebungsdruck liegen (DIN/ISO 3918). Das komplette Bewegen des Zitzengummis vom Öffnen über das Schließen bis zum nächsten Öffnen umfasst einen Pulszyklus (Abb. 2). 
Saugphase

Druckphase

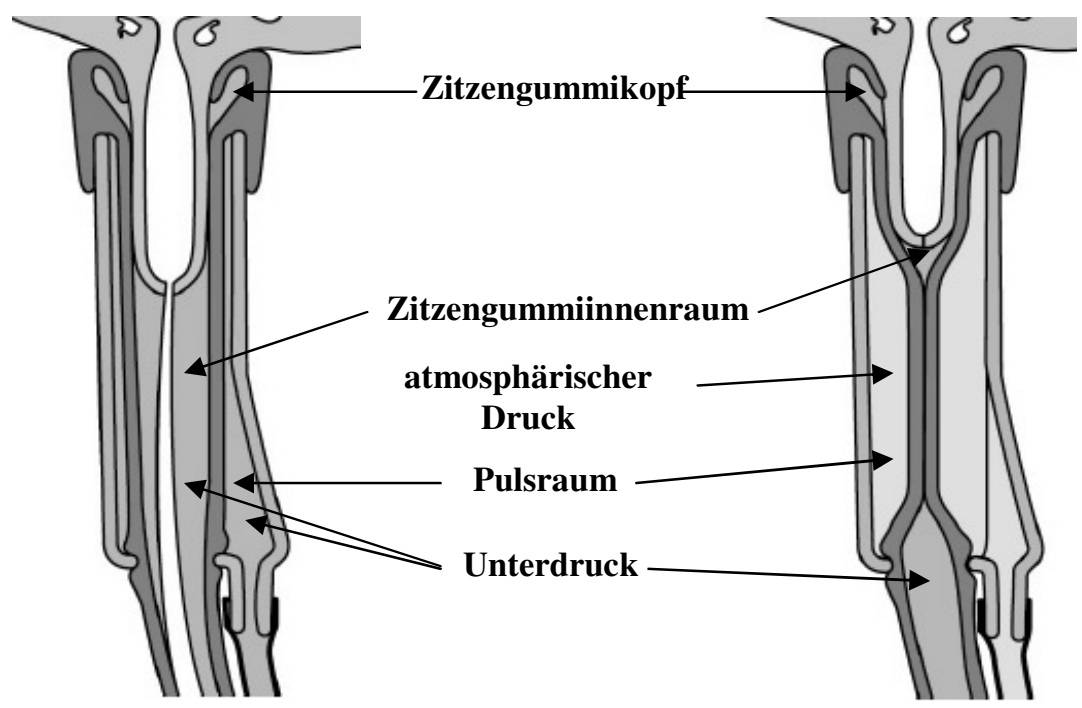

Abbildung 2: Stellung des Zitzengummis in den Melkphasen, verändert nach (DeLaval, 2008)

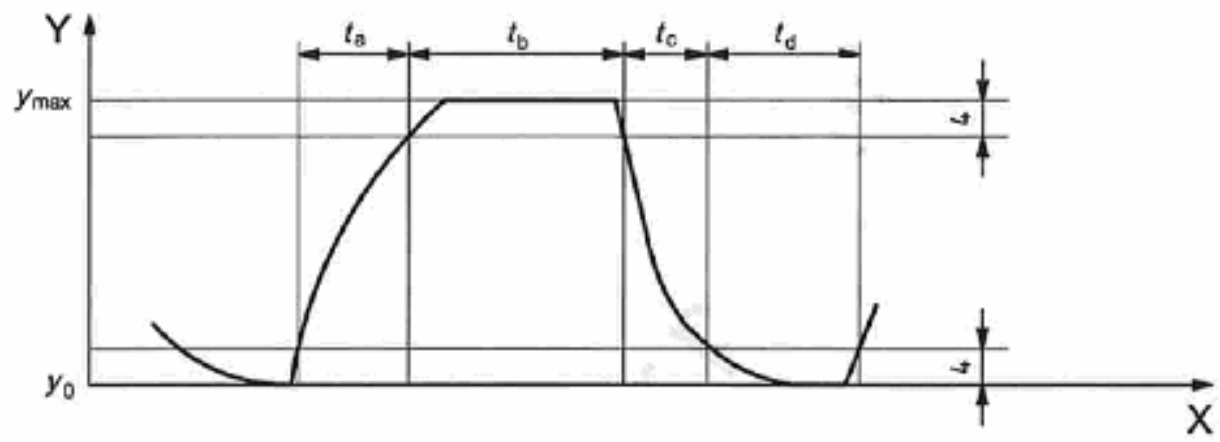

Abbildung 3: Darstellung des Vakuums im Pulsraum (aus DIN/ISO 3918) 
Wie stark die mechanische Einwirkung auf das Zitzengewebe ist, hängt davon $\mathrm{ab}$, welche Materialeigenschaften das Zitzengummi hat, wie stark es im eingebauten Zustand gedehnt wird und wie groß die Druckdifferenz zwischen Zitzengummiinnenraum und Pulsraum ist. Nicht zuletzt spielt auch das Verhältnis der einzelnen Phasen der Pulsation (Abb. 3) eine Rolle, da durch sie die mechanische Einwirkung zeitlich gesteuert wird.

Hamann und Mein (1996) untersuchten die Effekte der Taktzahlen 40 Zyklen/min, 60 Zyklen/min und 80 Zyklen/min bei einem Anteil der Saugphase von $50 \%, 60 \%, 70 \%$ und $80 \%$ des Pulszyklus. Die Dicke der Zitzen nahm bei Anteilen der Saugphase von $50 \%$ und $60 \%$ ab; bei einer Zunahme des Anteils der Saugphase war die Zitzendicke bei einer Taktzahl von 60 Zyklen/min am geringsten. Nach Grindal (1988) führt eine Verlängerung der Saugphase zu einer Zunahme von Zitzenläsionen und subkutanen Blutungen.

Billon und Gaudin (2001) vermuten, dass kürzere a-(Evakuierungs-) und c(Belüftungs-)Phasen zu schnelleren Bewegungen des Zitzengummis führen und daraus Kongestionen resultieren. Die Autoren konnten jedoch für die Anteile der a-/c-Phasen von $14 \% / 9 \%$ und $23 \% / 15 \%$ des Pulszyklus (bei 41 $\mathrm{kPa}, 60$ Zyklen/min) keine signifikanten Unterschiede der Dicke der Zitzenenden feststellen. Für die Vorderviertel wurde jedoch im Hinblick auf die Zitzenkondition ein signifikanter Unterschied ermittelt; die derjenigen Viertel, die mit langen Phasen gemolken wurden, war verbessert. Eine b-Phase (Vakuumphase) mit einer Dauer von über 1 sec. und eine d-Phase (Druckphase) mit einer Dauer von 200 ms führten ebenso wie eine b-Phase von $600 \mathrm{~ms}$ und eine d-Phase von $50 \mathrm{~ms}$ zu einer signifikanten Zunahme der Zitzendicke (Hamann und Mein, 1996). Ist die d-Phase kürzer als $150 \mathrm{ms,}$ nimmt den Autoren zufolge die Zitzendicke signifikant zu. Nach Mein et al. (2003 b) ist zur Verhinderung des Auftretens von Kongestionen eine d-Phase mit einer Länge von mindestens 150 ms notwendig. Kirk (2003b) sowie Reid und Johnson (2003) führen d-Phasen mit einer Länge von unter $200 \mathrm{~ms}$ als 
Ursache für die Zunahme von Irritationen der Zitzenspitze und von Hyperkeratosen auf. Østerås et al. (1995) konnten beobachten, dass Herden, die mit d-Phasen von 300,4 $\pm 3,53$ ms gemolken wurden, frei von Zitzenläsionen waren, wohingegen in Herden, die mit einer d-Phase von $288 \pm 3,60 \mathrm{~ms}$ gemolken wurden mindestens eine Läsion, die eine tierärztliche Behandlung erforderte, nachzuweisen war. Die Autoren empfehlen für hochverlegte Anlagen d-Phasen von über $250 \mathrm{~ms}$, bevorzugt von $300 \mathrm{~ms}$ und eine Pulsationsrate von über 55 Zyklen/min. Mein et al. (2003b) weisen darauf hin, dass die Gesamtzahl der Pulsationszyklen pro Melkvorgang sowie die Spannung des Zitzengummis vermindert werden sollten, um Zitzenkonditionsstörungen zu reduzieren. Eine Kontrolle und Steuerung der Druckdifferenz entlang der Zitzengummiwand während der d-Phase sind den Autoren zufolge wichtige Maßnahmen zur Reduzierung von Hyperkeratosen (Mein et al. 2003 b).

\subsection{5 Überdruckapplikation}

Durch die Applikation von Überdruck (Druck oberhalb vom Umgebungsdruck) in den Pulsraum kann das Vakuum in der Druckphase unter der Zitzenspitze gemindert werden, ohne dass mit einer verschlechterten Massagewirkung gerechnet werden muss.

Die Gewebefestigkeit nimmt bei einer Überdruckapplikation von $35 \mathrm{kPa}$ und einem Melkvakuum von $50 \mathrm{kPa}$ um $5 \%$ ab, beim konventionellen System ohne Überdruckapplikation ist eine Zunahme um $8 \%$ zu verzeichnen (Hamann, 1988b). Hamann und Mein (1988) konnten bei einer Überdruckapplikation von $35 \mathrm{kPa}$ und einem Melkvakuum von $50 \mathrm{kPa}$ eine Reduzierung der Dicke der Zitzenspitze um 8\%, verglichen mit dem Status vor dem Melken, ermitteln. Hamann et al. (1994) beobachteten bei Nutzung eines konventionellen Melksystems mit einem Vakuum von $50 \mathrm{kPa}$ nach dem Melken eine Zunahme der Zitzendicke um $12 \%$, und bei einem System mit einer Überdruckapplikation von $35 \mathrm{kPa}$ eine Zunahme der Zitzendicke um $2 \%$. 
Eine Überdruckapplikation von $20 \mathrm{kPa}$ führte in Untersuchungen von Geidel und Graff (2001) bei einem Melkvakuum von $43 \mathrm{kPa}$ zu einer geringeren Einengung des Zitzenkanals durch die Volumenzunahme der Zitzenwand.

\subsubsection{Zitzengummi}

Die unmittelbare Übertragung der durch die Druckdifferenz zwischen Pulsraum und Zitzengummiinnenraum des Melkbechers entstehenden Kraft auf das Zitzengewebe erfolgt durch das Zitzengummi. Durch die vakuumabhängige Bewegung des Zitzengummis findet die Kraftübertragung auf die Zitze statt.

Ein Einfaltdruck von über 13-14 kPa resultiert in einer Verschlechterung der Kondition der Zitzenenden aufgrund der Bildung von Hyperkeratosen. Dagegen ist ein Einfaltdruck von unter $8 \mathrm{kPa}$ zu niedrig, um der Entstehung von Kongestionen und Ödemen entgegenzuwirken (Mein et al., 2003a). Der Keratingehalt der Zitze ist proportional zur Spannung des Zitzengummis; eine hohe Spannung führt zu schweren Hyperplasien und Hyperkeratosen. Die Keratinmenge, die während des Melkens entfernt wird, wird jedoch nicht durch die Spannung des Zitzengummis beeinflusst (Capuco et al., 2000).

Bei Einsatz eines weichen Zitzengummis sind die Zitzen nach dem Melken kühler als bei Einsatz eines Standardzitzengummis, das unter hoher Spannung montiert wurde. Die Zitzenkondition der Zitzen, die mit dem weichen Gummi gemolken werden, normalisiert sich innerhalb von 20 Minuten nach dem Melken. Wird ein Zitzengummi, das unter hoher Spannung steht, verwendet, sind die Zitzenkanäle auch 20 Minuten nach dem Melken noch verlängert (Paulrud et al., 2005).

Nach Grindal (1988) können Zitzengummis mit weiten Öffnungen zu einer Überdehnung des Zitzengewebes führen. Gleeson und O`Callaghan (2001) untersuchten den Effekt eines Zitzengummis mit einer weiten, konischen Öffnung von 31,6-21,0 mm im Vergleich mit einem Zitzengummi mit einer 
engen Öffnung von 25,0-20,0 $\mathrm{mm}$. Sie konnten keine signifikanten Unterschiede der Zitzenkondition feststellen.

Gleeson et al. (2003) verglichen die Wirkung von engen, konischen Zitzengummis mit einer Öffnung von 25,0-20,0 $\mathrm{mm}$ bei alternierender Pulsation und einem Melkzeuggewicht von 1,65 kg mit der von weiten, konischen Zitzengummis bei simultaner Pulsation und einem Melkzeuggewicht von 3,2 kg. Die Autoren kamen zu der Erkenntnis, dass die Kombination mit dem engen Zitzengummi zu einer geringeren Ödembildung führte. Hamann et al. (1994) konnten nachweisen, dass ein Zitzengummi mit einer Öffnung von $24,6 \mathrm{~mm}$ bei $50 \mathrm{kPa}, 60 \mathrm{Zyklen} / \mathrm{min}$ und $70 \%$ Saugphasenanteil zu einer Zunahme der Zitzendicke um $12 \%$ führt. Im Gegensatz dazu resultierte aus einer geringeren Öffnung des Zitzengummis von 21,0 mm eine Zunahme der Zitzendicke von nur $1 \%$. Die Unterschiede waren signifikant. Boast et al. (2005) sind der Ansicht, dass ein Zitzengummi, das im Durchmesser kleiner ist als die Zitze, zu einer radialen Kompression und damit einhergehend zu einer Verlängerung der Zitze führt. Nach Wendt (1994) darf der Zitzendurchmesser maximal +/-20-25 \% vom Innendurchmesser des Zitzengummis abweichen.

Rønningen und Reitan (1990) konnten eine positive Korrelation zwischen der Penetrationstiefe der Zitze in das Zitzengummi und der Festigkeit der Zitzen der Vorderviertel ermitteln. Nach Mein et al. (2003a) kann die Penetrationstiefe durch eine Erhöhung des Melkzeuggewichtes sowie durch eine Erhöhung der Oberflächenreibung reduziert werden.

Runde Zitzengummis führen, verglichen mit eckigen Zitzengummis, zu einer Zunahme der Keratinisierung (Schukken et al., 2006). Die Autoren beobachteten bei Verwendung runder Zitzengummis 20\% mehr rissige Zitzen. Nach Hillerton et al. (2003) verlängern sich Zitzengummis mit zunehmender Nutzungsdauer, so dass die Zitzengummispannung und damit auch die Massagewirkung signifikant reduziert wird. Andererseits nimmt den Autoren zufolge der Anteil palpierbarer, dicker Ringe an der Zitzenbasis mit dem Alter des Zitzengummis ab. Grindal (1988) stellte fest, dass die Verwendung harter Zitzengummis in Kongestionen der Zitzenwand resultiert. 
Rasmussen et al. (1998) verglichen die Effekte der Höhen des Kopfstückbereichs von $30 \mathrm{~mm}$ bei einer Öffnung von $23 \mathrm{~mm}$ und von $18 \mathrm{~mm}$ bei einer Öffnung von $19 \mathrm{~mm}$ auf die Zitzenkondition. Die Verwendung des Zitzengummis mit der Kopfstückhöhe von $30 \mathrm{~mm}$ führte zu einer signifikant erhöhten Häufigkeit von roten und blauen Zitzen nach dem Melken.

\subsubsection{Melkzeug}

Die Gewichtslast, die während des maschinellen Milchentzuges an der Milchdrüse wirkt, kann das Melkverhalten (Melkgeschwindigkeit, Positionierung) und somit die Zitzenkondition beeinflussen. Hillerton et al. (2000) verglichen die Wirkung eines Melkzeugs mit einem Gewicht von < 3,2 $\mathrm{kg}$ bei alternierender Pulsation auf die Zitzenkondition mit derjenigen eines 3,5 kg schweren Melkzeugs bei simultaner Pulsation. Das schwere Melkzeug führte zu einem signifikant höheren Anteil roter und blauer Zitzen sowie palpierbarer Ringe an der Zitzenbasis. Nach Entfernung des schweren Melkzeugs waren mehr offene Zitzenkanäle festzustellen. Hinsichtlich des Schweregrads der Hyperkeratosen wurden keine Unterschiede beobachtet. Hillerton et al. (2002) konnten bei Verwendung verschiedener Zitzengummitypen in Verbindung mit unterschiedlichen Melkzeuggewichten $(2,3 \mathrm{~kg}, 2,8 \mathrm{~kg}, 3,5 \mathrm{~kg})$ keine signifikanten Unterschiede im Hinblick auf den Anteil verfärbter Zitzen beobachten. Rasmussen und Madsen (2000) kommen zu der Erkenntnis, dass beim Vergleich der Effekte der Melkzeuggewichte von 1,6 und 2,3 kg kein Einfluss auf die Zitzendicke zu beobachten ist. Auch hinsichtlich des Ausmelkgrades waren keine Unterschiede festzustellen. Ohnstad (1998) beobachtete bei einem Melkzeug, das schwerer als 2,4 kg war, einen höheren Ausmelkgrad als bei Verwendung eines Melkzeugs mit einem Gewicht von 2,4 kg, wobei die Nutzung des schwereren Sammelstückes in einem höheren Anteil an Kühen mit roten oder blauen Zitzen resultierte.

Nach Neijenhuis et al. (2004) führt die Vergrößerung des Durchmessers des kurzen Milchschlauchs zu einer Reduzierung des Anteils rauer Zitzenkuppen. 
Den Autoren zufolge ist dies eine Konsequenz aus der Stabilisierung des Vakuums durch die Erhöhung des Schlauchdurchmessers. 


\section{Material und Methoden}

\subsection{Betriebe}

\subsubsection{Leistungsstand}

Die Studie wurde im Zeitraum von September bis Dezember 2009 in 50 norddeutschen Betrieben durchgeführt. Die Jahresdurchschnittsmilchleistung der untersuchten Herden variierte von $7000 \mathrm{~kg} / \mathrm{Kuh}$ bis $10992 \mathrm{~kg} / \mathrm{Kuh}$ bei einem Durchschnitt von $9084 \mathrm{~kg} / \mathrm{Kuh}$. Die Daten wurden der Auswertung der offiziellen Milchleistungsprüfung entnommen, die vom Rechenzentrum VIT Verden bzw. vom LKV Schleswig-Holstein erstellt wurde.

\subsubsection{Technischer Zustand der Melkanlagen}

Eine Melkanlage, die der DIN ISO Prüfung nicht standhält, führt nicht zwangsläufig zu einer Verschlechterung der Eutergesundheit oder der Melkleistung. Die Mängel erhöhen jedoch das Risiko dafür. Um diesen Effekt in der vorliegenden Studie auszuschließen, wurden alle Melkanlagen der Prüfung nach DIN/ISO 5707: 1998 und DIN/ISO 6690: 1998 unterzogen. Hierzu wurde das niedersächsische Protokoll zur Überprüfung von Melkanlagen nach DIN/ISO 6690 verwendet (Anhang 1). Die Messungen erfolgten entsprechend der in Kapitel 2.3 beschriebenen Vorgehensweise mit dem Druckmessgerät MT52 ${ }^{\odot}$ (Bepro AG, Güttingen, Schweiz) und dem zugehörigen Luftdurchflussmessgerät (Anhang 3).

Es wurden ausschließlich Betriebe in die Untersuchungen einbezogen, die die nach DIN/ISO Prüfung geforderten Normen erfüllten. Dank der möglichen Vorauswahl aus früheren Prüfungen erfüllten alle Betriebe, die für die Untersuchungen geprüft wurden, diese Norm. 


\subsubsection{Melktechnik der Betriebe}

Die Melkanlage eines Betriebes stellt grundsätzlich ein Unikat dar, da sie für den einzelnen Betrieb und dessen räumliche Situation konfiguriert wurde. Dieser Umstand hat Auswirkungen auf die Regelcharakteristik des Vakuums bis hin zur Zitze. Weiterhin bestehen zahlreiche verschiedene Möglichkeiten der Kombination von Melkzeugen, Pulsatoren, Zitzengummis und Einstellungsvarianten (Vakuumhöhe, Pulsphasen etc.), so dass es in praxi kaum möglich ist, zwei exakt gleiche Melkanlagen zu finden. Für die Untersuchungen wurden Melkanlagen verschiedener Hersteller mit verschiedenen Ausstattungen und Einstellungen ausgewählt, um die Einflüsse der melktechnischen Variablen abzubilden. Die Melkleitung war bei allen untersuchten Betrieben tiefverlegt.

Insgesamt melkten 37 der untersuchten 50 Betriebe mit alternierender Pulsation und 13 Betriebe mit simultaner Pulsation. Der Pulsraum wurde in der Regel atmosphärisch belüftet. Lediglich in einem Betrieb wurde Überdruck in der Druckphase appliziert. Die Messung der Pulsation erfolgte mit dem Bilgery MT52 ${ }^{\odot}$ nach den Vorgaben der DIN/ISO 6690.

Als Betriebsvakuum ist das mittlere Vakuum definiert, welches im Milchabscheider herrscht, wenn alle Melkeinheiten in Betrieb sind. Es wird als mittleres Vakuum über 5 Sekunden erfasst (DIN/ISO 3918). Dieses bezieht sich immer auf den aktuellen Luftdruck und beschreibt die Druckdifferenz zwischen atmosphärischem Umgebungsdruck und dem Druck im Milchabscheider. Das Betriebsvakuum wurde auf allen untersuchten Betrieben mit dem Bilgery MT52 ${ }^{\odot}$ erfasst.

Die Daten über die Gewichte des in den Studienbetrieben verwendeten Melkzeuges wurden den Herstellerangaben entnommen.

Das Sammelstück hat die Aufgabe, die Milch der einzelnen Euterviertel zusammenzuführen und in den langen Milchschlauch abzuleiten. Weiterhin wird der Milch im Sammelstück Luft hinzugefügt, die deren Abtransport 
ermöglicht. Zur Erfassung der Sammelstückvolumina der Betriebe wurden die Herstellerangaben herangezogen.

Der Durchmesser des kurzen Milchschlauches, welcher die Milch aus dem Zitzengummiinnenraum zum Sammelstück leitet, hat hauptsächlich Einfluss auf den Verlauf des Vakuums unter der Zitze. Zur Feststellung der Schlauchdurchmesser der untersuchten Anlagen wurden die Herstellerangaben als Datenquelle genutzt.

Der Durchmesser des langen Milchschlauches, welcher die Milch aus dem Sammelstück zur Melkleitung transportiert, hat Einfluss auf den Verlauf des Vakuums im Sammelstück. Die Durchmesser der langen Milchschläuche betrugen $16 \mathrm{~mm}$, lediglich in einem Betrieb wies der entsprechende Schlauch einen Durchmesser von 14,5 mm auf (Herstellerangaben). Das Material des langen Milchschlauches war Silicon oder Gummi, dies und die Durchmesser konnten den Herstellerangaben entnommen werden.

Für die Beschreibung des Zitzengummis werden hauptsächlich die drei Größen Zitzengummikopföffnung, Zitzengummischaftdurchmesser und Einfaltdruckdifferenz vom Hersteller angegeben. Die Verfahren zur Erfassung dieser Parameter sind in der DIN/ISO 3918 beschrieben (Abb. 4). 


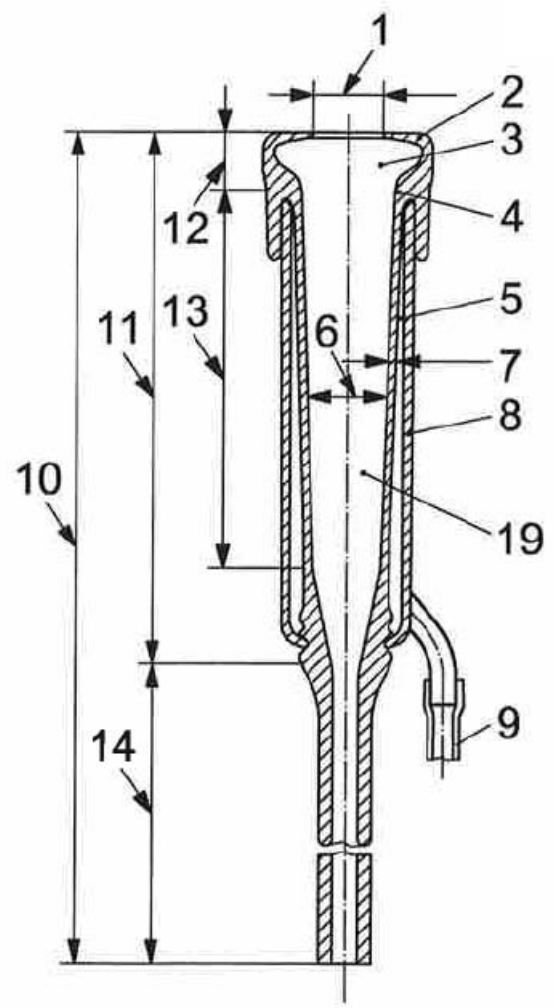

a) Zitzengummi geöffnet

1 Zitzengummikopföffnung

2 Lippe des Zitzengummikopfes

3 Innenraum des Zitzengummikopfes

4 Zitzengummihals

5 Pulsraum

6 Schaftdurchmesser

7 Wandstärke des Schaftes

8 Hülse

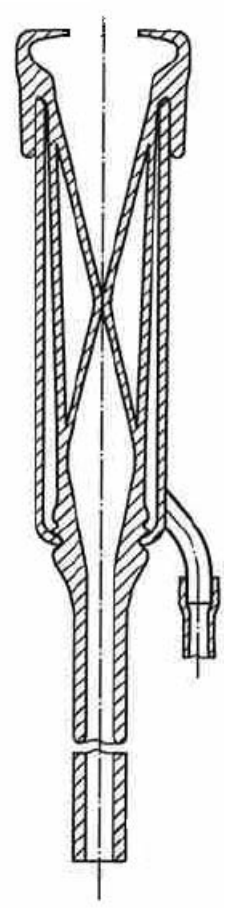

b) Zitzengummi bei Einfaltdruckdifferenz

9 kurzer Pulsschlauch

10 Zitzenbecher

11 Zitzengummi

12 Zitzengummikopf

13 Schaft

14 kurzer Milchschlauch

19 Zitzenraum

Abbildung 4: Zitzengummibegriffe und Maße (verändert nach DIN/ISO 3918)

Die Zitzengummikopföffnung hat Einfluss auf die Abdichtung des Zitzengummis zur Zitzenbasis. Folglich beeinflusst sie auch das Haftvermögen und die Häufigkeit von Lufteinbrüchen in das Melkzeug (Spohr, 2005). Die Maße in den vorliegend untersuchten Betrieben wurden den Herstellerangaben entnommen.

Der Zitzengummischaftdurchmesser wirkt sich auf die Abdichtung des Zitzengummis zum Zitzenschaft aus. Er beeinflusst die Reibung zwischen Zitzenoberfläche und Zitzengummi und damit auch das Haftvermögen 
(Wehowsky \& Tröger, 1994). Die Daten der Zitzengummischäfte der überprüften Melkanlagen wurden nach Herstellerangaben erhoben.

Die Einfaltdruckdifferenz ist die Kraft, die zum Schließen des Zitzengummis benötigt wird (Spencer \& Rogers, 2003). Die Erhebung der Daten erfolgte nach der in Kapitel 3.3.2 beschriebenen Methode.

\subsubsection{Melkarbeit in den Betrieben}

Die üblichen Verfahren der Vorreinigung, der Pflege und der Desinfektion der Zitzen nach dem Milchentzug wurden in einem Protokoll (Anhang 4) festgehalten. Sie wurden unterschieden nach:

$0=$ keine Vorreinigung

$1=$ Reinigung mit trockenen Papiertüchern

$2=$ Reinigung mit feuchten Papiertüchern

$3=$ Reinigung mit trockenen Textiltüchern

4 = Reinigung mit feuchten Textiltüchern

sowie

$0=$ keine Pflege- und Desinfektionsmaßnahmen nach dem Melken

1 = Eintauchen der Zitzen nach dem Melken

2 = Einsprühen der Zitzen nach dem Melken

und Zitzentauch- und Zitzensprühmittel:

$1=$ Jodhaltig $\quad 2=$ Milchsäurehaltig

3 = Zwei Wirkkomponenten (Chlordioxid und Milchsäure)

$4=$ sonstige 


\subsection{Tiere}

Es wurden insgesamt 248 Kühe (4-5 Tiere/Betrieb) der Rasse Deutsche Holstein untersucht. Die Tiere eines Betriebes wurden jeweils mit derselben melktechnischen Ausstattung und denselben Einstellungen gemolken.

\subsubsection{Leistungsstand}

Die Jahresleistungen der Herden wurden den jeweils aktuellen MLP-Berichten der untersuchten Betriebe entnommen. Die erfassten Gemelksleistungen entstammen den Untersuchungen vor Ort und wurden mit dem LactoCorder ${ }^{\circledR}$ (Kap. 3.3.2) aufgezeichnet. Da nur ein Gemelk berücksichtigt wurde und die Zwischenmelkzeit nicht immer 12 Stunden betrug, kann bei den Probanden von einer Tagesleistung zwischen ca. 17 und $55 \mathrm{~kg} / \mathrm{Tag}$ ausgegangen werden (lineare Hochrechnung).

\subsubsection{Laktationszahl und Laktationstag}

In die Studie wurden ausschließlich Tiere einbezogen, die sich in der 2. Laktation befanden. Ziel war es, Tiere zwischen dem 100. und 200. Laktationstag zu untersuchen. Dies war aufgrund der Herdenstrukturen jedoch nicht immer möglich, so dass geringe Abweichungen beim Laktationstag toleriert wurden.

\subsubsection{Eutergesundheitszustand der ausgewählten Tiere}

Ziel war es, Tiere ohne klinischen Mastitisbefund und mit Zellzahlwerten von unter 200.000 Zellen je ml Milch in die Untersuchungen einzubeziehen. Tiere mit Zellzahlen über 200.000 je ml Milch wurden jedoch in $6 \%$ der Fälle toleriert, da sie klinisch ohne Befund waren. Tiere mit weniger als vier laktierenden Eutervierteln wurden nur akzeptiert, wenn die anderen drei Euterviertel intakt waren. Dies war lediglich bei sieben Tieren der Fall (2,8\%). 
Die Erhebung der Daten erfolgte mittels der MLP-Auswertung der letzten Kontrolle vor dem Untersuchungstermin.

\subsection{Mess- und Beurteilungsmethoden}

\subsubsection{Druckmessung}

Zur Überprüfung der Melkanlagen nach DIN/ISO wurde das Messgerät MT52 ${ }^{\odot}$ und das zugehörige Luftdurchflussmessgerät (beide Bepro AG, Güttingen, Schweiz) verwendet (Technische Daten siehe Anhang).

Das Vakuum während des Melkvorgangs wurde mit dem Bilgery MT52 ${ }^{\odot}$ aufgezeichnet. Hierzu wurde das Gerät mit zwei internen und einem externen Sensor betrieben. Die Messungen erfolgten am hinteren linken Zitzenbecher. Der externe Sensor wurde an der Melkbecherhülse befestigt und mit einem 3 $\mathrm{cm}$ langen Schlauch mit einem Tubus verbunden, der von innen durch den Zitzengummikopf geführt wurde (Abb. 7). Die beiden internen Sensoren wurden jeweils über einen $50 \mathrm{~cm}$ langen, vakuumfesten Siliconschlauch mit 3 mm Innendurchmesser über eine Spezialnadel (NoKor ${ }^{\mathrm{TM}}$ Admix Needle, Nr. 300780, Becton Dickinson, Franklin Lakes, NJ, USA) mit dem oberen kurzen Pulsschlauch bzw. mit dem oberen kurzen Milchschlauch verbunden (Abb. 6). Die Messungen erfolgten an allen Messstellen (Abb. 5) mit einer Messrate von $100 \mathrm{~Hz}$ über einen Zeitraum von mindestens sechs Minuten, sofern der Melkvorgang nicht kürzer war. Zur Auswertung standen 248 Vakuummessungen für jede der genannten drei Messstellen zur Verfügung. 


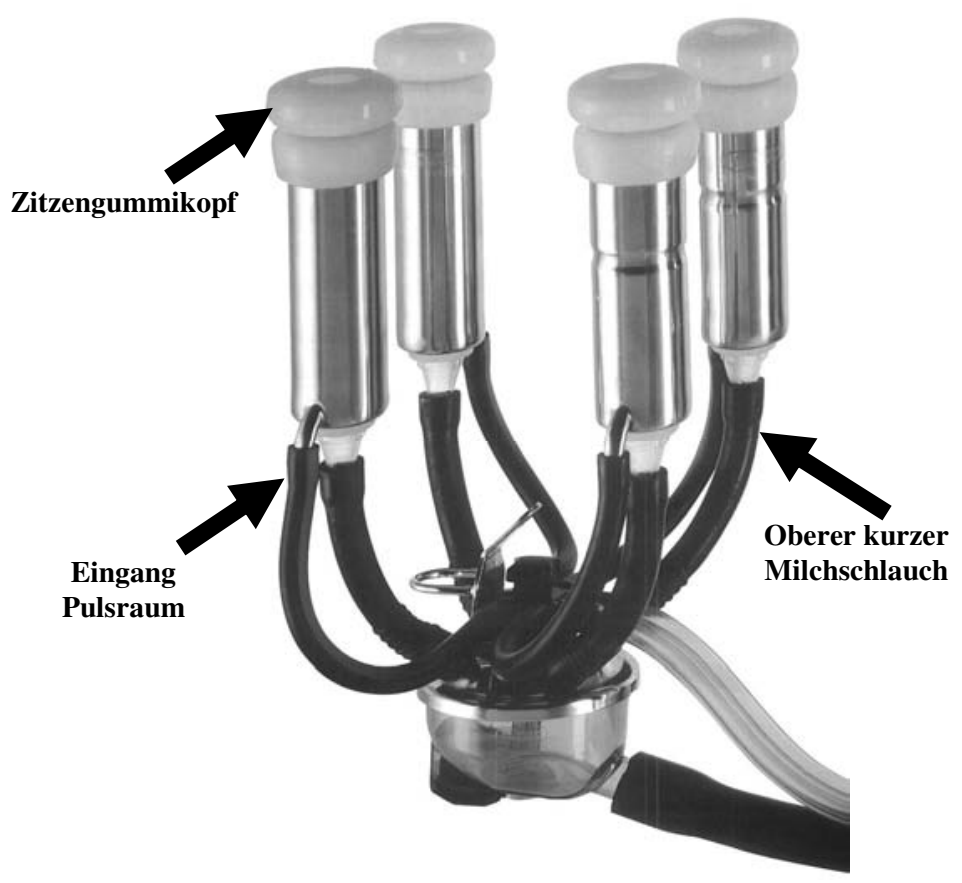

Abbildung 5: Die Messstellen im Melkzeug (verändert nach Werkbild GEA Farm Technologies, D 59199 Bönen)
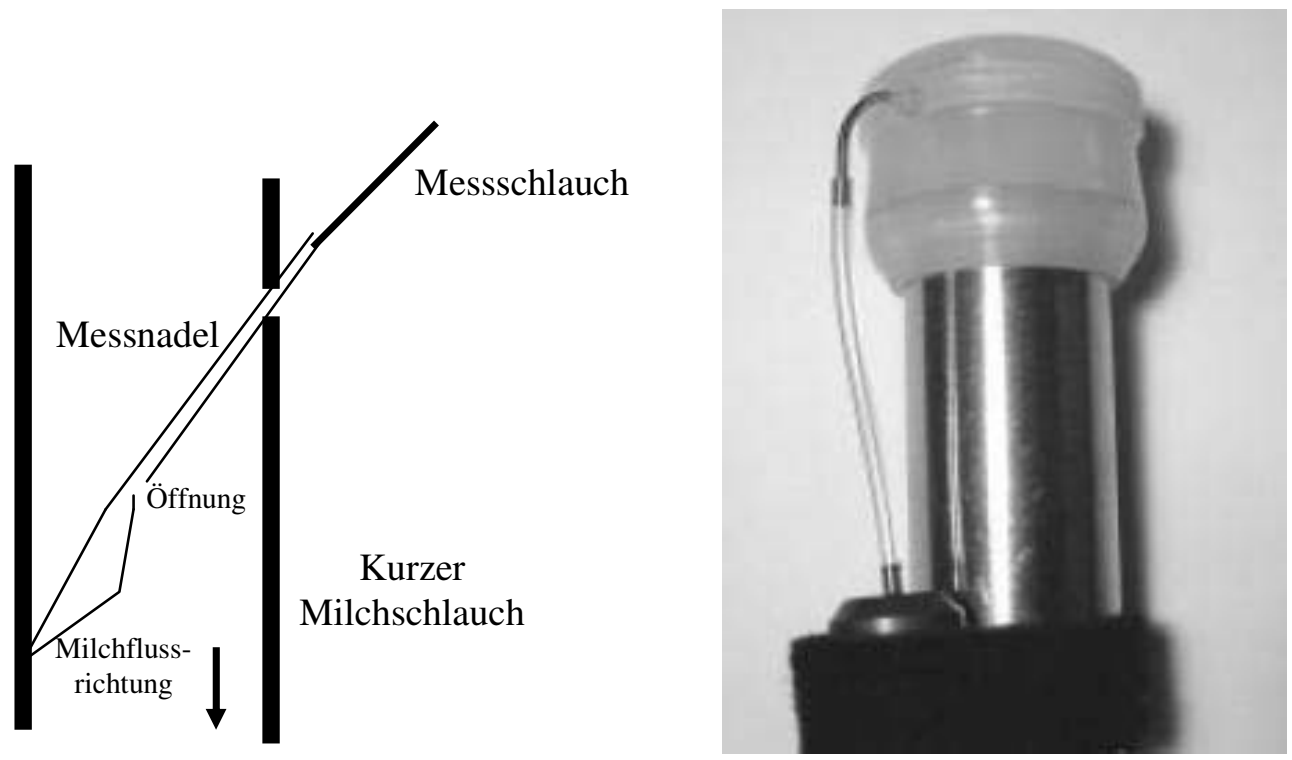

Abbildung 6: Messnadel im kurzen

Abbildung 7: Zitzengummikopf mit Milchschlauch (Schema) eingeführtem Tubus

(Werkbild Bepro AG, CH 8594

Güttingen) 


\subsubsection{Einfaltdruck des Zitzengummis}

Der Einfaltdruck der Zitzengummis wurde mit einem modifizierten Blutdruckmessgerät (Nr. 020-1-000, Boso, D 72417 Jungingen,) erfasst. Anstelle der Armmanschette wurde der Raum zwischen Zitzengummi und Zitzenbecherhülse (Pulsraum) mit Luft beaufschlagt, bis der Überdruck so hoch war, dass sich die gegenüberliegenden Zitzengummiwandungen berührten (Touchpoint, siehe auch Abb. 4). Der erhaltene Wert gibt die Druckdifferenz an, die zwischen Zitzengummiinnenraum und Pulsraum vorhanden sein muss, um das Zitzengummi $\mathrm{zu}$ schließen. Ist die Vakuumhöhe im Zitzengummiinneren und im Pulsraum im Verlauf bekannt, können die Zeit und die Kraft des auf die Zitze einwirkenden Zitzengummis bestimmt werden.

\subsubsection{Milchflussmessung}

Der Milchfluss jeder Kuh wurde über den gesamten Melkvorgang hinweg mit dem LactoCorder ${ }^{\circledR}$ (WMB AG, Balgach, Schweiz) aufgezeichnet. Dieser verfügt über die internationale Anerkennung als Gerät zur Milchleistungsprüfung durch ICAR (International Committee for Animal Recording). Der LactoCorder ${ }^{\circledR}$ besteht aus den zwei Hauptmodulen Hydraulikteil und Elektronikteil. Im Hydraulikteil, durch den die Milch geführt wird, erfolgt die Messung. Im Elektronikteil werden die Messwerte verarbeitet und gespeichert. Im LactoCorder ${ }^{\circledR}$ wird die pulsierend ankommende Milch beruhigt und von einem Teil der Transportluft getrennt. In einer Staukammer wird die Pegelhöhe über 60 Elektroden erfasst und nach 0,7 Sekunden neu bestimmt. Über die gleichzeitige Messung der Leitfähigkeit wird der Schaumanteil bestimmt und der Massenstrom berechnet. Dadurch kann der Massendurchfluss $(\mathrm{kg} / \mathrm{min}$.) auch bei variierendem Schaumanteil präzise gemessen werden. 
Zur Auswertung standen 248 Messungen zur Verfügung. Beispielhaft für die graphische Darstellung einer Messung ist Abbildung 8. Relevante Messdaten sind hierbei die gesamte Milchmenge des Gemelks (MGG), der höchste Milchfluss (HMF), die Dauer der Anstiegsphase (tAN), die Dauer der Plateauphase (tPL), die Dauer der Abstiegsphase (tAB), die Dauer der gesamtem Melkung (tMGG), das durchschnittliche Minutenhauptgemelk (DMHG), sowie die Zeit zwischen 400g/min und $200 \mathrm{~g} / \mathrm{min}$ am Ende der Melkung (t400).

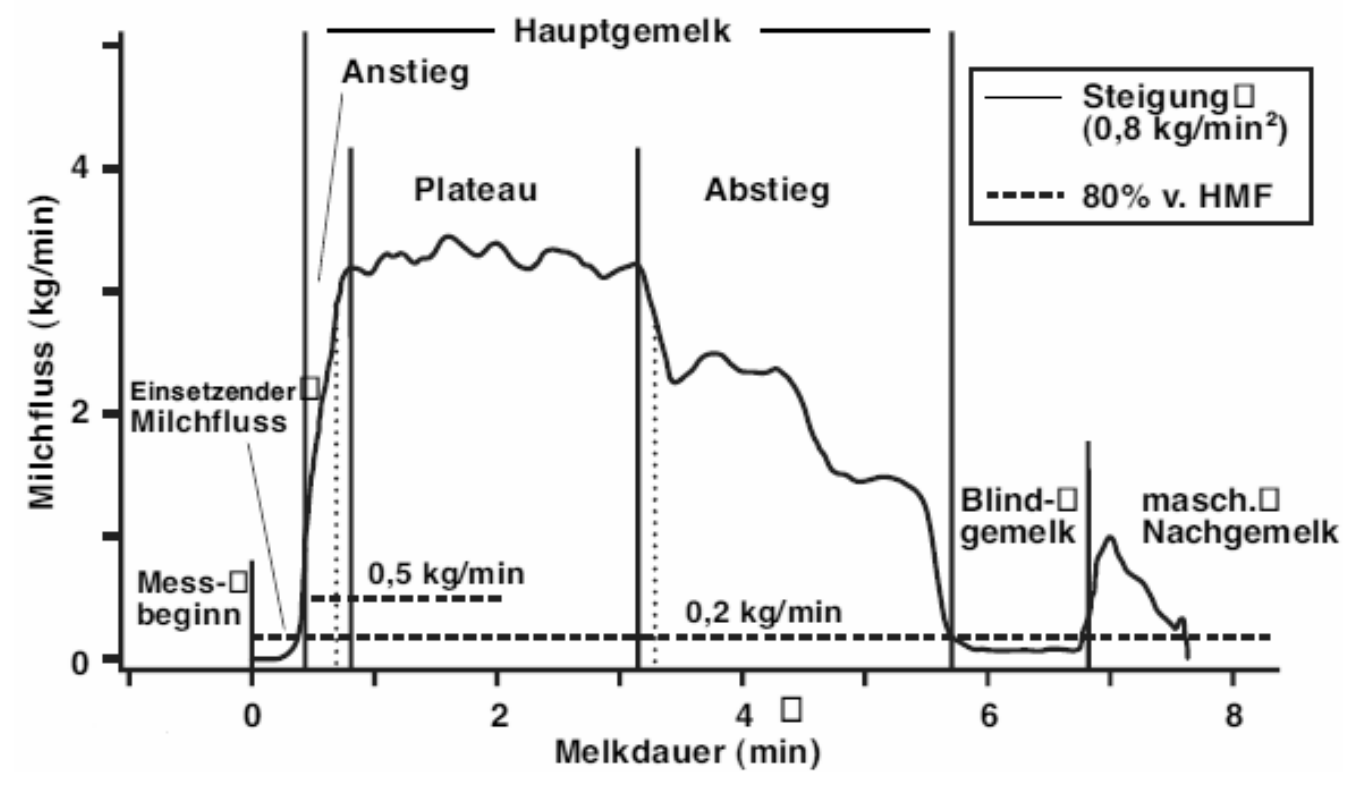

Abbildung 8: Beispiel eines Milchabgabeprofils (Aus: Bedienungsanleitung LactoCorder $^{\circledR}$, WMB AG, CH 9436 Balgach)

\subsubsection{Zitzendicke}

Die Dicke bzw. Festigkeit des Zitzengewebes der Zitzenspitze wurde mit einem nach Hamann modifizierten Cutimeter (Nr. 33865, Hauptner, Solingen, Germany) an der hinteren linken Zitze gemessen (Abb. 9). Dazu wurde die Feder des Kutimeters, welches normalerweise zur Messung der Hautdicke 
beim Tuberkulintest genutzt wird, gegen eine Feder mit geringerer Kraft (Nr. RZ-081K-02I, Gutekunst, Metzingen, Germany) ausgetauscht. Die Federkraft beträgt 4,621 N, wenn die Messschenkel $10 \mathrm{~mm}$ voneinander entfernt sind. Auf dem Cutimeter befindet sich eine Anzeige, die die Entfernung der beiden Messschenkel voneinander in mm anzeigt. Die Messungen wurden jeweils vor dem ersten Berühren der Zitzen und unmittelbar nach Melkzeugabnahme (binnen 10 Sekunden) durchgeführt.

Die Änderung der Gewebefestigkeit (G) wird nach folgender Formel (Formel 1) berechnet (Hamann et al., 1996):

$\mathrm{G}$ in $\%=\frac{\text { G nach dem Melken }-\mathrm{G} \text { vor dem Melken }}{\mathrm{G} \text { vor dem Melken }}$
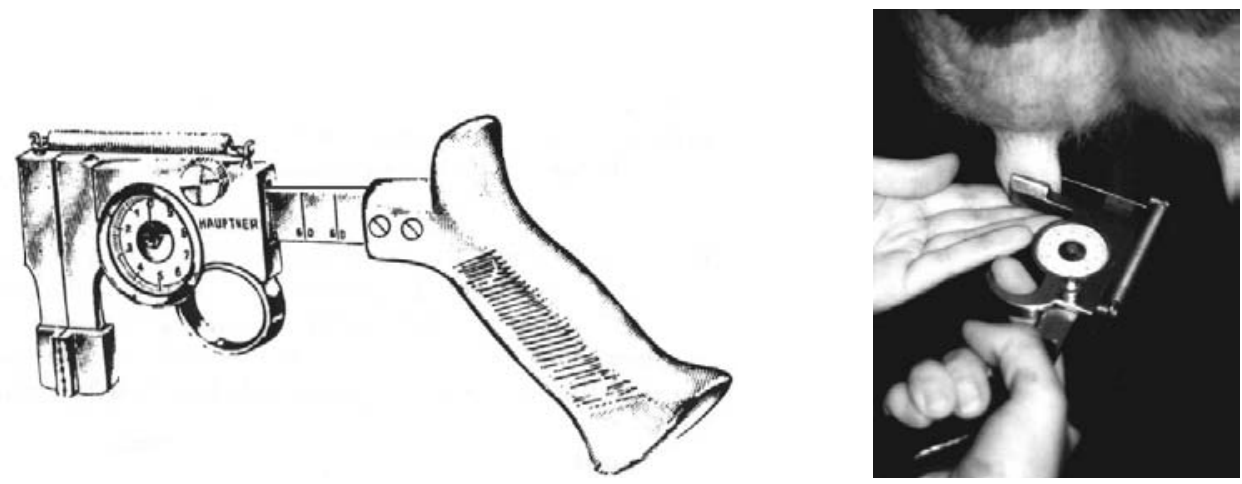

(Foto: Hansen S, 2002)

Abbildung 9: Cutimeter zur Messung der Gewebefestigkeit (Hamann J und Mein G A, 1988)

\subsubsection{Zitzenvermessung}

Die Zitzenmaße wurden immer an der hinteren linken Zitze erhoben, da an dieser Zitze auch die Vakuummessungen und die Beobachtungen zum Gewebe- und Hautzustand vor und nach dem Melken vorgenommen wurden. 
Die Länge und der Durchmesser wurden mit einer Zitzenvermessungslehre (Nr. 7750-0111-880, GEA Farm Technologies, 59199 Bönen, Deutschland), bestimmt. Auf der durchsichtigen, beleuchteten Lehre (Abb. 10) ist für die Länge und den Durchmesser jeweils eine Skala in Millimeter aufgebracht. Die Länge wurde von der Zitzenbasis bis zur Zitzenspitze und der Durchmesser in der Mitte der Zitze gemessen. Diese Messung wurde an der angerüsteten Zitze durchgeführt, um die Zitzenmaße in Bezug zu den Zitzengummimaßen setzen zu können (Abb. 11).

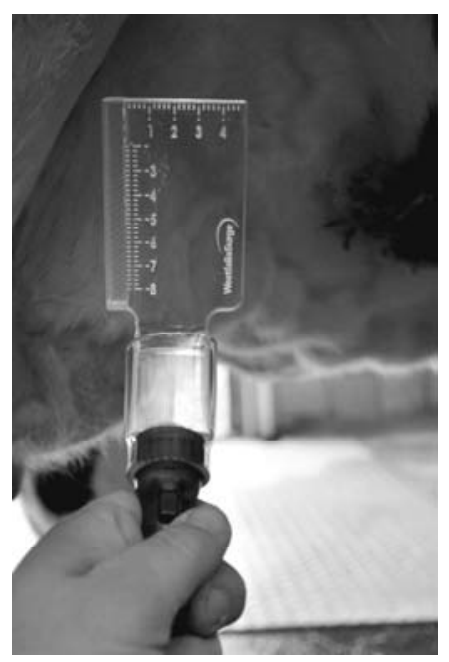

Abbildung 10: Messlehre zur Zitzenvermessung

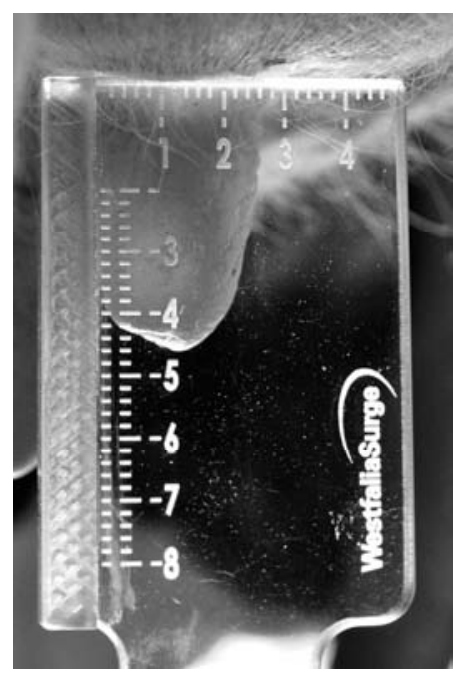

Abbildung 11: Einsatz der Messlehre zur Zitzenvermessung 
3.3.6 Zitzenform und Zitzenkuppenform

Die Zitzenformen aller vier Zitzen der ausgewählten Tiere wurden nach GRUNERT (1990) klassifiziert (Abb. 12):

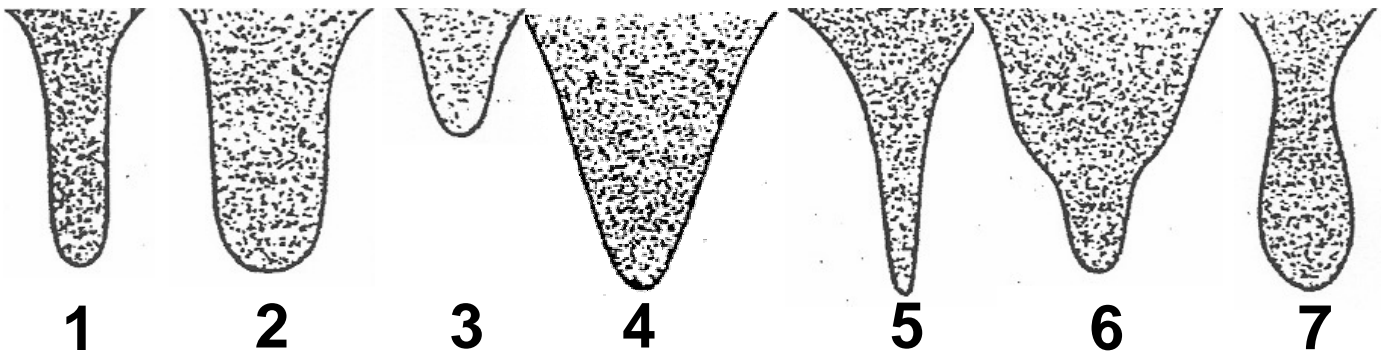

$\underline{\text { Zitzenform }}$

$1=$ normale Form

$2=$ Fleischzitze

3 = Kurzzitze

$4=$ Kegelzitze

$5=$ Bleistiftzitze

$6=$ milchbrüchige Zitze

7 = Flaschenzitze

Abbildung 12: $\quad$ Zitzenformen nach GRUNERT (1990) 
Die Zitzenkuppenformen aller vier Zitzen der ausgewählten Tiere wurden nach GRUNERT (1990) klassifiziert (Abb. 13):

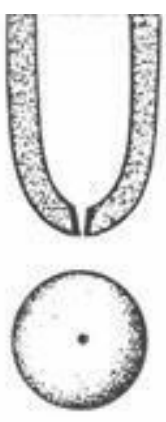

1
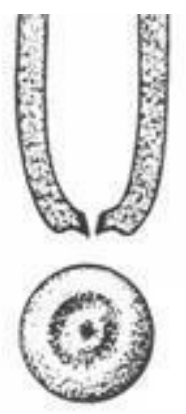

2

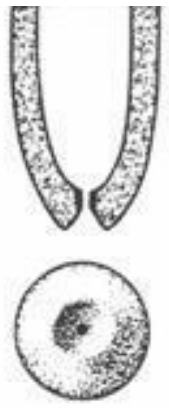

3
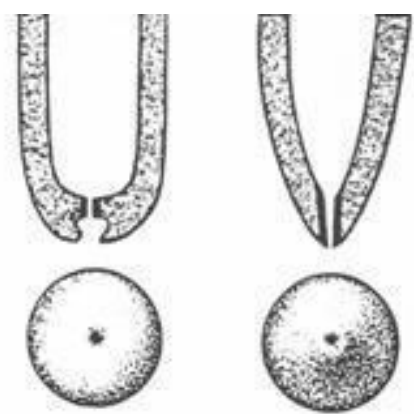

4

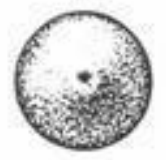

5

\section{Zitzenkuppenform}

$1=$ runde Zitze

$3=$ Trichterzitze

$5=$ Spitzzitze
$2=$ Tellerzitze

$4=$ Taschenzitze

Abbildung 13: $\quad$ Zitzenkuppenformen nach GRUNERT (1990)

\subsubsection{Beurteilung der Zitzenkondition}

Während der Untersuchungen wurde die Zitzenkondition vor und nach dem Melken bestimmt. Einige Parameter wurden durch Adspektion, andere durch Palpation erhoben. 


\subsubsection{Zitzenhaut}

Der Zustand der Zitzenhaut wurde vor dem Melkvorgang in eine der folgenden drei Stufen (Abb.14) eingeordnet:

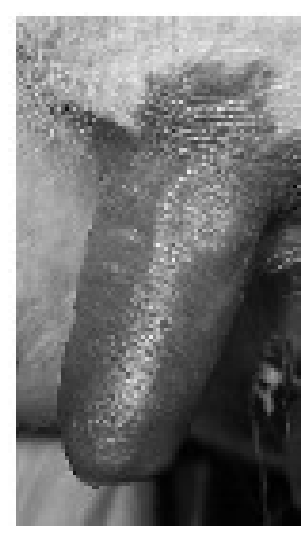

1

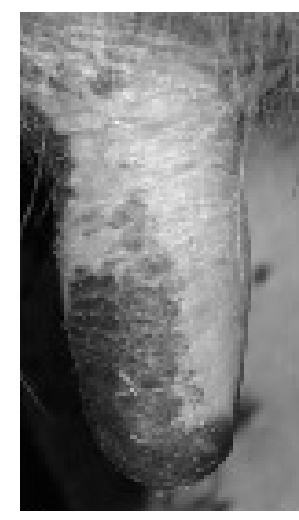

2

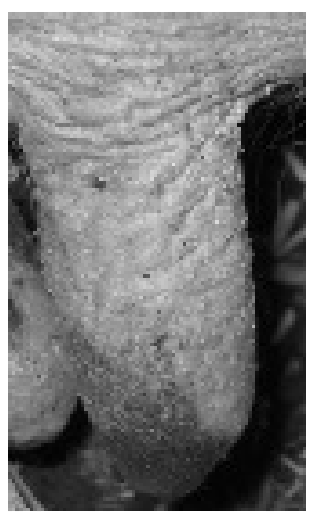

3

1 = glatt

$2=$ mittel (wenige Schuppen oder Risse)

3 = rau (Haut gerissen und/oder schuppig)

Abbildung 14: Stufen der Zitzenhautkondition

(Fotos: Reinecke F, 2006)

\subsubsection{Zitzenhautfarbe}

Die Farbe der Zitzenhaut wurde nach dem Melkvorgang bewertet und in drei Stufen eingeteilt:

$1=$ normal (Hautfarbe unverändert)

$2=\operatorname{rot}$

$3=$ blau 


\subsubsection{3 Ödeme}

Die Bildung von Ödemen sowohl an der Zitzenspitze (Kongestion) als auch an der Zitzenbasis (Ringwulst, Abb. 15) wurde unabhängig von der Cutimetermessung nach dem Melken palpatorisch erfasst. Dabei wurde folgende Einteilung vorgenommen:

Kongestion an der Zitzenspitze:

$0=$ normal (weiche Zitzenspitze)

$1=$ verhärtet (Zitzenspitze geschwollen)

Ringödem an der Zitzenbasis:

$0=$ kein Ringwulst

$1=$ Ringwulst

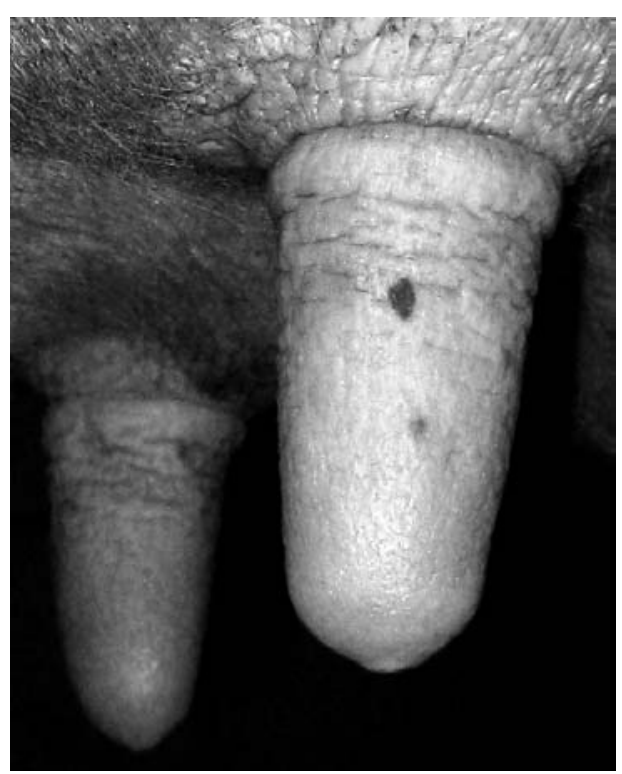

Abbildung 15: Zitzen mit Ringwulst an der Basis

(Foto: Reinecke F, 2009) 


\subsubsection{Hyperkeratosen}

Der Grad der Hyperkeratosen wurde für alle vier Zitzen jeder Kuh nach dem Schema von MEIN et al (2001) bewertet. Die Hyperkeratosen an der Zitzenkanalöffnung wurden einer der vier Kategorien „keine Ringbildung“, „glatter Ring“, „,rauer Ring“ bis „,sehr rauer Ring“ zugeordnet (Abb. 16).
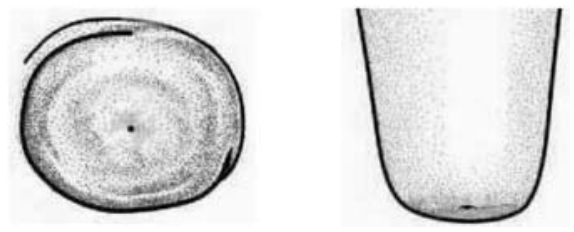

1 Keine Ringbildung. Die Zitzenspitze ist glatt mit einer kleinen, ebenen Öffnung.
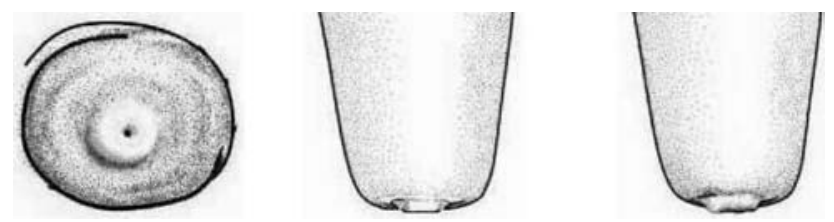

2 Glatter bzw. leicht rauer Ring. Ein leicht erhabener Ring liegt um die Öffnung. Der Ring ist glatt bzw. leicht rau.
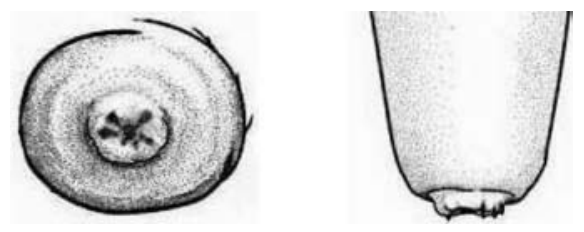

3 Rauer Ring. Ein erhabener, zerklüfteter rauer Ring mit abstehenden Keratinfortsätzen, Ringdicke 1-3 mm.
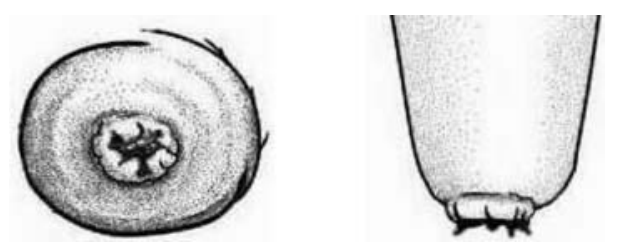

4 Sehr rauer Ring. Ein erhabener, rauer, stark zerklüfteter Ring mit abstehenden Keratinfortsätzen, Ringdicke $>4 \mathrm{~mm}$.

Abbildung 16: Einteilung der Hyperkeratosen (verändert nach Mein et al., 2001) 


\subsubsection{Hautfeuchte}

Die Feuchtigkeit an der Zitzenspitze nach dem Melken wurde mit $0=$ trocken $1=$ feucht bewertet, um feststellen zu können, ob die Zitzenspitze während des Milchentzugs mit Milch umspült wurde.

\subsubsection{Anrüsten der Versuchstiere}

Alle Tiere wurden standardisiert angerüstet, um keine Unterschiede in der Milchabgabe zu provozieren, die durch das Anrüsten bedingt wären. Das Vormelken erfolgte mit dem Faustmelkgriff, je Zitze wurden 3 Strahlen abgemolken. Dann wurde jede Zitze für ca. 5 Sekunden mit einem trockenen Papiertuch gereinigt. Es folgte eine Wartezeit von 30 Sekunden, so dass nach einer Minute nach der ersten Berührung das Melkzeug angesetzt wurde.

\subsubsection{Bestimmung des Ausmelkgrades}

Der Ausmelkgrad der Tiere wurde überprüft, indem aus jedem Viertel manuell die Restmilch in einen Messbecher gemolken wurde. Als obere Grenze für einen guten Ausmelkgrad wurden 300 ml Milch für das gesamte Euter und 100 ml für einzelne Viertel angenommen.

\subsection{Ablauf der Untersuchungen}

Vor den beim Melken durchgeführten Untersuchungen wurden sämtliche Melkanlagen nach DIN/ISO 6690:1998 geprüft. Dies beinhaltete auch die Messung aller Pulsatoren. Hierzu wurde das Messgerät Bilgery MT52 ${ }^{\odot}$ und für die Luftdurchflussmessungen auch das dazu gehörige Airflowmeter genutzt. Die Ergebnisse wurden in einem Datenprotokoll festgehalten, welches nach 
DIN/ISO 6690 Vorgaben erstellt wurde (Anhang 1, 2). Alle weiteren Parameter der Melktechnik und des Betriebes wurden ebenfalls erfasst. Dazu gehörten die Melkzeit (Abends/Morgens), der Melkzeugtyp und der Zitzengummityp, Länge, Durchmesser und Material des langen Milchschlauches, Zitzengummimaße und Einfaltdruck, Art der Zitzenvorreinigung und Art der Pflege-/Desinfektionsmaßnahme der Zitzen nach dem Melkvorgang.

Die Aufzeichnungen der Parameter von jeweils 4 bis 5 Kühen je Betrieb erfolgten während der Abend- oder Morgenmelkzeit. Alle Melkanlagen hatten tiefverlegte Melkleitungen. An dem Melkplatz des jeweiligen Probanden wurde zunächst der LactoCorder ${ }^{\circledR}$ (Kap. 3.3.2) eingebaut und das Melkzeug mit den nötigen Messvorrichtungen für Vakuummessungen ausgestattet (Kap. 3.3.1). Vor dem ersten Berühren der Zitzen wurden diese mit dem modifizierten Cutimeter gemessen. Dann wurden der Hautzustand, die Zitzenform und die Zitzenkuppenform erfasst. Die Zitzen wurden standardisiert vorgemolken und gereinigt (Kap. 3.3.7). Der Grad der Hyperkeratosen wurde erfasst und ca. eine Minute nach der ersten Berührung das Melkzeug angesetzt.

Die Milchflussrate jeder Kuh wurde über den gesamten Melkvorgang mit dem LactoCorder ${ }^{\circledR}$ sowie sämtliche Druckmessungen mit dem Bilgery MT52 ${ }^{\odot}$ bestimmt. Zur Auswertung standen somit 248 Messungen je Bereich (Milchflussprofile, Druckmessungen und Tierdaten) zur Verfügung.

Unmittelbar nach dem Melkvorgang wurden die Cutimetermessungen wiederholt durchgeführt und es erfolgte die Erhebung der Daten zu Zitzenkondition und Zitzenhautkondition. Dann wurde der Ausmelkgrad überprüft (Kap. 3.3.8).

Die erhobenen Daten, die nicht in den genannten Messgeräten gespeichert wurden, wurden in einem Protokoll festgehalten (Anhang A4 und A5). 


\subsection{Mathematisch-statistische Auswertung der Untersuchungsergebnisse}

Die Daten wurden unter Verwendung von Excel, Access 2000 (Microsoft Corporation) und SPSS (SPSS 13.0, Chicago USA) gesammelt und analysiert. Die Daten wurden auf Ausreißer und Plausibilität geprüft. Alle Datensätze konnten in die Auswertung einbezogen werden. Die statistische Einheit war die Kuh. Die statistische Signifikanzgrenze wurde mit $\mathrm{P} \leq 0,05$ festgelegt. Als Lagemaße wurden arithmetische Mittelwerte oder Mediane angegeben und als Streuungsmaße wurden Standardabweichungen oder Minimum und Maximum berechnet. In Abhängigkeit der Variablentypen (metrisch (normalverteilt oder nicht), ordinal, nominal) wurden unterschiedliche Testverfahren zur Untersuchung von Assoziationen und Zusammenhängen zwischen den Variablen gewählt. Zunächst wurden stets univariate Testverfahren verwandt. Statistische Unterschiede zwischen Verhältnissen wurden mit dem ChiQuadrat-Test oder mit dem Fisher Exact Test errechnet, für Mittelwertsunterschiede normalverteilter metrischer Variablen wurde der TTest nach Student oder einfaktorielle Varianzanalysen verwandt. Ansonsten wurde der Chi-Quadrat-Test gewählt. Zur Untersuchung von Beziehungen wurden Korrelationskoeffizienten in Abhängigkeit von den zu vergleichenden Variablen (normalverteilt, metrisch oder nicht normalverteilt oder ordinal skaliert) entweder nach Pearson oder nach Spearman kalkuliert. Als Signifikanztest der Korrelationsberechnungen wurde ein zweiseitiger T-Test durchgeführt. Nach Durchführung der univariaten Analysen erfolgten multivariate Untersuchungen. Hierbei wurden logistische Regressionen (binäre, ordinale, nominale) und mehrfaktorielle varianzanalytische Modelle berücksichtigt (Urban, 1993). 


\section{Ergebnisse}

\subsection{Betriebe}

\subsubsection{Fabrikate und Melkzeuge}

Alle Melkanlagen der 50 Betriebe erfüllten die Anforderungen nach DIN/ISO 5707 und 6690. Folgende Fabrikate waren bei den Untersuchungen beteiligt: DeLaval, WestfaliaSurge, Lemmer Fullwood, SAC, Boumatic, Happel und Miele. In den Betrieben wurden 12 verschiedene Melkzeugtypen verwendet (Tabelle 1).

Tabelle 1: Häufigkeit der Melkanlagenfabrikate und verwendete Melkzeuge auf den untersuchten Betrieben $(n=50)$

\begin{tabular}{|c|c|c|c|c|c|c|c|}
\hline & DeLaval & $\begin{array}{c}\text { Westfalia } \\
\text { Surge }\end{array}$ & $\begin{array}{l}\text { Lemmer } \\
\text { Fullwood }\end{array}$ & SAC & Boumatic & Happel & Miele \\
\hline $\begin{array}{c}\text { Anzahl } \\
\text { Betriebe }\end{array}$ & 15 & 15 & 8 & 6 & 4 & 1 & 1 \\
\hline $\begin{array}{l}\text { Anteil \% } \\
\text { Betriebe }\end{array}$ & 30 & 30 & 16 & 12 & 8 & 2 & 2 \\
\hline $\begin{array}{l}\mathrm{M} \\
\mathrm{E} \\
\mathrm{L}\end{array}$ & Harmony & $\begin{array}{c}\text { Classic } \\
300\end{array}$ & Clearflow & Uniflow2 & $\begin{array}{c}\text { Flo-star } \\
\text { Max }\end{array}$ & S90 & Champion \\
\hline $\begin{array}{l}K \\
Z \\
E\end{array}$ & $\begin{array}{c}\text { Harmony } \\
\text { Plus }\end{array}$ & $\begin{array}{l}\text { Classic } \\
300 \mathrm{E}\end{array}$ & & & & & \\
\hline U & HCC 150 & $200 \mathrm{ccm}$ & & & & & \\
\hline$G$ & & Eclipse & & & & & \\
\hline
\end{tabular}


Die 12 verschiedenen Melkzeuge wogen zwischen $1600 \mathrm{~g}$ und $2800 \mathrm{~g}$ mit einem Mittelwert von $2162 \mathrm{~g}$, einem Median von $2380 \mathrm{~g}$ und einer Standardabweichung von $379 \mathrm{~g}$.

\subsubsection{Pulsation}

In 37 Betrieben (74\%) wurden die Kühe mit alternierender und in 13 Betrieben (26\%) mit simultaner Pulsation gemolken. Die Pulsrate variierte von 55 bis 62 Zyklen/min. Die Daten der einzelnen Phasen der Pulsation sind in Tabelle 2 dargestellt.

Tabelle 2: Pulsationscharakteristika der untersuchten Betriebe $(n=50)$

\begin{tabular}{|c|c|c|c|c|c|c|}
\hline & $\begin{array}{c}\text { A Phase } \\
\text { in } \mathrm{ms}^{1}\end{array}$ & $\begin{array}{c}\text { B Phase } \\
\text { in } \mathrm{ms}\end{array}$ & $\begin{array}{c}\text { Saughase } \\
\text { in ms }\end{array}$ & $\begin{array}{c}\text { C Phase } \\
\text { in ms }\end{array}$ & $\begin{array}{c}\text { D Phase } \\
\text { in ms }\end{array}$ & $\begin{array}{c}\text { Pulsrate } \\
\text { Zyklen/Min. }^{2}\end{array}$ \\
\hline Minimum & 96 & 418 & 591 & 66 & 167 & 55 \\
\hline Maximum & 266 & 584 & 733 & 184 & 342 & 62 \\
\hline Mittelwert & 145 & 487 & 632 & 112 & 270 & 59 \\
\hline Median & 140 & 481 & 639 & 103 & 267 & 60 \\
\hline SD $^{3}$ & 30 & 35 & 32 & 27 & 33 & 2 \\
\hline
\end{tabular}

${ }^{1} \mathrm{~ms}=$ Millisekunden

${ }^{2}$ Min. $=$ Minute

${ }^{3} \mathrm{SD}=$ Standardabweichung

\subsubsection{Vakuumverhältnisse}

Die Vakuumverhältnisse wurden im Milchsystem (Betriebsvakuum) und im Melkzeug während des Melkens an der Zitze (Kurzer Milchschlauch und Zitzengummikopf) gemessen. Das Betriebsvakuum lag auf den Betrieben zwischen 36 und 46,5 $\mathrm{kPa}$ bei einem Mittelwert von 41,2 $\mathrm{kPa}$ und einer Standardabweichung von 2,15 kPa. Das mittlere Vakuum während des 
höchsten Milchflusses lag im kurzen Milchschlauch zwischen 25,8 und 39,4 kPa bei einem Mittelwert von 33,9 kPa und einer Standardabweichung von 2,6 $\mathrm{kPa}$. Die Fluktuation der Werte im kurzen Milchschlauch variierte von 3,1 kPa bis 30,2 kPa bei einem Mittelwert von 10,9 kPa und einer Standardabweichung von $5,71 \mathrm{kPa}$. Das Vakuum im Zitzengummikopf in der Plateauphase des Milchflusses erreichte Werte von $1 \mathrm{kPa}$ bis $34 \mathrm{kPa}$ bei einem Mittelwert von 12 $\mathrm{kPa}$ und einer Standardabweichung von $7,23 \mathrm{kPa}$.

Tabelle 3: Vakuumverhältnisse im Melkzeug während des Melkens

\begin{tabular}{|c|c|c|c|c|}
\hline & $\begin{array}{c}\text { Betriebsvakuum } \\
\text { in } \mathrm{kPa}^{1}\end{array}$ & $\begin{array}{c}\text { Mittleres } \\
\text { Vakuum } \\
\text { im } \mathrm{KMS}^{2} \\
\text { in kPa }\end{array}$ & $\begin{array}{c}\text { Fluktuation im } \\
\qquad \mathrm{KMS} \\
\text { in } \mathrm{kPa}\end{array}$ & $\begin{array}{c}\text { Vakuum im } \\
\mathrm{ZGK}^{3} \\
\text { in } \mathrm{kPa}\end{array}$ \\
\hline Minimum & 36 & 25,8 & 3,1 & 1 \\
\hline Maximum & 46,5 & 39,4 & 30,2 & 34 \\
\hline Mittelwert & 41,2 & 33,9 & 10,9 & 12 \\
\hline Median & 41,5 & 34,2 & 8,4 & 10 \\
\hline SD & 2,15 & 2,6 & 5,71 & 7,23 \\
\hline
\end{tabular}

\footnotetext{
${ }^{1} \mathrm{kpa}=$ KiloPascal

${ }^{2} \mathrm{KMS}=$ Kurzer Milchschlauch

${ }^{3}$ ZGK $=$ Zitzengummikopf
} 


\subsubsection{Zitzengummidesign}

Durchmesser der Kopföffnung (Kopf) und Durchmesser des Schaftes (Schaft) sowie die Einfaltdruckdifferenz (EDkPa) der Zitzengummis wurden bestimmt. Die Ergebnisse sind in Tabelle 4 dargestellt.

Tabelle 4: Zitzengummimaße und Einfaltdruckdifferenz

\begin{tabular}{|c|c|c|c|}
\hline & $\begin{array}{c}\text { Durchmesser } \\
\text { Kopföffnung } \\
\text { in } \mathrm{mm}\end{array}$ & $\begin{array}{c}\text { Durchmesser } \\
\text { Schaft } \\
\text { in } \mathrm{mm}\end{array}$ & $\begin{array}{c}\text { Einfaltdruck- } \\
\text { differenz } \\
\text { in } \mathrm{kPa}\end{array}$ \\
\hline Minimum & 20 & 21,5 & 6,9 \\
\hline Maximum & 24 & 27 & 16 \\
\hline Mittelwert & 21,6 & 23,8 & 10,5 \\
\hline Median & 22 & 23,5 & 10,4 \\
\hline SD & 1 & 1 & 2 \\
\hline
\end{tabular}

\subsection{Tiere}

\subsubsection{Eutergesundheit und Leistung}

Es wurden ausschließlich Tiere ohne klinische Anzeichen einer Mastitis in die Studie einbezogen. Die Laktationstage lagen zwischen 52 und 234 bei einem Mittelwert von 151 Tagen. $93 \%$ aller untersuchten Tiere waren zwischen 90 und 210 Tagen in der Laktation. Die durchschnittliche Zellzahl lag zwischen 10.000 und 478.000 somatischen Zellen/ml bei einem Mittel von 92.000 Zellen/ml und einem Median von 70.000 Zellen/ml bei der letzten Milchleistungsprüfung. Die Gemelksmenge bei der Untersuchung variierte von $1,84 \mathrm{~kg}$ bis $29,73 \mathrm{~kg}$ bei einem Mittelwert von 14,63 kg. 
Tabelle 5: Zellgehalte und Gemelksmengen der untersuchten Tiere $(n=248)$

\begin{tabular}{|c|c|c|c|c|c|}
\hline & Minimum & Maximum & Mittelwert & Median & $\mathrm{SD}^{1}$ \\
\hline $\begin{array}{c}\text { Somatische } \\
\text { Zellzahl/ml } \\
\text { Milch (kZellen/ml) }\end{array}$ & 10 & 478 & 92 & 70 & 75 \\
\hline Gemelksmenge (L) & 1,84 & 29,73 & 14,63 & 14,48 & 3,8 \\
\hline
\end{tabular}

${ }^{1} \mathrm{SD}=$ Standardabweichung

\subsubsection{Milchflussparameter}

Als relevante Milchflussparameter der Tiere wurden die Gemelksmenge (MGG), die Melkdauer (tMGG), der höchste Milchfluss (HMF), die Dauer der Melkabschnitte „Anstieg“(tAN), „Plateau“(tPL), „Abstieg zwischen 400 und 200 Gramm/Minute“ (t400) und „Abstieg“(tAB) sowie das Auftreten von Lufteinbrüchen (LE) festgehalten. Lufteinbrüche traten bei 5 Tieren (2\%) auf. Bimodalitäten in den Milchabgabeprofilen traten nicht auf.

Tabelle 6: Milchflussparameter der untersuchten Tiere $(n=248)$

\begin{tabular}{|c|c|c|c|c|c|c|c|}
\hline & $\begin{array}{c}\mathrm{MGG}^{1} \\
\text { in } \mathrm{kg}\end{array}$ & $\begin{array}{c}\mathrm{tMGG}^{2} \\
\text { in min }\end{array}$ & $\begin{array}{c}\mathrm{HMF}^{3} \\
\text { in } \mathrm{kg} / \mathrm{min}\end{array}$ & $\begin{array}{c}\mathrm{tAN}^{4} \\
\text { in min }\end{array}$ & $\begin{array}{c}\mathrm{tPL}^{5} \\
\text { in min }\end{array}$ & $\begin{array}{c}\mathrm{tAB}^{6} \\
\text { in min }\end{array}$ & $\begin{array}{c}\mathrm{T}_{400^{7}} \\
\text { in min }\end{array}$ \\
\hline Minimum & 1,84 & 3,1 & 1,26 & 0,09 & 0,05 & 0,47 & 0,00 \\
\hline Maximum & 29,73 & 11,95 & 7,59 & 1,91 & 7,42 & 7,84 & 1,82 \\
\hline Mittelwert & 14,63 & 6,69 & 3,95 & 0,83 & 2,18 & 2,80 & 0,24 \\
\hline Median & 14,48 & 6,61 & 3,85 & 0,79 & 2,01 & 2,69 & 0,14 \\
\hline $\mathrm{SD}$ & 3,79 & 1,17 & 1,12 & 0,33 & 1,37 & 1,18 & 0,24 \\
\hline
\end{tabular}

\footnotetext{
${ }^{1} \mathrm{MGG}=$ Gesamtgemelk in Kilogramm

${ }^{2}$ tMGG $=$ Dauer Gesamtgemelk

${ }^{3} \mathrm{HMF}=$ Höchster Milchfluss

${ }^{4} \mathrm{tAN}=$ Dauer des Anstiegs

${ }^{5} \mathrm{tPL}=$ Dauer der Plateauphase

${ }^{6} \mathrm{tAB}=$ Dauer des Abstiegs

${ }^{7}$ t400 = Dauer des Abstiegs zwischen 400 g/Min. und 200 g/Min. am Ende des Melkvorgangs
} 


\subsubsection{Zitzenhaut}

Der Zustand der Zitzenhaut wurde in drei Kategorien eingeteilt. In die Stufe 1 (glatte Zitzenhaut) wurden 131 Tiere, in die Stufe 2 (mittel) 93 Tiere und in die Stufe 3 (rau) 24 Tiere eingestuft. Nach dem Melkvorgang hatten 110 Tiere keine Veränderung der Zitzenhautfarbe, 136 Tiere rote Zitzen und 2 Tiere blaue Zitzen. Trocken waren nach dem Melkvorgang die Zitzen von 223 Tieren, feucht die von 25 Tieren.

Tabelle 7: Zitzenhautbeschaffenheit vor und nach dem Melken $(n=248)$

\begin{tabular}{|c|c|c|c|c|c|c|c|c|}
\cline { 2 - 9 } \multicolumn{1}{c|}{} & \multicolumn{3}{c|}{ Vor dem Melken } & \multicolumn{4}{c|}{ Nach dem Melken } \\
\cline { 2 - 9 } \multicolumn{1}{c|}{} & glatt & Mittel & rau & normal & rot & blau & trocken & feucht \\
\hline Anzahl & 131 & 93 & 24 & 110 & 136 & 2 & 223 & 25 \\
\hline Anteil Tiere \% & 53 & 38 & 10 & 44 & 55 & 1 & 90 & 10 \\
\hline
\end{tabular}

\subsubsection{Zitzenmaße}

Die Zitzenlänge der hinteren linken Zitzen erstreckte sich von 28 Millimeter bis 70 Millimeter bei einem Mittelwert von 45 Millimetern. Die Zitzendicke variierte von 18 Millimetern bis 32 Millimetern bei einem Mittelwert von 24 Millimetern.

Tabelle 8: Zitzenmaße der hinteren linken Zitzen $(n=248)$

\begin{tabular}{|c|c|c|}
\hline & Länge in $\mathrm{mm}$ & $\begin{array}{c}\text { Durchmesser } \\
\text { in } \mathrm{mm}\end{array}$ \\
\hline Minimum & 28 & 18 \\
\hline Maximum & 70 & 32 \\
\hline Mittelwert & 45 & 24 \\
\hline Median & 44 & 24 \\
\hline SD & 7 & 2 \\
\hline
\end{tabular}




\subsubsection{Zitzenform und Zitzenkuppenform}

Die Formen der Zitzen und der Zitzenkuppen wurden von allen vier Zitzen jeder Kuh erfasst. Die normale Form (Kategorie 1) kam mit $87 \%$ am häufigsten vor, milchbrüchige Zitzen (6) mit $6 \%$ und Flaschenzitzen (7) mit 5 $\%$ sowie Fleischzitzen (2) mit 0,4\% und Bleistiftzitzen (5) mit 0,1\%. Die anderen Zitzenformen aus dem Bewertungsschema (Kurzzitze und Kegelzitze) wurden nicht angetroffen.

Bei den Zitzenkuppenformen dominierten runde Zitzen (Kategorie 1) mit 83 $\%$, Tellerzitzen (2) machten $9 \%$ aus und Spitzzitzen hatten einen Anteil von 8 $\%$. Lediglich 0,2\% entfielen auf Taschenzitzen (4). Trichterzitzen (3) kamen nicht vor.

Tabelle 9: Häufigkeit der Zitzenformen $(n=985)$

\begin{tabular}{|c|c|c|c|c|c|}
\hline & Normale & Fleisch- & Bleistift- & Milchbrüchige & Flaschen- \\
& Zitze & zitze & zitze & zitze \\
\hline Anzahl vl (Anteil) & $212(87 \%)$ & $1(0,4 \%)$ & $1(0,4 \%)$ & $16(7 \%)$ & $14(6 \%)$ \\
\hline Anzahl vr ${ }^{2}$ (Anteil) & $215(87 \%)$ & $1(0,4 \%)$ & 0 & $15(6 \%)$ & $16(6 \%)$ \\
\hline Anzahl $h^{3}$ (Anteil) & $218(88 \%)$ & $1(0,4 \%)$ & 0 & $17(7 \%)$ & $11(4 \%)$ \\
\hline Anzahl hr ${ }^{4}$ (Anteil) & $220(89 \%)$ & $1(0,4 \%)$ & 0 & $16(6 \%)$ & $10(4 \%)$ \\
\hline Anzahl gesamt & $865(88 \%)$ & $4(0,4 \%)$ & $1(0,1 \%)$ & $64(6 \%)$ & $51(5 \%)$ \\
\hline (Anteil) & & & & & \\
\hline
\end{tabular}

$\begin{array}{ll}{ }^{1} \mathrm{vl}=\text { vorne links } & { }^{2} \mathrm{vr}=\text { vorne rechts } \\ { }^{3} \mathrm{hl}=\text { hinten links } & { }^{4} \mathrm{hr}=\text { hinten rechts }\end{array}$

$$
{ }^{4} \mathrm{hr}=\text { hinten rechts }
$$


Tabelle 10: Häufigkeit der Zitzenkuppenformen $(\mathbf{n}=985)$

\begin{tabular}{|c|c|c|c|c|c|}
\hline & $\begin{array}{c}\text { Runde } \\
\text { Zitze }\end{array}$ & zeller- & Trichter- & Taschen- & Spitz- \\
zitze & zitze & Zitze \\
\hline Anzahl vl (Anteil) & $201(82 \%)$ & $20(8 \%)$ & 0 & 0 & $23(9 \%)$ \\
\hline Anzahl vr (Anteil) & $198(80 \%)$ & $25(10 \%)$ & 0 & 0 & $25(10 \%)$ \\
\hline Anzahl hl (Anteil) & $205(83 \%)$ & $22(9 \%)$ & 0 & $1(0,4 \%)$ & $19(8 \%)$ \\
\hline Anzahl hr (Anteil) & $212(86 \%)$ & $20(8 \%)$ & 0 & $1(0,4 \%)$ & $13(5 \%)$ \\
\hline Anzahl gesamt & $816(83 \%)$ & $87(9 \%)$ & 0 & $2(0,2 \%)$ & $80(8 \%)$ \\
\hline (Anteil) & & & & & \\
\hline
\end{tabular}

${ }^{1} \mathrm{vl}=$ vorne links

${ }^{3} \mathrm{hl}=$ hinten links

$$
\begin{aligned}
& { }^{2} \mathrm{vr}=\text { vorne rechts } \\
& { }^{4} \mathrm{hr}=\text { hinten rechts }
\end{aligned}
$$




\subsubsection{Grad der Hyperkeratosen}

Der Grad der Hyperkeratosen nach Mein et al. (2001), eingeteilt in vier Stufen, ist in Tabelle 11 für die jeweiligen Viertel getrennt dargestellt.

Der Mittelwert über alle Zitzen lag bei 2,06, während der Mittelwert der Vorderzitzen bei 2,18 und der der Hinterzitzen bei 1,96 lag.

Tabelle 11: Verteilung der Hyperkeratosenstufen nach Eutervierteln

\begin{tabular}{|c|c|c|c|c|c|}
\hline & Stufe 1 & Stufe 2 & Stufe 3 & Stufe 4 & Median \\
\hline $\begin{array}{c}\text { Anzahl Viertel vl } \\
\text { (Anteil) }\end{array}$ & $\begin{array}{c}51 \\
(21 \%)\end{array}$ & $\begin{array}{c}127 \\
(52 \%)\end{array}$ & $\begin{array}{c}55 \\
(23 \%)\end{array}$ & $\begin{array}{c}11 \\
(5 \%)\end{array}$ & 2 \\
\hline $\begin{array}{c}\text { Anzahl Viertel vr } \\
\text { (Anteil) }\end{array}$ & $\begin{array}{c}38 \\
(15 \%)\end{array}$ & $\begin{array}{c}124 \\
(50 \%)\end{array}$ & $\begin{array}{c}72 \\
(29 \%)\end{array}$ & $\begin{array}{c}13 \\
(5 \%)\end{array}$ & 2 \\
\hline $\begin{array}{c}\text { Anzahl Viertel hl } \\
\text { (Anteil) }\end{array}$ & $\begin{array}{c}69 \\
(28 \%)\end{array}$ & $\begin{array}{c}129 \\
(52 \%)\end{array}$ & $\begin{array}{c}45 \\
(18 \%)\end{array}$ & $\begin{array}{c}4 \\
(2 \%)\end{array}$ & 2 \\
\hline $\begin{array}{c}\text { Anzahl Viertel hr } \\
\text { (Anteil) }\end{array}$ & $\begin{array}{c}54 \\
(22 \%)\end{array}$ & $\begin{array}{c}149 \\
(60 \%)\end{array}$ & $\begin{array}{c}40 \\
(16 \%)\end{array}$ & $\begin{array}{c}4 \\
(2 \%)\end{array}$ & 2 \\
\hline $\begin{array}{c}\text { Anzahl gesamt } \\
\text { (Anteil) }\end{array}$ & $\begin{array}{c}212 \\
(22 \%)\end{array}$ & $\begin{array}{c}529 \\
(54 \%)\end{array}$ & $\begin{array}{c}212 \\
(22 \%)\end{array}$ & $\begin{array}{c}32 \\
(3 \%)\end{array}$ & \\
\hline
\end{tabular}

$\begin{array}{ll}{ }^{1} \mathrm{vl}=\text { vorne links } & { }^{2} \mathrm{vr}=\text { vorne rechts } \\ { }^{3} \mathrm{hl}=\text { hinten links } & { }^{4} \mathrm{hr}=\text { hinten rechts }\end{array}$

\subsubsection{Zitzengewebefestigkeit (Zitzendicke)}

Die mit dem modifizierten Cutimeter gemessene Zitzendicke der hinteren linken Zitze betrug vor dem Melkvorgang zwischen 0,73 $\mathrm{cm}$ und 1,52 $\mathrm{cm}$ bei einem Mittelwert von $1,12 \mathrm{~cm}$ und $0,78 \mathrm{~cm}$ bis $1,43 \mathrm{~cm}$ nach dem Melkvorgang bei einem Mittelwert von 1,09 cm. 
Die Differenz der Gewebefestigkeit vor und nach dem Melkvorgang als Maß für die Gewebsveränderung durch das Melken erstreckte sich von $-37,8 \%$ bis $+38,1 \%$. Die relative Änderung erstreckte sich von $0 \%$ bis $38,1 \%$ mit einem Mittelwert von 9,39 \% und einer Standardabweichung von 7,57\%. Bei 158 Tieren (64\%) betrug der Wert der Veränderung mehr als 5\%.

Tabelle 12: Gewebefestigkeit der Zitzen in cm Kutimeterwert $(n=248)$

\begin{tabular}{|c|c|c|c|c|}
\hline & Vor dem & Nach dem & Differenz & $\begin{array}{c}\text { Relative } \\
\text { Änderung } \\
\text { in \% }\end{array}$ \\
\hline Minimum & 0,73 & 0,78 & $-37,8$ & 0 \\
\hline Maximum & 1,52 & 1,43 & $+38,1$ & 38,1 \\
\hline Mittelwert & 1,12 & 1,09 & - & 9,39 \\
\hline SD & 0,14 & 0,14 & - & 7,57 \\
\hline
\end{tabular}

4.2.8 Ödematisierung an der Zitzenbasis und Kongestion an der Zitzenspitze

Eine ringförmige Ödematisierung des Gewebes an der Zitzenbasis wurde bei 64 Tieren (26\%) und eine Kongestion der Zitzenspitze bei 96 Tieren (39\%) nach dem Melkvorgang festgestellt. 


\subsection{Einfluss der untersuchten Merkmale auf die Zitzenkondition (univariate Datenanalyse)}

Im Rahmen der Untersuchung wurden melktechnische Parameter und Zitzenkonditionsdaten erfasst. Die Zusammenhänge und Abhängigkeiten werden im Folgenden beschrieben.

\subsubsection{Grad der Hyperkeratosen}

Der Grad der Hyperkeratosen als Mittelwert über die Zitzen eines Tieres ergab rechnerisch 13 Stufen von 1 bis 4, da auch ein geringer Anteil an Tieren mit nur drei Zitzen vorhanden war. Es konnte kein signifikanter Unterschied zwischen dem Grad der Hyperkeratosen und den Variablen „Dauer der Melkung“ (P = 0,18), „Abstiegsdauer“ $(\mathrm{P}=0,15)$ und der ,Dauer des Abstiegs zwischen 400 Gramm je Minute bis 200 Gramm je Minute“ $(P=0,58)$ festgestellt werden (Kruskal-Wallis Test). 
Tabelle 13: Durchschnittliche Melkdauer und durchschnittliche Melkdauer mit geringem Milchfluss nach Hyperkeratoseklassen der Tiere $(n=248)$

\begin{tabular}{|l|c|c|c|}
\hline GHKALL & $\begin{array}{c}\mathrm{tMGG}^{2} \\
\text { in min }\end{array}$ & $\begin{array}{c}\mathrm{tAB}^{3} \\
\text { in min }\end{array}$ & $\begin{array}{c}\mathrm{t} 400^{4} \\
\text { in min }\end{array}$ \\
\hline Stufe 1,00 & 6,06 & 2,70 & 0,22 \\
\hline Stufe 1,25 & 6,56 & 2,48 & 0,18 \\
\hline Stufe 1,50 & 6,39 & 2,64 & 0,31 \\
\hline Stufe 1,75 & 6,42 & 2,53 & 0,27 \\
\hline Stufe 2,00 & 6,66 & 2,84 & 0,23 \\
\hline Stufe 2,25 & 7,25 & 3,11 & 0,22 \\
\hline Stufe 2,50 & 6,66 & 2,67 & 0,25 \\
\hline Stufe 2,67 & 8,63 & 3,04 & 0,14 \\
\hline Stufe 2,75 & 7,59 & 3,07 & 0,17 \\
\hline Stufe 3,00 & 6,99 & 3,15 & 0,20 \\
\hline Stufe 3,25 & 8,31 & 4,07 & 0,08 \\
\hline Stufe 3,50 & 6,04 & 2,06 & 0,16 \\
\hline Stufe 4,00 & 5,95 & 2,69 & 0,23 \\
\hline$P^{5}$ & 0,18 & 0,15 & 0,58 \\
\hline
\end{tabular}

${ }^{1}$ GHKALL = Durchschnittlicher Grad der Hyperkeratose aller Zitzen des Tieres

${ }^{2} \mathrm{tMGG}=$ Dauer Gesamtgemelk

${ }^{3} \mathrm{tAB}=$ Dauer des Abstiegs

${ }^{4}$ t400 = Zeit zwischen Milchfluss 400 Gramm/Minute bis 200 Gramm/Minute am Melkende

${ }^{5} \mathrm{P}=$ Signifikanz 
Die Einflüsse der verschiedenen Phasenlängen und die Länge des gesamten Pulszyklus auf den Grad der Hyperkeratosen wurde mit dem Kruskal-Wallis Test überprüft. Es konnte für keine der Variablen (Phase A, P =0,88; Phase B, $\mathrm{P}=0,84$; Phase $\mathrm{C}, \mathrm{P}=0,85$; Phase $\mathrm{D}, \mathrm{P}=0,72$; Dauer des Pulszyklus, $\mathrm{P}=$ 0,94) ein signifikanter Unterschied in den Hyperkeratoseklassen nachgewiesen werden.

Tabelle 14: Dauer der Pulsationsphasen nach Hyperkeratoseklassen der Tiere $(n=248)$

\begin{tabular}{|l|c|c|c|c|c|c|}
\hline GHKALL $^{1}$ & $\begin{array}{c}\text { SaugPh } \\
\text { in ms }\end{array}$ & $\begin{array}{c}\text { PulsAms }^{3} \\
\text { in ms }\end{array}$ & $\begin{array}{c}\text { PulsBms }^{4} \\
\text { in ms }\end{array}$ & $\begin{array}{c}\text { PulsCms } \\
\text { in ms }\end{array}$ & $\begin{array}{c}\text { PulsDms }^{6} \\
\text { in ms }\end{array}$ & $\begin{array}{c}\text { ZykIDau }^{7} \\
\text { in ms }\end{array}$ \\
\hline Stufe 1,00 & 636 & 151 & 485 & 115 & 276 & 1027 \\
\hline Stufe 1,25 & 651 & 148 & 503 & 123 & 258 & 1032 \\
\hline Stufe 1,50 & 635 & 140 & 494 & 107 & 274 & 1015 \\
\hline Stufe 1,75 & 628 & 140 & 488 & 108 & 274 & 1009 \\
\hline Stufe 2,00 & 629 & 148 & 481 & 112 & 270 & 1011 \\
\hline Stufe 2,25 & 627 & 146 & 482 & 112 & 272 & 1011 \\
\hline Stufe 2,50 & 633 & 142 & 491 & 109 & 268 & 1010 \\
\hline Stufe 2,67 & 635 & 145 & 490 & 109 & 288 & 1032 \\
\hline Stufe 2,75 & 631 & 146 & 485 & 112 & 279 & 1022 \\
\hline Stufe 3,00 & 630 & 147 & 483 & 116 & 257 & 1003 \\
\hline Stufe 3,25 & 630 & 137 & 492 & 119 & 255 & 1004 \\
\hline Stufe 3,50 & 639 & 142 & 498 & 110 & 250 & 1000 \\
\hline Stufe 4,00 & 643 & 159 & 484 & 123 & 255 & 1021 \\
\hline $\mathrm{P}$ & 0,89 & 0,88 & 0,84 & 0,85 & 0,72 & 0,94 \\
\hline
\end{tabular}

${ }^{1}$ GHKALL = Durchschnittlicher Grad der Hyperkeratose aller Zitzen des Tieres

${ }^{2}$ SaugPh $=$ Dauer der Saugphase

${ }^{3}$ PulsAms = Dauer der Evakuierungsphase

${ }^{4}$ PulsBms = Dauer der Vakuumphase

${ }^{5}$ PulsCms = Dauer der Belüftungsphase

${ }^{6}$ PulsDms $=$ Dauer der Druckphase

${ }^{7}$ ZykIDau = Gesamtdauer des Pulszyklus 
Die Hyperkeratosegrade waren für die Hinterzitzen niedriger als für die Vorderzitzen und für die linken Zitzen niedriger als für die rechten Zitzen. Die mit simultaner Pulsation gemolkenen Zitzen hatten niedrigere Werte als die mit alternierender Pulsation gemolkenen. Ein signifikanter Unterschied zwischen den beiden Pulsationsarten konnte jedoch nicht festgestellt werden (MannWhitney-U-Test).

Tabelle 15: Bewertung der Hyperkeratosen nach Pulsationsarten und Vierteln $(n=985)$

\begin{tabular}{|c|c|c|c|c|c|}
\hline & $\mathrm{GHKVL}^{1}$ & $\mathrm{GHKVR}^{2}$ & $\mathrm{GHKHL}^{3}$ & $\mathrm{GHKHR}^{4}$ & $\mathrm{GHKALL}^{5}$ \\
\hline Alternierend & & & & & \\
Mittelwert & 2,14 & 2,28 & 1,97 & 1,99 & 2,10 \\
Median & 2 & 2 & 2 & 2 & 2 \\
SD & 0,77 & 0,78 & 0,70 & 0,66 & 0,60 \\
\hline Simultan & & & & & \\
Mittelwert & 2,00 & 2,14 & 1,85 & 1,92 & 1,98 \\
Median & 2 & 2 & 2 & 2 & 2 \\
SD & 0,80 & 0,77 & 0,78 & 0,69 & 0,66 \\
\hline $\mathrm{P}^{6}$ & 0,16 & 0,18 & 0,21 & 0,43 & 0,25 \\
\hline
\end{tabular}

\footnotetext{
${ }^{1}$ GHKVL = Durchschnittlicher Grad der Hyperkeratose aller vorderen linken Zitzen

${ }^{2}$ GHKVR = Durchschnittlicher Grad der Hyperkeratose aller vorderen rechten Zitzen

${ }^{3} \mathrm{GHKHL}=$ Durchschnittlicher Grad der Hyperkeratose aller hinteren linken Zitzen

${ }^{4}$ GHKHR = Durchschnittlicher Grad der Hyperkeratose aller hinteren rechten Zitzen

${ }^{5}$ GHKALL = Durchschnittlicher Grad der Hyperkeratose aller Zitzen des Tieres

${ }^{6} \mathrm{P}=$ Signifikanz
} 
Der Einfluss der Vakuumverhältnisse auf den Grad der Hyperkeratosen wurde mit dem Kruskall-Wallis-Test überprüft. Das Betriebsvakuum zeigte keinen Einfluss auf den Grad der Hyperkeratosen $(\mathrm{P}=0,94)$. Das mittlere Vakuum unter der Zitze im kurzen Milchschlauch hatte einen signifikanten Einfluss auf den Grad der Hyperkeratosen $(\mathrm{P}=0,05)$, die Vakuumfluktuationen im kurzen Milchschlauch hatten keinen Einfluss auf den Grad der Hyperkeratosen $(\mathrm{P}=$ $0,33)$.

Tabelle 16: Bewertung der Hyperkeratosen nach Vakuumverhältnissen ( $n=248$ )

\begin{tabular}{|l|c|c|c|}
\hline GHKALL & $\begin{array}{c}\mathrm{BV}^{2} \\
\text { In kPa }\end{array}$ & $\begin{array}{c}\text { MittVak } \\
\text { In kPa }\end{array}$ & $\begin{array}{c}\text { VDKMS } \\
\text { In kPa }\end{array}$ \\
\hline Stufe 1,00 & 41,51 & 33,34 & 13,86 \\
\hline Stufe 1,25 & 41,26 & 33,59 & 12,49 \\
\hline Stufe 1,50 & 41,21 & 33,29 & 11,01 \\
\hline Stufe 1,75 & 41,40 & 33,77 & 9,93 \\
\hline Stufe 2,00 & 41,05 & 33,80 & 10,45 \\
\hline Stufe 2,25 & 41,78 & 35,18 & 9,30 \\
\hline Stufe 2,50 & 40,98 & 33,38 & 11,47 \\
\hline Stufe 2,67 & 41,03 & 34,88 & 9,90 \\
\hline Stufe 2,75 & 40,17 & 32,56 & 12,87 \\
\hline Stufe 3,00 & 41,19 & 34,45 & 10,25 \\
\hline Stufe 3,25 & 42,08 & 35,68 & 10,80 \\
\hline Stufe 3,50 & 41,13 & 37,75 & 6,43 \\
\hline Stufe 4,00 & 41,2 & 34,03 & 13,53 \\
\hline P & 0,94 & 0,05 & 0,33 \\
\hline
\end{tabular}

${ }^{1}$ GHKALL = Durchschnittlicher Grad der Hyperkeratose aller Zitzen des Tieres

${ }^{2} \mathrm{BV}=$ Betriebsvakuum

${ }^{3}$ MittVak = Mittleres Vakuum im kurzen Milchschlauch beim höchsten Milchfluss

${ }^{4}$ VDKMS = Vakuumfluktuation im kurzen Milchschlauch beim höchsten Milchfluss 
Die Variablen Melkzeuggewicht, Sammelstückvolumen, Durchmesser kurzer Milchschlauch, Zitzengummischaftdurchmesser und Einfaltdruck des Zitzengummis wurden ebenfalls mit dem Kruskall-Wallis-Test auf ihren Einfluss auf den Grad der Hyperkeratose hin überprüft. Die Ergebnisse ließen keinen Einfluss auf den Grad der Hyperkeratosen erkennen.

Tabelle 17: Bewertung der Hyperkeratosen nach Melkzeug- und Zitzengummieigenschaften $(n=248)$

\begin{tabular}{|c|c|c|c|c|c|}
\hline GHKALL $^{1}$ & $\begin{array}{l}\text { Melkzeug- } \\
\text { gewicht } \\
\text { in g }\end{array}$ & $\begin{array}{c}\text { Sammelstück- } \\
\text { volumen } \\
\text { in ml }\end{array}$ & $\begin{array}{l}\text { Durchmesser } \\
\qquad \mathrm{KMS}^{2} \\
\text { in } \mathrm{mm}\end{array}$ & $\begin{array}{l}\text { Durchmesser } \\
\text { Zitzengummi- } \\
\text { schaft } \\
\text { in } \mathrm{mm}\end{array}$ & $\begin{array}{c}\mathrm{ED}^{3} \\
\text { des } \\
\text { Zitzengummis } \\
\text { in } \mathrm{kPa}\end{array}$ \\
\hline Stufe 1,00 & 2109 & 361 & 10,84 & 23,55 & 10,03 \\
\hline Stufe 1,25 & 2219 & 319 & 10,25 & 24,06 & 9,97 \\
\hline Stufe 1,50 & 2147 & 348 & 10,81 & 23,80 & 10,52 \\
\hline Stufe 1,75 & 2154 & 345 & 10,83 & 23,72 & 10,75 \\
\hline Stufe 2,00 & 2123 & 355 & 10,95 & 23,78 & 10,97 \\
\hline Stufe 2,25 & 2309 & 328 & 10,27 & 23,97 & 10,56 \\
\hline Stufe 2,50 & 2101 & 362 & 11,09 & 23,87 & 10,58 \\
\hline Stufe 2,67 & 2027 & 407 & 11,83 & 23,67 & 8,80 \\
\hline Stufe 2,75 & 2367 & 311 & 10,00 & 24,07 & 10,36 \\
\hline Stufe 3,00 & 2212 & 337 & 10,58 & 23,89 & 10,04 \\
\hline Stufe 3,25 & 2523 & 248 & 9,10 & 23,96 & 8,96 \\
\hline Stufe 3,50 & 1890 & 340 & 11,67 & 22,67 & 9,42 \\
\hline Stufe 4,00 & 2293 & 383 & 10,50 & 23,5 & 9,87 \\
\hline$P$ & 0,17 & 0,17 & 0,46 & 0,88 & 0,64 \\
\hline
\end{tabular}

${ }^{1}$ GHKALL = Durchschnittlicher Grad der Hyperkeratose aller Zitzen des Tieres

${ }^{2} \mathrm{KMS}=$ kurzer Milchschlauch $\quad{ }^{3} \mathrm{ED}=$ Einfaltdruckdifferenz 
Bei den Melkzeugtypen ließ sich eine Reihenfolge in Bezug auf den Grad der Hyperkeratosen erkennen. Die Ergebnisse je Melkzeug variierten von 1,92 bis 2,65 beim Grad der Hyperkeratosen. Ein signifikanter Einfluss des Melkzeugtyps konnte jedoch nicht nachgewiesen werden $(\mathrm{P}=0,35)$. Lediglich für den Einfluss des Melkzeugtyps auf den Grad der Hyperkeratosen der vorderen linken Zitze wurde die Signifikanzgrenze erreicht (Kruskall-WallisTest).

Tabelle 18: Bewertung der Hyperkeratosen nach Melkzeugtyp (n= 985)

\begin{tabular}{|c|c|c|c|c|c|}
\hline Melkzeugtyp & $\mathrm{GHKVL}^{1}$ & $\mathrm{GHKVR}^{2}$ & $\mathrm{GHKHL}^{3}$ & $\mathrm{GHKHR}^{4}$ & $\mathrm{GHKALL}^{5}$ \\
\hline $200 \mathrm{ccm}$ & 2,20 & 2,40 & 1,60 & 2,20 & 2,10 \\
\hline Champion & 2,40 & 2,40 & 1,80 & 2,00 & 2,15 \\
\hline Classic & 2,09 & 2,34 & 1,94 & 2,00 & 2,09 \\
\hline ClassicE & 2,17 & 2,38 & 1,90 & 2,00 & 2,11 \\
\hline Clearflow & 1,92 & 2,10 & 1,80 & 1,88 & 1,92 \\
\hline Eclipse & 3,00 & 3,00 & 2,40 & 2,20 & 2,65 \\
\hline FloStarMax & 2,21 & 2,40 & 2,05 & 2,10 & 2,19 \\
\hline Harmony & 2,00 & 2,00 & 2,00 & 2,00 & 2,00 \\
\hline HarmonyPlus & 2,10 & 2,20 & 2,00 & 1,95 & 2,06 \\
\hline HCC 150 & 2,50 & 2,60 & 2,00 & 1,90 & 2,25 \\
\hline S90 & 2,20 & 2,20 & 2,20 & 2,20 & 2,20 \\
\hline Uniflow & 1,96 & 2,04 & 1,84 & 1,88 & 1,93 \\
\hline P & 0,05 & 0,09 & 0,89 & 0,97 & 0,35 \\
\hline
\end{tabular}

\footnotetext{
${ }^{1}$ GHKVL = Durchschnittlicher Grad der Hyperkeratose aller vorderen linken Zitzen

${ }^{2}$ GHKVR = Durchschnittlicher Grad der Hyperkeratose aller vorderen rechten Zitzen

${ }^{3} \mathrm{GHKHL}=$ Durchschnittlicher Grad der Hyperkeratose aller hinteren linken Zitzen

${ }^{4}$ GHKHR = Durchschnittlicher Grad der Hyperkeratose aller hinteren rechten Zitzen

${ }^{5}$ GHKALL = Durchschnittlicher Grad der Hyperkeratose aller Zitzen des Tieres
} 
Der Einfluss des Melkanlagenfabrikats auf den Grad der Hyperkeratosen stellte sich nach dem Kruskall-Wallis-Test als nicht signifikant heraus. Dies gilt für die einzelnen Viertel (GHKVL, P = 0,48; GHKVR, P = 0,23; GHKHL, P = 0,72; GHKHR, $\mathrm{P}=0,75$ ) und auch für alle Zitzen des Tieres (GHKALL, $\mathrm{P}=$ $0,51)$.

Tabelle 19: Bewertung der Hyperkeratosen nach Melkanlagenfabrikat ( $\mathrm{n}=985)$

\begin{tabular}{|c|c|c|c|c|c|}
\hline Fabrikat & $\mathrm{GHKVL}^{1}$ & $\mathrm{GHKVR}^{2}$ & $\mathrm{GHKHL}^{3}$ & $\mathrm{GHKHR}^{4}$ & $\mathrm{GHKALL}^{5}$ \\
\hline Boumatic & 2,21 & 2,40 & 2,05 & 2,10 & 2,19 \\
\hline DeLaval & 2,10 & 2,16 & 1,99 & 1,96 & 2,05 \\
\hline Happel & 2,20 & 2,20 & 2,20 & 2,20 & 2,20 \\
\hline Fullwood & 1,92 & 2,10 & 1,80 & 1,88 & 1,92 \\
\hline Miele & 2,40 & 2,40 & 1,80 & 2,00 & 2,15 \\
\hline SAC & 2,03 & 2,10 & 1,90 & 1,90 & 1,98 \\
\hline WestfaliaSurge & 2,19 & 2,41 & 1,93 & 2,03 & 2,14 \\
\hline P & 0,48 & 0,23 & 0,72 & 0,75 & 0,51 \\
\hline
\end{tabular}

${ }^{1}$ GHKVL = Durchschnittlicher Grad der Hyperkeratose aller vorderen linken Zitzen

${ }^{2}$ GHKVR = Durchschnittlicher Grad der Hyperkeratose aller vorderen rechten Zitzen

${ }^{3} \mathrm{GHKHL}=$ Durchschnittlicher Grad der Hyperkeratose aller hinteren linken Zitzen

${ }^{4}$ GHKHR = Durchschnittlicher Grad der Hyperkeratose aller hinteren rechten Zitzen

${ }^{5}$ GHKALL = Durchschnittlicher Grad der Hyperkeratose aller Zitzen des Tieres 
Die varianzanalytische Untersuchung der Hyperkeratosenstufen 1 bis 4 ergab keinen signifikanten Einfluss der Zitzenlänge auf den Grad der Hyperkeratose $(\mathrm{P}=0,08)$, jedoch eine signifikant höhere Häufigkeit der längeren Zitzen in den höheren Stufen 3 und $4(\mathrm{P}=0,01)$. Die Zitzendicke hatte keinen signifikanten Einfluss auf den Grad der Hyperkeratose $(\mathrm{P}=0,99)$.

Tabelle 20: Bewertung der Hyperkeratosen nach Zitzenmaßen $(\mathrm{n}=248)$

\begin{tabular}{|c|c|c|c|c|c|c|c|c|}
\hline $\mathrm{GHKHL}^{1}$ & $\begin{array}{c}\text { Zitzlaen }^{2} \\
\text { in mm }\end{array}$ & $\begin{array}{l}\text { Min. } \\
\mathrm{mm}\end{array}$ & $\begin{array}{l}\text { Max. } \\
\text { mm }\end{array}$ & SD & $\begin{array}{c}\text { ZitzDick }^{3} \\
\text { in } \mathrm{mm}\end{array}$ & $\begin{array}{l}\text { Min. } \\
\text { mm }\end{array}$ & $\begin{array}{l}\text { Max. } \\
\text { mm }\end{array}$ & SD \\
\hline Stufe 1,00 & 43,51 & 30 & 66 & 7,11 & 24,04 & 20 & 28 & 1,84 \\
\hline Stufe 2,00 & 45,16 & 30 & 70 & 6,51 & 24,12 & 18 & 32 & 2,01 \\
\hline Stufe 3,00 & 46,38 & 28 & 62 & 7,27 & 24,07 & 18 & 30 & 2,06 \\
\hline Stufe 4,00 & 45,40 & 30 & 55 & 10,29 & 24,00 & 23 & 25 & 0,71 \\
\hline$P$ & \multicolumn{4}{|c|}{0,08} & \multicolumn{4}{|c|}{0,99} \\
\hline
\end{tabular}

${ }^{1} \mathrm{GHKHL}=$ Durchschnittlicher Grad der Hyperkeratose aller hinteren linken Zitzen

${ }^{2}$ ZitLaen $=$ Zitzenlänge

${ }^{3}$ ZitzDick $=$ Zitzendicke

Tabelle 21: Bewertung der Hyperkeratosen nach Zitzenlänge in Gruppen $(n=248)$

\begin{tabular}{|c|c|c|c|c|c|}
\hline $\mathrm{GHKHL}^{1}$ & $\begin{array}{c}\text { Zitzlaen }^{2} \\
\text { in mm }\end{array}$ & $\begin{array}{l}\text { Min. } \\
\mathrm{mm}\end{array}$ & $\begin{array}{l}\text { Max } \\
\mathrm{mm}\end{array}$ & SD & \\
\hline Stufe 1,00 & 43,51 & 30 & 66 & 7,11 & \\
\hline Stufe 2,00 & 45,16 & 30 & 70 & 6,51 & \\
\hline Stufe 3,00 & 46,38 & 28 & 62 & 7,27 & \multirow{2}{*}{$P=0,01$} \\
\hline Stufe 4,00 & 45,40 & 30 & 55 & 10,29 & \\
\hline$P$ & \multicolumn{4}{|c|}{0,08} & \\
\hline
\end{tabular}

\footnotetext{
${ }^{1} \mathrm{GHKHL}=$ Durchschnittlicher Grad der Hyperkeratose aller hinteren linken Zitzen

${ }^{2}$ ZitLaen $=$ Zitzenlänge

${ }^{3}$ ZitzDick $=$ Zitzendicke
} 
Der Einfluss der Zitzenformen auf den Grad der Hyperkeratose wurde mit dem Kruskal-Wallis-Test geprüft. Es konnte kein signifikanter Einfluss dieser Variablen festgestellt werden. Die Ergebnisse sind in Tabelle 22 dargestellt.

Tabelle 22: Bewertung der Hyperkeratosen nach Zitzenformen $(n=985)$

\begin{tabular}{|c|c|c|c|c|c|c|}
\hline & $\begin{array}{c}\text { Normale } \\
\text { Zitze }\end{array}$ & $\begin{array}{c}\text { Fleisch- } \\
\text { zitze }\end{array}$ & $\begin{array}{c}\text { Bleistift- } \\
\text { zitze }\end{array}$ & $\begin{array}{c}\text { Milchbrüchige- } \\
\text { Zitze }\end{array}$ & $\begin{array}{c}\text { Flaschen- } \\
\text { zitze }\end{array}$ & $\mathrm{P}$ \\
\hline GHKVL & 2,11 & 2,00 & 4,00 & 1,72 & 2,50 & 0,32 \\
\hline GHKVR & 2,24 & 3,00 & - & 1,93 & 2,56 & 0,22 \\
\hline GHKHL & 1,96 & 2,00 & - & 1,72 & 1,73 & 0,34 \\
\hline GHKHR & 1,99 & 2,00 & - & 1,81 & 2,00 & 0,43 \\
\hline GHKGES & 2,08 & 2,25 & 4,00 & 1,80 & 2,20 & 0,22 \\
\hline
\end{tabular}

${ }^{1}$ GHKVL = Durchschnittlicher Grad der Hyperkeratose aller vorderen linken Zitzen

${ }^{2}$ GHKVR = Durchschnittlicher Grad der Hyperkeratose aller vorderen rechten Zitzen

${ }^{3} \mathrm{GHKHL}=$ Durchschnittlicher Grad der Hyperkeratose aller hinteren linken Zitzen

${ }^{4}$ GHKHR = Durchschnittlicher Grad der Hyperkeratose aller hinteren rechten Zitzen

${ }^{5}$ GHKGES = Durchschnittlicher Grad der Hyperkeratose der Zitzenform 
Die Zitzenkuppenform als Einflussfaktor auf den Grad der Hyperkeratose konnte nach dem Kruskal-Wallis-Test für einzelne Viertel als signifikant bestätigt werden, jedoch nicht für alle Viertel eines Tieres. Zitzenkuppen der Form „Spitzzitze“ wiesen signifikant häufiger $(\mathrm{P}=0,02)$ ausgeprägte Hyperkeratosen der Stufen 3 und 4 auf (LSD-Posthoc Test mit Bonferroni Korrektur).

Tabelle 23: Bewertung der Hyperkeratosen nach Zitzenkuppenformen $(n=985)$

\begin{tabular}{|c|c|c|c|c|c|c|}
\hline & $\begin{array}{c}\text { Runde } \\
\text { Zitze }\end{array}$ & $\begin{array}{c}\text { Teller- } \\
\text { zitze }\end{array}$ & $\begin{array}{c}\text { Trichter- } \\
\text { zitze }\end{array}$ & $\begin{array}{c}\text { Taschen- } \\
\text { zitze }\end{array}$ & $\begin{array}{c}\text { Spitz- } \\
\text { Zitze }\end{array}$ & $P$ \\
\hline GHKVL & 2,08 & 1,95 & - & - & 2,52 & 0,05 \\
\hline GHKVR & 2,19 & 2,12 & - & - & 2,83 & 0,0006 \\
\hline GHKHL & 1,90 & 2,00 & 1,00 & - & 2,26 & 0,03 \\
\hline GHKHR & 1,96 & 2,05 & - & 1,00 & 2,13 & 0,09 \\
\hline GHKGES & 2,03 & 2,03 & 1,00 & 1,00 & 2,44 & 0,15 \\
\hline
\end{tabular}

${ }^{1} \mathrm{GHKVL}=$ Durchschnittlicher Grad der Hyperkeratose aller vorderen linken Zitzen

${ }^{2}$ GHKVR = Durchschnittlicher Grad der Hyperkeratose aller vorderen rechten Zitzen

${ }^{3} \mathrm{GHKHL}=$ Durchschnittlicher Grad der Hyperkeratose aller hinteren linken Zitzen

${ }^{4}$ GHKHR = Durchschnittlicher Grad der Hyperkeratose aller hinteren rechten Zitzen

${ }^{5}$ GHKGES = Durchschnittlicher Grad der Hyperkeratose der Zitzenkuppenform 


\subsubsection{Hautfarbe}

Ein signifikanter Einfluss der Variablen „Dauer des Melkvorgangs“ ( $\mathrm{P}=0,25)$, „Dauer des Abstiegs“ ( $\mathrm{P}=0,61)$ und „Dauer des Abstiegs zwischen 400 Gramm je Minute bis 200 Gramm je Minute“ $(P=0,11)$ auf die Hautfarbe nach dem Melken konnte nicht nachgewiesen werden (Kruskal-Wallis-Test).

Tabelle 24: Durchschnittliche Melkdauer und durchschnittliche Melkdauer mit geringem Milchfluss in den Hautfarbenklassen der Zitzen nach dem Melken $(n=248)$

\begin{tabular}{|c|c|c|c|}
\hline & $\begin{array}{c}\mathrm{tMGG} \\
\text { in min }\end{array}$ & $\begin{array}{c}\mathrm{tAB}^{2} \\
\text { in min }\end{array}$ & $\begin{array}{c}\mathrm{t} 400^{3} \\
\text { in min }\end{array}$ \\
\hline $\begin{array}{c}\text { Mittelwert } \\
\text { Median }\end{array}$ & 6,83 & 2,83 & 0,24 \\
SD & 6,75 & 2,75 & 0,19 \\
Hautfarbe rot & 1,65 & 1,05 & 0,20 \\
\hline Mittelwert & 6,57 & 2,78 & 0,23 \\
Median & 6,23 & 2,59 & 0,14 \\
SD & 1,77 & 1,28 & 0,27 \\
\hline Hautfarbe blau & & & \\
Mittelwert & 6,89 & 2,73 & 0,07 \\
Median & 6,89 & 2,73 & 0,07 \\
SD & 1,15 & 2,15 & 0,03 \\
\hline P & 0,25 & 0,61 & 0,11 \\
\hline
\end{tabular}

\footnotetext{
${ }^{1} \mathrm{tMGG}=$ Dauer Gesamtgemelk

${ }^{2} \mathrm{tAB}=$ Dauer des Abstiegs

${ }^{3}$ t400 = Zeit zwischen Milchfluss 400 Gramm/Minute bis 200 Gramm/Minute am Melkende
} 
Die Dauer der einzelnen Pulsationsphasen, der Saugphase und auch die Dauer des gesamten Pulszyklus hatten keinen signifikanten Einfluss auf die Hautfarbe der Zitzen nach dem Melken (Kruskal-Wallis-Test).

Tabelle 25: Dauer der Pulsationsphasen in den Hautfarbenklassen der Zitzen $(n=248)$

\begin{tabular}{|c|c|c|c|c|c|c|}
\hline & $\begin{array}{c}\text { SaugPh } \\
\text { in } \mathrm{ms}\end{array}$ & $\begin{array}{c}\text { PulsAms }^{2} \\
\text { in } \mathrm{ms}\end{array}$ & $\begin{array}{c}\text { PulsBms }^{3} \\
\text { in } \mathrm{ms}\end{array}$ & $\begin{array}{c}\text { PulsCms }^{4} \\
\text { in } \mathrm{ms}\end{array}$ & $\begin{array}{c}\text { PulsDms }^{5} \\
\text { In ms }\end{array}$ & $\begin{array}{c}\text { ZykIDau }^{6} \\
\text { in ms }\end{array}$ \\
\hline $\begin{array}{c}\text { Hautfarbe } \\
\text { normal }\end{array}$ & 636 & 146 & 490 & 113 & 267 & 1017 \\
\hline $\begin{array}{c}\text { Hautfarbe } \\
\text { rot }\end{array}$ & 628 & 144 & 485 & 110 & 272 & 1011 \\
\hline $\begin{array}{c}\text { Hautfarbe } \\
\text { blau }\end{array}$ & 620 & 141 & 479 & 115 & 230 & 965 \\
\hline P & 0,55 & 0,94 & 0,75 & 0,87 & 0,12 & 0,08 \\
\hline
\end{tabular}

${ }^{1}$ SaugPh $=$ Dauer der Saugphase

${ }^{3}$ PulsBms = Dauer der Vakuumphase

${ }^{2}$ PulsAms = Dauer der Evakuierungsphase

${ }^{5}$ PulsDms $=$ Dauer der Druckphase

${ }^{4}$ PulsCms = Dauer der Belüftungsphase

${ }^{6}$ ZykIDau $=$ Gesamtdauer des Pulszyklus

Die Pulsationsart hatte einen signifikanten Einfluss auf die Hautfarbe nach dem Melken $(\mathrm{P}=0,009)$. Dies konnte unter Anwendung des Chi-Quadrat Anpassungstests ermittelt werden.

Tabelle 26: Anteil der Zitzen in den Hautfarbenklassen nach Pulsationsart $(n=248)$

\begin{tabular}{|c|c|c|}
\hline & Alternierend & Simultan \\
\hline Hautfarbe normal & $75(41 \%)$ & $35(54 \%)$ \\
\hline Hautfarbe rot & $106(58 \%)$ & $30(46 \%)$ \\
\hline Hautfarbe blau & $2(1 \%)$ & - \\
\hline P & \multicolumn{2}{|c|}{0,009} \\
\hline
\end{tabular}


Für das Betriebsvakuum wurde kein signifikanter Einfluss auf die Hautfarbe nach dem Melken nachgewiesen $(\mathrm{P}=0,32)$. Ebenso hatte das mittlere Vakuum im kurzen Milchschlauch keinen signifikanten Einfluss auf diese Variable ( $\mathrm{P}=$ 0,37), während ein signifikanter Einfluss der Fluktuation des Vakuums im kurzen Milchschlauch auf die Hautfarbe der Zitzen nach dem Melken ermittelt wurde $\mathrm{P}=0,04)$. Es wurde der Kruskal-Wallis-Test angewendet.

Tabelle 27: Mittlere Vakuumhöhen in den Hautfarbenklassen der Zitzen $(n=248)$

\begin{tabular}{|c|c|c|c|}
\hline & $\mathrm{BV}^{1}$ & MittVak $^{2}$ & VDKMS $^{3}$ \\
in $\mathrm{kPa}$ & in $\mathrm{kPa}$ & in $\mathrm{kPa}$ \\
\hline Hautfarbe normal & 41,17 & 33,57 & 11,79 \\
\hline Hautfarbe rot & 41,28 & 34,10 & 10,17 \\
\hline Hautfarbe blau & 40,20 & 34,50 & 6,7 \\
\hline $\mathrm{P}$ & 0,32 & 0,37 & 0,04 \\
\hline
\end{tabular}

${ }^{1} \mathrm{BV}=$ Betriebsvakuum

${ }^{2}$ MittVak = Mittleres Vakuum im kurzen Milchschlauch beim höchsten Milchfluss

${ }^{3}$ VDKMS = Vakuumfluktuation im kurzen Milchschlauch beim höchsten Milchfluss 
Die Einflüsse der Melkzeug- und Zitzengummiparameter auf die Hautfarbe nach dem Melken wurden mit dem Kruskal-Wallis-Test ermittelt. Für die Variablen Melkzeuggewicht $(P=0,07)$, Sammelstückvolumen $(P=0,15)$, Durchmesser kurzer Milchschlauch $(\mathrm{P}=0,36)$ und Durchmesser Zitzengummischaft $(P=0,14)$ konnten keine signifikanten Unterschiede in den Hautfarbenklassen gefunden werden. Die Einfaltdruckdifferenz hatte einen signifikanten Einfluss $(\mathrm{P}=0,04)$ auf die Hautfarbe der Zitze nach dem Melken.

Tabelle 28: Mittlere Werte der Melkzeug- und Zitzengummidaten in den Hautfarbenklassen der Zitzen nach dem Melken $(n=248)$

\begin{tabular}{|c|c|c|c|c|c|}
\hline & $\begin{array}{l}\text { Melkzeug- } \\
\text { gewicht } \\
\text { in g }\end{array}$ & $\begin{array}{l}\text { Sammelstück- } \\
\text { volumen } \\
\text { in } \mathrm{ml}\end{array}$ & $\begin{array}{l}\text { Durchmesser } \\
\qquad \mathrm{KMS}^{1} \\
\text { in } \mathrm{mm}\end{array}$ & $\begin{array}{l}\text { Durchmesser } \\
\text { Zitzengummi- } \\
\text { schaft } \\
\text { in mm }\end{array}$ & $\begin{array}{c}\mathrm{ED}^{2} \text { des } \\
\text { Zitzengummis } \\
\text { in } \mathrm{kPa}\end{array}$ \\
\hline Hautfarbe normal & 2209 & 340 & 10,60 & 23,96 & 10,41 \\
\hline Hautfarbe rot & 2126 & 353 & 10,91 & 23,67 & 10,63 \\
\hline Hautfarbe blau & 2470 & 300 & 10,00 & 24 & 6,93 \\
\hline $\mathrm{P}$ & 0,07 & 0,15 & 0,36 & 0,14 & 0,04 \\
\hline
\end{tabular}


Die Melkzeugtypen unterschieden sich in Hinblick auf die Hautfarbe nach dem Melken teilweise signifikant. Dies konnte mit dem Chi-Quadrat-Test nachgewiesen werden. Die Ergebnisse sind in Tabelle 29 dargestellt, signifikante Unterschiede sind durch unterschiedliche Kleinbuchstaben gekennzeichnet.

Tabelle 29: Anteil der Hautfarbenklassen der Zitzen $(n=248)$ nach Melkzeugtyp

\begin{tabular}{|c|c|c|c|}
\hline Melkzeugtyp & Haut normal & Haut rot & Haut blau \\
\hline $200 \mathrm{ccm}^{\mathrm{a}}$ & $40 \%$ & $60 \%$ & - \\
\hline Champion $^{\mathrm{b}}$ & $60 \%$ & $40 \%$ & - \\
\hline Classic $^{\mathrm{b}}$ & $49 \%$ & $46 \%$ & $6 \%$ \\
\hline ClassicE $^{\mathrm{a}}$ & $43 \%$ & $57 \%$ & - \\
\hline Clearflow $^{\mathrm{a}}$ & $50 \%$ & $50 \%$ & - \\
\hline Eclipse $^{\mathrm{a}}$ & $40 \%$ & $60 \%$ & - \\
\hline FloStarMax $^{\mathrm{a}}$ & $35 \%$ & $65 \%$ & - \\
\hline Harmony $^{\mathrm{d}}$ & $29 \%$ & $71 \%$ & - \\
\hline HarmonyPlus $^{\mathrm{a}}$ & $40 \%$ & $60 \%$ & - \\
\hline HCC $150^{\mathrm{c}}$ & $70 \%$ & $30 \%$ & - \\
\hline S90 $^{\mathrm{b}}$ & $60 \%$ & $40 \%$ & - \\
\hline Uniflow $^{\mathrm{a}}$ & $48 \%$ & $52 \%$ & - \\
\hline
\end{tabular}

${ }^{a}=$ signifikanter Unterschied zu b, c, d

${ }^{\mathrm{b}}=$ signifikanter Unterschied zu a, c, d

${ }^{c}$ = signifikanter Unterschied zu a, b, d

${ }^{d}=$ signifikanter Unterschied zu a, b, c 
Der Einfluss des Melkanlagenfabrikats auf die Hautfarbe nach dem Melken war unterschiedlich ausgeprägt. Die Fabrikate unterschieden sich teilweise signifikant, wie Tabelle 30 veranschaulicht (Chi-Quadrat-Test):

Tabelle 30: Anteil der Hautfarbenklassen der Zitzen $(n=248)$ nach Melkanlagenfabrikat

\begin{tabular}{|c|c|c|c|}
\hline Fabrikat & Haut normal & Haut rot & Haut blau \\
\hline Boumatic $^{\mathrm{a}}$ & $35 \%$ & $65 \%$ & $0 \%$ \\
\hline DeLaval $^{\mathrm{a}, \mathrm{b}}$ & $40 \%$ & $60 \%$ & $0 \%$ \\
\hline Happel $^{\mathrm{c}}$ & $60 \%$ & $40 \%$ & $0 \%$ \\
\hline Fullwood $^{c}$ & $50 \%$ & $50 \%$ & $0 \%$ \\
\hline Miele $^{\mathrm{c}}$ & $60 \%$ & $40 \%$ & $0 \%$ \\
\hline SAC $^{\mathrm{a}}$ & $47 \%$ & $53 \%$ & $0 \%$ \\
\hline WestfaliaSurge $^{\mathrm{b}}$ & $45 \%$ & $52 \%$ & $3 \%$ \\
\hline
\end{tabular}

${ }^{a}=$ signifikanter Unterschied zu b, c

${ }^{\mathrm{b}}=$ signifikanter Unterschied zu a, c

${ }^{c}=$ signifikanter Unterschied zu a, b

Ein signifikanter Einfluss der Zitzenmaße auf die Hautfarbe nach dem Melken konnte weder für die Zitzenlänge $(\mathrm{P}=0,22)$ noch für die Zitzendicke ( $\mathrm{P}=$ 0,54) ermittelt werden (Kruskal-Wallis-Test, Tabelle 31).

Tabelle 31: Maße der Zitzen $(n=248)$ in den Hautfarbenklassen

\begin{tabular}{|c|c|c|c|c|c|c|}
\hline & $\begin{array}{c}\text { Zitzlaen }^{1} \\
\text { in } \mathrm{mm}\end{array}$ & Min. & Max. & ZitzDick $^{2}$ & Min. & Max. \\
Haut normal & 45,00 & 30 & 66 & 24,20 & 18 & 28 \\
\hline Haut rot & 44,78 & 28 & 70 & 24 & 18 & 32 \\
\hline Haut blau & 51,50 & 51 & 52 & 24 & 24 & 24 \\
\hline
\end{tabular}

${ }^{1}$ ZitLaen $=$ Zitzenlänge $\quad{ }^{2}$ ZitzDick $=$ Zitzendicke 


\subsubsection{Gewebefestigkeit}

Der T-Test für unabhängige Variablen ergab für die Melkdauer, die Dauer des Milchflussabstiegs und die Melkdauer mit geringem Milchfluss keine signifikanten Unterschiede in Abhängigkeit von der Gewebefestigkeitsänderung der Zitzen.

Tabelle 32: Melkdauer, Abstiegsdauer und Melkdauer mit geringem Milchfluss und Gewebefestigkeitsveränderung der Zitzen $(n=248)$ nach dem Melken

\begin{tabular}{|c|c|c|c|}
\hline & $\begin{array}{c}\mathrm{tMGG}^{1} \\
\text { in min }\end{array}$ & $\begin{array}{c}\mathrm{tAB} \\
\text { in min }\end{array}$ & $\begin{array}{c}\mathrm{t} 400^{3} \\
\text { in min }\end{array}$ \\
\hline Mewebefestigkeitsveränderung $\leq 5 \%$ & & & \\
Median & 6,74 & 2,88 & 0,25 \\
SD & 6,35 & 2,61 & 0,19 \\
Gewebefestigkeitsveränderung $>5 \%$ & 1,83 & 1,37 & 0,24 \\
Mittelwert & 6,66 & 2,75 & 0,22 \\
Median & 6,67 & 2,71 & 0,14 \\
SD & 1,66 & 1,07 & 0,24 \\
\hline
\end{tabular}

${ }^{1} \mathrm{tMGG}=$ Dauer Gesamtgemelk

${ }^{2} \mathrm{tAB}=$ Dauer des Abstiegs

${ }^{3}$ t $400=$ Zeit zwischen Milchfluss 400 Gramm/Minute bis 200 Gramm/Minute am Melkende 
Zwischen den untersuchten Gruppen der Gewebefestigkeitsänderung konnten für keine der Variablen der „Dauer der Pulsationsphasen“ signifikante Unterschiede ermittelt werden (T-Test).

Tabelle 33: Dauer der Pulsationsphasen und Gewebefestigkeitsänderung der Zitzen $(n=248)$

\begin{tabular}{|c|c|c|c|c|c|c|}
\hline & $\begin{array}{c}\text { SaugPh } \\
\text { in } \mathrm{ms}\end{array}$ & $\begin{array}{c}\text { PulsAms }^{2} \\
\text { in } \mathrm{ms}\end{array}$ & $\begin{array}{c}\text { PulsBms }^{3} \\
\text { in } \mathrm{ms}\end{array}$ & $\begin{array}{c}\text { PulsCms }^{4} \\
\text { in } \mathrm{ms}\end{array}$ & $\begin{array}{c}\text { PulsDms }^{5} \\
\text { in ms }\end{array}$ & $\begin{array}{c}\text { ZykIDau }^{6} \\
\text { in ms }\end{array}$ \\
\hline $\begin{array}{c}\text { Gewebefestigkeits- } \\
\text { veränderung } \leq 5 \%\end{array}$ & 633 & 143 & 490 & 112 & 267 & 1012 \\
\hline $\begin{array}{c}\text { Gewebefestigkeits- } \\
\text { veränderung }>5 \%\end{array}$ & 631 & 146 & 485 & 111 & 271 & 1014 \\
\hline
\end{tabular}

${ }^{1}$ SaugPh $=$ Dauer der Saugphase

${ }^{3}$ PulsBms = Dauer der Vakuumphase

${ }^{2}$ PulsAms $=$ Dauer der Evakuierungsphase

${ }^{5}$ PulsDms $=$ Dauer der Druckphase

${ }^{4}$ PulsCms = Dauer der Belüftungsphase

${ }^{6}$ ZykIDau $=$ Gesamtdauer des Pulszyklus

Zwischen den beiden untersuchten Gruppen der Gewebefestigkeitsänderung konnten keine signifikanten Unterschiede in Bezug auf die Pulsationsart ermittelt werden (Chi-Quadrat-Test).

Tabelle 34: Anteil der Gewebefestigkeitsveränderungen der Zitzen $(n=248)$ nach Pulsationsart

\begin{tabular}{|c|c|c|}
\hline & Alternierend & Simultan \\
\hline Gewebefestigkeitsveränderung $\leq 5 \%$ & $37 \%$ der Tiere & $34 \%$ der Tiere \\
\hline Gewebefestigkeitsveränderung $>5 \%$ & $63 \%$ der Tiere & $66 \%$ der Tiere \\
\hline Gewebefestigkeitsveränderung absolut & & \\
Mittelwert & $9,6 \%$ & $8,7 \%$ \\
Median & $8,1 \%$ & $7,5 \%$ \\
SD & $7,89 \%$ & $6,6 \%$ \\
\hline
\end{tabular}


Die Vakuumverhältnisse hatten keinen signifikanten Einfluss auf die Gewebefestigkeitsveränderung. Die Gruppen der Gewebefestigkeitsänderung wiesen keine signifikanten Unterschiede in Bezug auf diese Variablen auf (TTest).

Tabelle 35: Mittlere Vakuumhöhen und Gewebefestigkeitsveränderung der Zitzen $(n=248)$

\begin{tabular}{|l|c|c|c|}
\hline & $\mathrm{BV}^{1}$ & MittVak $^{2}$ & VDKMS $^{3}$ \\
in $\mathrm{kPa}$ & in $\mathrm{kPa}$ & in kPa \\
\hline Gewebefestigkeitsveränderung $\leq 5 \%$ & 41,26 & 33,93 & 10,78 \\
\hline Gewebefestigkeitsveränderung $>5 \%$ & 41,20 & 33,80 & 10,90 \\
\hline Gewebefestigkeitsveränderung $\leq 10 \%$ & 41,08 & 33,92 & 10,97 \\
\hline Gewebefestigkeitsveränderung $>10 \%$ & 41,50 & 33,80 & 10,70 \\
\hline
\end{tabular}

${ }^{1}$ BV = Betriebsvakuum ${ }^{2}$ MittVak = Mittleres Vakuum im kurzen Milchschlauch beim höchsten Milchfluss

${ }^{3}$ VDKMS $=$ Vakuumfluktuation im kurzen Milchschlauch beim höchsten Milchfluss 
Die Gruppen der Gewebefestigkeitsänderung wiesen keine signifikanten Unterschiede in Bezug auf die Variablen „Melkzeugdaten“ und ,Zitzengummidaten“ auf (T-Test).

Tabelle 36: Werte der Melkzeug- und Zitzengummidaten und Gewebefestigkeitsveränderung der Zitzen $(n=248)$

\begin{tabular}{|c|c|c|c|c|c|}
\hline & $\begin{array}{l}\text { Melkzeug- } \\
\text { gewicht } \\
\text { in g }\end{array}$ & $\begin{array}{l}\text { Sammelstück- } \\
\text { volumen } \\
\text { in } \mathrm{ml}\end{array}$ & $\begin{array}{l}\text { Durchmesser } \\
\qquad \mathrm{KMS}^{1} \\
\text { in } \mathrm{mm}\end{array}$ & $\begin{array}{l}\text { Durchmesser } \\
\text { Zitzengummi- } \\
\text { schaft } \\
\text { in mm }\end{array}$ & $\begin{array}{c}\mathrm{ED}^{2} \text { des } \\
\text { Zitzengummis } \\
\text { in } \mathrm{kPa}\end{array}$ \\
\hline $\begin{array}{l}\text { Gewebefestigkeits- } \\
\text { veränderung } \leq 5 \%\end{array}$ & 2165 & 348 & 10,73 & 23,73 & 10,60 \\
\hline $\begin{array}{l}\text { Gewebefestigkeits- } \\
\text { veränderung >5\% }\end{array}$ & 2166 & 346 & 10,79 & 23,84 & 10,44 \\
\hline $\begin{array}{l}\text { Gewebefestigkeits- } \\
\text { veränderung } \leq 10 \%\end{array}$ & 2200 & 340 & 10,62 & 23,80 & 10,41 \\
\hline $\begin{array}{l}\text { Gewebefestigkeits- } \\
\text { veränderung >10\% }\end{array}$ & 2111 & 358 & 11,00 & 23,83 & 10,64 \\
\hline
\end{tabular}

${ }^{1} \mathrm{KMS}=$ kurzer Milchschlauch

${ }^{2} \mathrm{ED}=$ Einfaltdruckdifferenz 
Ein signifikanter Einfluss der Zitzenmaße auf die Gewebefestigkeitsänderung konnte weder für die Zitzenlänge noch für die Zitzendicke ermittelt werden (TTest).

Tabelle 37: Zitzenmaße und Gewebefestigkeitsveränderung der Zitzen $(n=248)$

\begin{tabular}{|l|c|c|c|c|c|c|}
\hline & $\begin{array}{c}\text { Zitzlaen } \\
\text { in } \mathrm{mm}\end{array}$ & $\begin{array}{c}\text { Min. } \\
\mathrm{mm}\end{array}$ & $\begin{array}{c}\text { Max. } \\
\mathrm{Mm}\end{array}$ & $\begin{array}{c}\text { ZitzDick }^{2} \\
\text { in } \mathrm{mm}\end{array}$ & $\begin{array}{c}\text { Min. } \\
\mathrm{mm}\end{array}$ & $\begin{array}{c}\text { Max. } \\
\mathrm{Mm}\end{array}$ \\
\hline $\begin{array}{l}\text { Gewebefestigkeits- } \\
\text { veränderung } \leq 5 \%\end{array}$ & 44,52 & 30 & 60 & 23,99 & 18 & 30 \\
\hline $\begin{array}{l}\text { Gewebefestigkeits- } \\
\text { veränderung }>5 \%\end{array}$ & 45,16 & 28 & 70 & 24,14 & 18 & 32 \\
\hline $\begin{array}{l}\text { Gewebefestigkeits- } \\
\text { veränderung } \leq 10 \%\end{array}$ & 44,97 & 30 & 62 & 23,98 & 18 & 30 \\
\hline $\begin{array}{l}\text { Gewebefestigkeits- } \\
\text { veränderung }>10 \%\end{array}$ & 44,85 & 28 & 70 & 24,25 & 18 & 32 \\
\hline
\end{tabular}

${ }^{1}$ ZitLaen = Zitzenlänge

${ }^{2}$ ZitzDick = Zitzendicke 


\subsubsection{Kongestion der Zitzenspitze}

Für das Auftreten von Kongestionen konnte ein signifikanter Einfluss der Melkdauer nachgewiesen werden. Die Abstiegsdauer und die Dauer mit geringem Milchfluss hatten keinen signifikanten Einfluss auf das Auftreten von Kongestionen der Zitzenspitze (Mann-Whitney-U-Test). Die signifikanten Unterschiede sind in Tabelle 38 mit unterschiedlichen Kleinbuchstaben gekennzeichnet.

Tabelle 38: Melkdauer, Abstiegsdauer und Melkdauer mit geringem Milchfluss in Bezug zu vorhandener Kongestion der Zitzenspitze ( $n=248)$

\begin{tabular}{|c|c|c|c|}
\hline & $\begin{array}{c}\mathrm{tMGG} \\
\text { in min }\end{array}$ & $\begin{array}{c}\mathrm{tAB}^{2} \\
\text { in min }\end{array}$ & $\begin{array}{c}\mathrm{t} 400^{3} \\
\text { in min }\end{array}$ \\
\hline $\begin{array}{c}\text { Keine Kongestion } \\
\text { Mittelwert }\end{array}$ & $6,48^{\mathrm{a}}$ & $2,77^{\mathrm{a}}$ & $0,24^{\mathrm{a}}$ \\
Median & $6,30^{\mathrm{a}}$ & 2,61 & 0,19 \\
$\mathrm{SD}$ & $1,62^{\mathrm{a}}$ & 1,14 & 0,24 \\
\hline Kongestion & & & \\
Mittelwert & $7,02^{\mathrm{b}}$ & $2,85^{\mathrm{a}}$ & $0,22^{\mathrm{a}}$ \\
Median & $6,82^{\mathrm{b}}$ & 2,75 & 0,14 \\
$\mathrm{SD}$ & $1,83^{\mathrm{b}}$ & 1,25 & 0,23 \\
\hline
\end{tabular}

\footnotetext{
${ }^{a}=$ signifikanter Unterschied zu b

${ }^{\mathrm{b}}=$ signifikanter Unterschied zu a

${ }^{1}$ tMGG = Dauer Gesamtgemelk

${ }^{2} \mathrm{tAB}=$ Dauer des Abstiegs

${ }^{3}$ t400 = Zeit zwischen Milchfluss 400 Gramm/Minute bis 200 Gramm/Minute am Melkende
} 
Zwischen den Gruppen „keine Kongestion“ und „Kongestion“ konnten für keine der Variablen „Pulsationsphasenlängen“ signifikante Unterschiede ermittelt werden (Mann-Whitney-U-Test).

Tabelle 39: Dauer der Pulsationsphasen und das Auftreten von Kongestionen an der Zitzenspitze $(\mathbf{n}=\mathbf{2 4 8})$

\begin{tabular}{|c|c|c|c|c|c|c|}
\hline & $\begin{array}{c}\text { SaugPh } \\
\text { in ms }\end{array}$ & $\begin{array}{c}\text { PulsAms }^{2} \\
\text { in ms }\end{array}$ & $\begin{array}{c}\text { PulsBms } \\
\text { in } \mathrm{ms}\end{array}$ & $\begin{array}{c}\text { PulsCms } \\
\text { in ms }\end{array}$ & $\begin{array}{c}\text { PulsDms } \\
\text { in ms }\end{array}$ & $\begin{array}{c}\text { ZykIDau }^{6} \\
\text { in ms }\end{array}$ \\
\hline Keine Kongestion & 633 & 145 & 487 & 114 & 270 & 1017 \\
\hline Kongestion & 630 & 144 & 486 & 108 & 269 & 1007 \\
\hline$P$ & n.s. $^{7}$ & n.s. & n.s. & n.s. & n.s. & n.s. \\
\hline
\end{tabular}

${ }^{1}$ SaugPh $=$ Dauer der Saugphase

${ }^{3}$ PulsBms = Dauer der Vakuumphase

${ }^{5}$ PulsDms $=$ Dauer der Druckphase

${ }^{7}$ n.s. $=$ nicht signifikant
${ }^{2}$ PulsAms $=$ Dauer der Evakuierungsphase

${ }^{4}$ PulsCms = Dauer der Belüftungsphase

${ }^{6}$ ZyklDau $=$ Gesamtdauer des Pulszyklus

Die beiden Gruppen „keine Kongestion“ und „Kongestion“ wiesen keine signifikanten Unterschiede in Bezug auf die Variablen „Simultane Pulsation“ und ,alternierende Pulsation“ auf (Chi-Quadrat-Test).

Tabelle 40: Anteil der Kongestionen der Zitzenspitze (n= 248) nach Pulsationsart

\begin{tabular}{|c|c|c|}
\hline Keine Kongestion & Alternierend & Simultan \\
\hline Kongestion & $\begin{array}{c}58 \% \\
\text { der Tiere }\end{array}$ & $\begin{array}{c}69 \% \\
\text { der Tiere }\end{array}$ \\
\hline Der Tiere & $\begin{array}{c}31 \% \\
\text { der Tiere }\end{array}$ \\
\hline n.s. & n.s. \\
\hline
\end{tabular}


Für das Betriebsvakuum und die Fluktuation des Vakuums im kurzen Milchschlauch wurde kein signifikanter Einfluss auf das Auftreten von Kongestionen nachgewiesen. Ein signifikanter Einfluss des mittleren Vakuums im kurzen Milchschlauch auf das Auftreten von Kongestionen wurde ermittelt $(\mathrm{P}=0,04)$. Es wurde der Mann-Whitney-U-Test angewendet.

Tabelle 41: Vakuumhöhen und Kongestionen der Zitzenspitze $(n=248)$

\begin{tabular}{|c|c|c|c|}
\hline & $\begin{array}{c}\mathrm{BV}^{1} \\
\text { in } \mathrm{kPa}\end{array}$ & $\begin{array}{c}\text { MittVak }^{2} \\
\text { in } \mathrm{kPa}\end{array}$ & $\begin{array}{c}\mathrm{VDKMS}^{3} \\
\text { in } \mathrm{kPa}\end{array}$ \\
\hline $\begin{array}{c}\text { Keine Kongestion } \\
\text { Mittelwert }\end{array}$ & 41,17 & 33,60 & 11,30 \\
Median & 41,50 & 34,10 & 8,95 \\
SD & 2,05 & 2,68 & 5,66 \\
\hline $\begin{array}{c}\text { Kongestion } \\
\text { Mittelwert }\end{array}$ & 41,31 & 34,29 & 10,17 \\
Median & 41,00 & 34,58 & 7,75 \\
SD & 2,31 & 2,43 & 5,77 \\
\hline P & n.s. & 0,04 & n.s. \\
\hline
\end{tabular}

${ }^{1} \mathrm{BV}=$ Betriebsvakuum

${ }^{2}$ MittVak = Mittleres Vakuum im kurzen Milchschlauch beim höchsten Milchfluss

${ }^{3}$ VDKMS = Vakuumfluktuation im kurzen Milchschlauch beim höchsten Milchfluss 
Die beiden Gruppen „Keine Kongestion“ und „Kongestion“ wiesen keine signifikanten Unterschiede in Bezug auf die Variablen „Melkzeugdaten“ und „Durchmesser Zitzengummischaft“ auf (Mann-Whitney-U-Test). Die Variable „Einfaltdruck des Zitzengummis“ hingegen hatte einen signifikanten Einfluss $(\mathrm{P}=0,01)$

Tabelle 42: Werte der Melkzeug- und Zitzengummidaten und das Auftreten von Kongestionen an der Zitzenspitze $(n=248)$

\begin{tabular}{|c|c|c|c|c|c|}
\hline & Melkzeug- & Sammelstück- & Durchmesser \\
gewicht & volumen & $\mathrm{KMS}^{1}$ & Durchmesser & Zitzengummi- \\
in $\mathrm{g}$ & in $\mathrm{ml}$ & in $\mathrm{mm}$ & in $\mathrm{mm}$ & in $\mathrm{KPa}^{2}$ des \\
\hline Keine Kongestion & 2134 & 351 & 10,81 & 23,67 & 10,77 \\
\hline Kongestion & 2216 & 340 & 10,70 & 24,00 & 10,08 \\
\hline $\mathrm{P}$ & n.s. & n.s. & n.s. & n.s. & 0,01 \\
\hline
\end{tabular}

${ }^{1} \mathrm{KMS}=$ kurzer Milchschlauch

${ }^{2} \mathrm{ED}=$ Einfaltdruckdifferenz 
Zwischen den beiden untersuchten Gruppen (keine Kongestion, Kongestion) konnte nur für die Variable Zitzendicke ein signifikanter Unterschied ermittelt werden $(P=0,002)$. Die Zitzenlänge hatte keinen signifikanten Einfluss (Mann-Whitney-U-Test).

Tabelle 43: Zitzenmaße und das Auftreten von Kongestionen an der Zitzenspitze (n= 248)

\begin{tabular}{|c|c|c|c|c|c|c|}
\hline & $\begin{array}{c}\text { Zitzenlänge } \\
\text { in mm }\end{array}$ & $\begin{array}{c}\text { Min. } \\
\mathrm{mm}\end{array}$ & $\begin{array}{c}\text { Max. } \\
\text { Mm }\end{array}$ & $\begin{array}{c}\text { Zitzendicke } \\
\text { in } \mathrm{mm}\end{array}$ & $\begin{array}{c}\text { Min. } \\
\mathrm{mm}\end{array}$ & $\begin{array}{c}\text { Max. } \\
\mathrm{mm}\end{array}$ \\
\hline Keine Kongestion & & 30 & 70 & & 20 & 32 \\
Medtelwert & 45,39 & & & 24,44 & \\
SD & 64,00 & & & 24,00 & & \\
\hline Kongestion & & & 62 & & & \\
Mittelwert & 44,20 & & & 23,50 & & \\
Median & 44,00 & & & 24,00 & & \\
SD & 6,81 & & & 1,89 & & \\
\hline P & n.s. & & & 0,002 & & \\
\hline
\end{tabular}

\footnotetext{
${ }^{1}$ ZitLaen $=$ Zitzenlänge

${ }^{2}$ ZitzDick = Zitzendicke
} 


\subsubsection{Ringbildung}

Zwischen den untersuchten Gruppen „keine Ringbildung“ und „Ringbildung“ konnte für die Variable „Zitzengummikopföffnung“ ein signifikanter Unterschied festgestellt werden $(\mathrm{P}=0,0003)$. Für die Variablen „Zitzengummischaft“ und „Differenz Zitzengummischaft zu Zitzendicke“ konnten keine signifikanten Unterschiede ermittelt werden.

Tabelle 44: Mittlere Werte der Zitzengummidaten und das Auftreten von Ringbildung an der Zitzenbasis $(n=248)$

\begin{tabular}{|c|c|c|c|}
\hline & $\begin{array}{l}\text { Durchmesser } \\
\text { Zitzengummi- } \\
\text { schaft } \\
\text { in mm }\end{array}$ & $\begin{array}{c}\text { Differenz } \\
\text { Zitzengummi- } \\
\text { schaft } \\
\text { zu Zitzendicke } \\
\text { in mm }\end{array}$ & $\begin{array}{l}\text { Durchmesser } \\
\text { Zitzengummi- } \\
\text { kopföffnung } \\
\text { in mm }\end{array}$ \\
\hline \multicolumn{4}{|c|}{ Keine Ringbildung } \\
\hline Mittelwert & 23,81 & 1,85 & 21,78 \\
\hline Median & 23,50 & 1,50 & 22,00 \\
\hline SD & 1,36 & 1,50 & 1,06 \\
\hline \multicolumn{4}{|l|}{ Ringbildung } \\
\hline Mittelwert & 23,77 & 1,89 & 21,20 \\
\hline Median & 23,50 & 1,75 & 21,63 \\
\hline SD & 1,20 & 1,49 & 1,17 \\
\hline $\mathrm{P}$ & n.s. & n.s. & 0,0003 \\
\hline
\end{tabular}




\subsection{Einfluss der untersuchten Merkmale auf die Zitzenkondition (multivariate Datenanalyse)}

Zur multivariaten Bewertung der Zusammenhänge zwischen melktechnischen und morphologischen Variablen und den Zitzenkonditionsvariablen wurden logistische Regressionen zu den Variablen berechnet, die in der univariaten Analyse signifikante Abhängigkeiten gezeigt haben $(\mathrm{P}<0,05)$. In Abhängigkeit von der Variablenart (ordinal: Hyperkeratosen, Hautfarbe; binominal: Kongestion, Kutimeterdifferenz $>5 \%<5 \%$ ) wurden ordinale oder binäre logistische Regressionen verwandt. Zur Beurteilung der Qualität der berechneten Modelle wurde die Hosmer und Lemeshow Goodness of fit bzw. die Pearson Goodness of Fit Statistik berechnet. Diese war in allen Modellen > 0,6, sodass von einer genügend großen Sicherheit der Modelle ausgegangen werden kann.

\subsubsection{Grad der Hyperkeratosen}

Euterviertel mit ausgeprägten Hyperkeratosen (Grad 3-4) an der Zitzenkanalöffnung, die nicht physiologisch sind, konnten signifikant häufiger bei längeren Zitzen $(\mathrm{P}<0,001)$, bei niedriger Vakuumdifferenz im kurzen Milchschlauch beim höchsten Milchfluss in $\mathrm{kPa}(\mathrm{P}=0,0029)$ und bei alternierender Pulsation $(\mathrm{P}=0,047)$ gefunden werden.

Spitzzitzen als Zitzenkuppenform erreichten ebenfalls auch in der multivariaten Betrachtung signifikant häufiger einen hohen Hyperkeratosegrad $(P=0,002)$

\subsubsection{Hautfarbe}

Rote oder blaue Verfärbungen der Haut nach dem Melken traten in der ordinalen logistischen Regression signifikant häufiger bei niedrigen Einfaltdrücken des Zitzengummis auf $(\mathrm{P}=0,034)$. 


\subsubsection{Gewebefestigkeit}

Signifikante Unterschiede zwischen melktechnischen und morphologischen Variablen in Bezug auf die Änderung der Gewebefestigkeit waren in der multivariaten Analyse nicht vorhanden.

\subsubsection{Kongestion der Zitzenspitze}

Die Kongestion der Zitzenspitze als Ausdruck einer unzureichenden Massage des Zitzengewebes wurde häufiger bei langer Melkdauer, längeren A-, B- und D-Phasen des Pulsationszyklus und seltener bei kürzerer Zyklusdauer, höheren Einfaltdrücken der Zitzengummis, einer größeren Zitzendicke und einem niedrigeren Betriebsvakuum festgestellt (Tabelle 45).

Tabelle 45: Ergebnisse der binären logistischen Regression für das Auftreten von Kongestionen anhand von melktechnischen und morphologischen Variablen

\begin{tabular}{|c|c|c|c|}
\hline & $\begin{array}{c}\text { Odd's } \\
\text { Ratio }\end{array}$ & $\begin{array}{c}\text { Konfidenzintervall } \\
95 \%\end{array}$ & $\begin{array}{c}\text { Signi- } \\
\text { fikanz }\end{array}$ \\
\hline Dauer der gesamten Melkung (min.) & 1,25 & $1,01-1,55$ & 0,001 \\
\hline Länge der A-Phase der Pulsation (ms) & 1,09 & $1,03-1,15$ & 0,005 \\
\hline Länge der B-Phase der Pulsation (ms) & 1,06 & $1,02-1,10$ & 0,004 \\
\hline Länge der D-Phase der Pulsation (ms) & 1,05 & $1,01-1,08$ & 0,01 \\
\hline Dauer eines Zyklus (ms) & 0,94 & $0,90-0,97$ & 0,001 \\
\hline Einfaltdruck des Zitzengummis (kPa) & 0,76 & $0,64-0,92$ & 0,004 \\
\hline Zitzendicke & 0,72 & $0,59-0,88$ & 0,001 \\
\hline Betriebsvakuum & 1,28 & $1,03-1,58$ & 0,024 \\
\hline
\end{tabular}




\section{Diskussion}

Den an der Zitze wirksamen Einflüssen durch den maschinellen Milchentzug kommt eine besondere Rolle in Bezug auf die Gesunderhaltung des Zitzengewebes zu. Die auf die Zitze wirkenden Kräfte führen nicht selten zu unerwünschten Veränderungen der Zitzenkondition. Störungen der Zitzenkondition können die Entstehung von Mastitiden begünstigen (Mein et al., 2004). Die Erhaltung oder Entwicklung einer zufrieden stellenden Zitzenkondition ist Ziel der Tierhalter, der Melktechnikindustrie und auch beratender Institutionen. Optimierungsprozesse basieren dabei üblicherweise auf Erfahrungswissen und nur wenig auf wissenschaftlichen Untersuchungen (Hubal und Krömker, 2010). Die vorliegende Studie versucht im Rahmen einer Querschnittsuntersuchung mögliche Beziehungen zwischen der Melktechnik und der Zitzenkondition aufzuzeigen und so Hypothesen für weitere beweisende Studien zu initiieren.

\subsection{Betriebsauswahl und Versuchstiere}

Die untersuchten Betriebe hatten eine Jahresdurchschnittsmilchleistung von $9084 \mathrm{~kg} / \mathrm{Kuh}$ und lagen damit um $500 \mathrm{~kg}$ über dem niedersächsischen Durchschnitt (LWK Niedersachsen, 2010). Die Tatsache, dass alle Melkanlagen der Betriebe intakt und nach DIN/ISO ausgelegt waren, minimierte das Risiko für Einflüsse der Melktechnik auf die Zitzenkondition, die aus fehlerhafter oder unzureichend dimensionierter Melktechnik hervorgehen könnten. Da verschiedene Fabrikate mit unterschiedlichen Einstellungen gewählt wurden, war eine große Bandbreite an Varianten der Melktechnik vorhanden. Die Verteilung der Betriebe nach Melkanlagenfabrikaten entsprach etwa ihren Marktanteilen in Niedersachsen (LWK Niedersachsen, 2010). Dies galt auch für die Melkzeugtypen und Pulsationsarten.

Einige der in die Studie einbezogenen Tiere erfüllten die Einschlusskriterien (100.-200. Laktationstag, $<200.000$ Zellen/ml) nicht. So waren insgesamt $7 \%$ 
der Tiere kürzer als 90 und länger als 210 Tage in der Laktation, 7 \% der Tiere wiesen über 200.000 Zellen/ml in der letzten Milchleistungsprüfung auf. Alle in die Studie einbezogenen Tiere zeigten jedoch keine Anzeichen klinischer Mastitiden.

Die Gemelksmengen der Tiere entsprachen mit durchschnittlich 14,63 kg dem Leistungsniveau der untersuchten Herden. Lediglich ein Tier mit 1,84 kg Gemelksmenge hatte bei der betreffenden Melkzeit Minderleistung, die wahrscheinlich auf eine Brunst zurückzuführen war. Da nur ein Gemelk berücksichtigt wurde und die Zwischenmelkzeit nicht immer 12 Stunden betrug, kann bei den Probanden von einer Tagesleistung zwischen ca. 17 und $55 \mathrm{~kg} /$ Tag ausgegangen werden (lineare Hochrechnung). Da alle Tiere standardisiert vom Autor angerüstet wurden, traten keine verzögerten Milchejektionen (Bimodalitäten) auf. Der Ausmelkgrad war bei allen Tieren als gut zu bezeichnen, da bei keinem Tier mehr als drei Strahlen Milch je Euterviertel (ca. $30 \mathrm{ml}$ ) nach dem Melkvorgang gewonnen werden konnte. Einer der Gründe hierfür kann die gute Anrüstung sein.

\subsection{Zitzenmorphologie}

Die Zitzenmaße der Tiere entsprachen für die hinteren Zitzen mit einer Länge von $28 \mathrm{~mm}$ bis $70 \mathrm{~mm}$ und einem Mittelwert von $45 \mathrm{~mm}$ auch den Werten von Untersuchungen mit größeren Stichproben. So stellte Graff (2005) bei 5855 Tieren Werte zwischen $20 \mathrm{~mm}$ und $80 \mathrm{~mm}$ mit einem Mittelwert von $45 \mathrm{~mm}$ fest. Die in der vorliegenden Studie ermittelten Werte der Zitzendurchmesser (18-32 mm, Mittelwert $24 \mathrm{~mm}$ ) entsprachen ebenfalls denen von Graff (2005), mit jeweils einem Minimum von $18 \mathrm{~mm}$, einem Maximum von $36 \mathrm{~mm}$ und einem Mittelwert von 23,5 mm. In den untersuchten Betrieben hatten jeweils über $80 \%$ der Tiere normale Zitzen und runde Zitzenkuppen, die auf züchterische Ursachen zurückzuführen sind. Vergleichsdaten dazu liegen aufgrund verschiedener Beurteilungssysteme nur unzureichend vor. 
Bei der Analyse der Daten zur Bewertung der Zitzenmaße im Hinblick auf die Ausprägung von Hyperkeratosen zeigte sich, dass signifikant mehr längere Zitzen in den Beurteilungsstufen 3 und 4 anzutreffen sind. Dies lässt sich auch aus den Ergebnissen von Rønningen und Reitan (1990) ableiten. Die Autoren haben bei einer höheren Penetrationstiefe der Zitzen in das Zitzengummi schlechtere Zitzenkonditionen festgestellt. Der Zitzendurchmesser hatte in dieser Studie einen signifikanten Einfluss auf das Auftreten von Kongestionen. Dies bestätigen auch die Untersuchungen von Gleeson et al. (2003), die bei engeren Zitzengummis und dazu im Verhältnis dickeren Zitzen eine geringere Ödembildung beobachteten.

Spitze Zitzen erreichten in der vorliegenden Studie im Vergleich zu anderen Kuppenformen signifikant höhere Hyperkeratosegrade $(\mathrm{P}=0,02)$. Dies wurde auch durch Untersuchungen von Seykora und McDaniel (1985) bestätigt.

\subsection{Einflüsse der melktechnischen Variablen}

Die Einflüsse der melktechnischen und der morphologischen Variablen wurden auf die Einzelwirkung auf die Zitzenkonditionsparameter (univariat) und auf die wechselseitige Wirkung auf die Zitzenkonditionsparameter (multivariat) untersucht. Für die multivariate Bewertung wurden ausschließlich Variablen gewählt, die in der univariaten Analyse signifikante Abhängigkeiten gezeigt hatten.

\subsubsection{Melkdauer}

Für die Melkdauer konnte in der univariaten Datenanalyse kein signifikanter Einfluss auf den Hyperkeratosegrad festgestellt werden. Dem gegenüber stellten Thompson und Sieber (1980) fest, dass eine mittlere Melkdauer der Herde unter 5 Minuten den Anteil an glatten, nicht herausgestülpten Zitzenkanalöffnungen erhöht $(20 \%)$. Bei einer mittleren Melkdauer von 6 Minuten sinkt dieser Anteil auf $10 \%$. In der vorliegenden Studie lag jedoch die 
Melkdauer in keiner der Hyperkeratosenstufen unter 6 Minuten. Neijenhuis et al. (2000) ermittelten für den Einfluss der Maschinenhaftzeit auf die Rauhigkeit der Hyperkeratose einen Korrelationskoeffizienten von $r=0,22$ ( $P$ $=0,08)$.

Für das Auftreten von Kongestionen konnte ein signifikanter Einfluss der Melkdauer festgestellt werden. Auch andere Autoren wiesen einen Zusammenhang zwischen der Melkdauer und der Zitzenkondition nach (Reid und Johnson, 2003; Graff et al., 2007).

Im Gegensatz zu der vorliegenden Studie wurden jedoch in den zitierten Arbeiten überwiegend einzelne Herden intensiv untersucht. Aufgrund der Einbeziehung ausschließlich von Tieren in der 2. Laktation und zwischen dem 100. und 200. Laktationstag und der damit verbundenen höheren durchschnittlichen Milchmengen lassen sich längere durchschnittliche Melkzeiten mit geringerer Schwankungsbreite erklären. Andererseits können so alters- und laktationsabhängige Einflüsse minimiert werden.

Bei der multivariaten Datenanalyse stellte sich ein 1,25-mal höheres Risiko für die Bildung von Kongestionen der Zitzenspitze bei längerer Melkdauer heraus. Dieser Zusammenhang wurde in der Literatur bisher nicht beschrieben.

\subsubsection{Pulsation}

Für die univariaten Einflüsse der verschiedenen Phasenlängen und die Länge des gesamten Pulszyklus auf die Zitzenkondition konnte für keine der Variablen ein signifikanter Unterschied in den Hyperkeratoseklassen, den Hautfarbenklassen, den Gewebefestigkeitsklassen und den Kongestionen nachgewiesen werden. Bei der multivariaten Analyse stellte sich jedoch heraus, dass längere A-, B- und D-Phasen bei kürzerem Pulszyklus häufiger der Grund für Kongestionen sind. Billon und Gaudin (2001) hingegen konnten für die Aund C-Phase einen positiven Einfluss der Dauer für die Entstehung von Kongestionen, allerdings nur bei Vordervierteln, feststellen. Dies hängt möglicherweise aber auch mit der längeren Blindmelkzeit der Vorderviertel 
zusammen. In verschiedenen experimentellen Arbeiten wurden die Effekte von Phasenlängen, die so in praxi nicht angetroffen werden konnten, untersucht. So wurden D-Phasen von unter 200 ms (Kirk, 2003; Reid und Johnson, 2003) und B-Phasen von 600-1000 ms (Billon und Gaudin, 2001) angewendet, um extreme Bedingungen zu schaffen. Die Effekte waren dadurch häufig deutlicher, als dies in der vorliegenden Praxisstudie festgestellt werden konnte, ausgeprägt.

Die Art der Pulsation hatte einen signifikanten Einfluss auf die Hautfarbe der Zitzen nach dem Melken. Die simultane Pulsation verursachte signifikant weniger rote und blaue Zitzen $(P=0,009)$. Hierzu lagen in der vorliegenden Literatur keine Ergebnisse vor. Es wurde häufig nur der Zusammenhang zwischen Pulsation und Hyperkeratosen, selten auch $\mathrm{zu}$ Kongestionen beschrieben. Die Durchschnitte der Hyperkeratoseneinstufungen in der vorliegenden Studie waren bei den mit simultaner Pulsation gemolkenen Tieren niedriger, dies war jedoch nicht signifikant.

\subsubsection{Vakuumhöhen}

Das Betriebsvakuum hatte univariat keinen signifikanten Einfluss auf die Zitzenkondition. In der multivariaten Analyse stellte sich heraus, dass das Risiko für Kongestionen mit sinkendem Betriebsvakuum abnimmt. Dies konnten auch schon Hamann und Mein (1988) feststellen. Das mittlere Vakuum im kurzen Milchschlauch hatte einen signifikanten Einfluss auf das Auftreten von Kongestionen und den Grad der Hyperkeratosen. Die Vakuumfluktuation im kurzen Milchschlauch hatte einen signifikanten Einfluss auf die Hautfarbe der Zitze nach dem Melken. In Bezug auf Hyperkeratosen wurden ähnliche Beobachtungen auch von Ebendorff und Ziesack (1991) bei jedoch größeren Differenzen zwischen den untersuchten Vakuumhöhen (45 zu $50 \mathrm{kPa})$ gemacht. Für Kongestionen stellten die Autoren keine Unterschiede fest. Auch Ryšánek et al. (2001) kamen zum Zusammenhang zwischen Vakuum im kurzen Milchschlauch und der Ausprägung von Hyperkeratosen zu 
vergleichbaren Ergebnissen. Ortega et al. (2008) setzen das Vakuum im Sammelstück in Bezug zum Einfaltdruck des Zitzengummis. Hierauf wird noch im Kapitel 5.3.5 eingegangen.

\subsubsection{Melkzeug}

Das Melkzeuggewicht und das Sammelstückvolumen hatten in der vorliegenden Studie keinen signifikanten Einfluss auf die Zitzenkondition. Hillerton et al. (2000) stellten ebenfalls keine Unterschiede hinsichtlich der Hyperkeratosen in Bezug zum Melkzeuggewicht fest. Zitzen, die mit einem schweren Melkzeug gemolken wurden, waren häufiger rot oder blau verfärbt. Im Gegensatz zu den Versuchen mit dem leichten Melkzeug wurde bei Einsatz des schweren Melkzeugs mit simultaner Pulsation Milch entzogen. Auch Rasmussen und Madsen (2000) stellten keine signifikanten Unterschiede des Melkzeuggewichts in Bezug zur Gewebefestigkeitsveränderung fest. Ohnstad (1998) stellte bei einem Melkzeug mit einem Gewicht über 2,4 $\mathrm{kg}$ einen höheren Anteil an Kühen mit roten und blauen Zitzen fest.

Bei den in dieser Studie untersuchten Melkzeugen als Zusammenstellung von Sammelstück und Zitzenbechern mit den entsprechenden Zitzengummis stellten sich signifikante Unterschiede in ihrer Wirkung auf die Hautfarbe der Zitzen nach dem Melken heraus. Dies beruht nicht nur auf dem verwendeten Melkzeug, sondern auch auf den anderen Parametern, die bei Verwendung der Melkzeuge wirksam wurden (Pulsation, Vakuumhöhen). Ähnliche Untersuchungen, in denen eine annähernd gleiche Anzahl von Melkzeugtypen untersucht wurde, konnten in der Literatur nicht gefunden werden.

\subsubsection{Zitzengummi}

Die in der vorliegenden Studie untersuchten Zitzengummis deckten einen weiten Bereich sowohl beim Durchmesser der Kopföffnung (20-24 mm) und des Schaftes (21,5-27 mm) als auch bei der Eigenschaft Einfaltdruckdifferenz 
(6,9-16 kpa) ab. Bei den Zitzengummis ließen sich in der univariaten und in der multivariaten Datenanalyse signifikante Einflüsse des Einfaltdruckes auf die Hautfarbe und das Auftreten von Kongestionen feststellen. Außerdem konnte ein signifikanter Einfluss der Zitzengummikopföffnung auf die Ringbildung an der Zitzenbasis ermittelt werden. Die Einfaltdrücke sind in Bezug zur Vakuumhöhe unter der Zitze und dem Zeitablauf zu sehen, um die einwirkende Kraft auf die Zitze berechnen zu können. Mein et al. (2003) stellten infolge dessen einen „Korridor“ der einwirkenden Drücke des Zitzengummis auf die Zitze zwischen 8 und $13 \mathrm{kPa}$ als erforderlich fest, um der Entstehung einerseits von Ödemen und Kongestionen und andererseits von Hyperkeratosen entgegenzuwirken. Auch Ortega et al. (2008) empfehlen eine Vakuumhöhe im Sammelstück, die 26-27 kPa über der Einfaltdruckdifferenz des Zitzengummis liegen sollte.

Ein signifikanter Einfluss der Zitzengummimaße auf den Grad der Hyperkeratosen konnte in dieser Studie nicht nachgewiesen werden. Dies stellten Gleeson und O`Callaghan (2001) auch fest, allerdings benutzten sie verschiedene Melkzeuge und Pulsationsarten, so dass keine unmittelbare Vergleichbarkeit gegeben war. Rønningen und Reitan (1990) hingegen ermittelten einen Zusammenhang zwischen der Penetrationstiefe der Zitze und der Gewebefestigkeit nach dem Melken. Die Zitzenlänge ist dabei entscheidend für die Penetrationstiefe (Kap. 5.2).

\subsubsection{Melkanlagenfabrikat}

Ein signifikanter Unterschied zwischen den Melkanlagenfabrikaten konnte nur für die Hautfarbe der Zitzen nach dem Melken ermittelt werden. Dies deckt sich mit den Beobachtungen zu den Melkzeugtypen, die abhängig sind vom Melkanlagenfabrikat. Die Gründe für diese Unterschiede liegen in der Bevorzugung bestimmter Pulsationsarten (alternierend/simultan) durch die Hersteller. Zwischen den Pulsationsarten bestehen jedoch in Bezug auf die Hautfarbe der Zitzen nach dem Melken signifikante Unterschiede. Studien, in 
denen Untersuchungen zu den Effekten des Melkanlagenfabrikats auf die Zitzenkondition durchgeführt wurden, sind nicht bekannt. 


\section{Schlussfolgerungen}

Die Ergebnisse der vorliegenden Studie haben deutlich gezeigt, dass verschiedene melktechnische Parameter unterschiedliche Einflüsse auf die Zitzenkondition haben. Der Fokus dieser Studie wurde auf Untersuchungen in kommerziellen Milchviehbetrieben gelegt. Experimentelle Arbeiten zu ausgewählten Einzelparametern wurden daher nicht durchgeführt.

Für Untersuchungen der Zitzenkondition in Abhängigkeit von melktechnischen Parametern sollte bevorzugt eine möglichst homogene Tiergruppe (gleiche Laktationsnummer, gleiches Laktationsstadium) ausgewählt werden, um altersund laktationsbedingte Einflüsse auf die Zitzenkondition minimieren zu können. Die Vorbereitung der Tiere vor dem Melkvorgang und die Beurteilung der Zitzenmorphologie und Zitzenkondition sollte standardisiert vorgenommen werden.

Für die Empfehlungen in der praktischen Beratung lassen sich aus dieser Studie einige wesentliche Ansätze ableiten. So ist eine an die Zitzenmaße angepasste Dimensionierung der Zitzengummis (Länge, Schaftdurchmesser, Kopföffnungsdurchmesser) zur Verhinderung des Auftretens von ausgeprägten Hyperkeratosen, Kongestionen und Ringen an der Zitzenbasis notwendig. Der Einfaltdruck des Zitzengummis sollte mit dem Vakuum unter der Zitze so abgestimmt werden, dass einerseits die Kraft des Zitzengummis ausreicht, Ödeme und Kongestionen zu minimieren und andererseits die Kraft nicht so groß wird, dass eine Bildung von unerwünschten Hyperkeratosen unterstützt wird.

Die Ergebnisse dieser Studie bezüglich der Melkdauer lassen die Aussage zu, dass eine möglichst kurze Melkdauer zur Vermeidung von Kongestionen anzustreben ist. Die Dauer des Pulsationszyklus sollte tendenziell kürzer $(\leq 1000 \mathrm{~ms}$ ) sein und das Betriebsvakuum nicht zu hoch (unterer Wert der Herstellerangabe), um Kongestionen zu vermeiden. Dies hat jedoch keinen Einfluss auf die Ausprägung von Hyperkeratosen. 
Zur Reduzierung des Auftretens von Hyperkeratosen der Stufen 3 und 4 sollte darauf geachtet werden, dass der Anteil an Tieren mit Spitzzitzen gering gehalten wird (Zucht), das Zitzengummi zur Zitzenlänge passt (Zitze sollte im Bereich der Zitzengummibewegung liegen) und die Fluktuation im kurzen Milchschlauch beim höchsten Milchfluss ausreichend groß ist.

Das Melkanlagenfabrikat stellt keinen Risikofaktor für unerwünschte Zitzenkonditionsstörungen dar. Hier ist die Auswahl der Komponenten (Melkzeug, Zitzengummi) und der Einstellungen (Vakuumhöhe, Pulsation) entscheidend.

Abschließend kann gesagt werden, dass zur Absicherung der ermittelten Daten weitere Untersuchungen, insbesondere zum Verlauf der Zitzenkonditionsparameter über die gesamte Laktation und über Laktationen hinweg notwendig sind. Dies sollte in Form einer Longitudinalstudie erfolgen. 


\section{Zusammenfassung}

Zahlreiche Untersuchungen beschäftigten sich bisher mit den Zusammenhängen zwischen Zitzenkondition und Mastitisgeschehen. Hierbei stellte sich wiederholt heraus, dass mit einer schlechten Zitzenkondition ein erhöhtes Mastitisrisiko einhergeht. Bisher fehlen jedoch Untersuchungen, die melktechnische Parameter in Bezug zur Zitzenkondition stellen und dabei auch die verschiedenen Kombinationen dieser Parameter als ganze Systeme betrachten. Das Ziel der vorliegenden Studie war es, mögliche melktechnische und morphologische Einflussfaktoren auf die Zitzenkondition zu identifizieren, um hieraus Empfehlungen ableiten zu können, welche dieser Kombinationen bei welchen morphologischen Gegebenheiten vorzuziehen sind.

Für die vorliegende Arbeit wurden Untersuchungen auf 50 Betrieben mit unterschiedlichen melktechnischen Parametern durchgeführt. Es wurden 4-5 Tiere je Betrieb untersucht (Deutsche Holsteins, 2. Laktation, überwiegend 100. - 200. Laktationstag). Dabei wurden alle Melkanlagen zuerst einer technischen Prüfung nach DIN/ISO 6690 unterzogen, deren positives Ergebnis Einschlusskriterium war. Es wurden Parameter zur Melktechnik (Fabrikat, Vakuum, Pulsation, Zitzengummi, Melkzeug), zur Milchabgabe (Gemelksmenge, Milchflüsse, Zeit), zur Zitzenmorphologie (Länge, Durchmesser, Form) und zur Zitzenkondition (Hyperkeratosen, Hautzustand, Hautfarbe, Ödeme, Kongestionen und Gewebefestigkeit) erhoben.

Die Einflüsse der verschiedenen melktechnischen und morphologischen Variablen auf die Zitzenkondition von Milchkühen wurden statistisch analysiert. Hierbei zeigte sich, dass Hyperkeratosen, die nicht physiologisch sind (Grade 3 \& 4), häufiger bei längeren Zitzen, bei spitzer Zitzenkuppenform, bei niedriger Fluktuation des Vakuums im kurzen Milchschlauch und bei alternierender Pulsation auftraten.

Rote und blaue Verfärbungen der Zitzenhaut sowie Kongestionen der Zitzenspitze waren häufiger bei niedrigen Einfaltdrücken des Zitzengummis. Weiterhin konnten Einflüsse der A-, B- und D-Phase, der Pulszyklusdauer 
sowie der Melkdauer auf das Auftreten von Kongestionen festgestellt werden. Auch das Betriebsvakuum, der Zitzendurchmesser und die Zitzenlänge nahmen Einfluss auf dieses Zitzenkonditionsmerkmal. Die Bildung von Ödemen an der Zitzenbasis wurde vom Durchmesser der Zitzengummikopföffnung beeinflusst. Die rote oder blaue Verfärbung der Zitzenhaut nach dem Melken wurde bei alternierender Pulsation und bei geringerer Fluktuation im kurzen Milchschlauch häufiger beobachtet.

Das Melkanlagenfabrikat hatte keinen Einfluss auf die Zitzenkondition, wohl aber die gewählten Melkzeuge, die verwendeten Zitzengummis und die Einstellungen der Melkanlage (Vakuum, Pulsation). 


\section{Summary}

Numerous studies deal with the effects of teat condition on mastitis matters. There is no doubt that pour teat condition increases the risk of mastitis. Studies that look at the interactions between milking technique variables and teat condition, understanding it as a whole system within all included variables are not published yet. This study tried to identify influence factors on teat condition coming from milking technique and also from teat morphology to finally construct recommendations, which milking technique combinations are preferable for certain teat morphologies.

In this study, 248 cows in $2^{\text {nd }}$ lactation (100-200 days in milk) were investigated on 50 Farms with different milking technique and different settings. All installations were tested according to ISO 6690 and fulfilled the performance requirements. Parameters according to milking technique (brand, vacuum, pulsation, liner, cluster), milk flow (amount, flow rate, duration), morphology of teats (length, diameter, form) and teat condition (hyperkeratosis, skin shape, skin colour, oedema, congestion, thickness) were determined.

The influences of the different variables of milking technique and teat morphology on teat condition were estimated by statistic analysis. Pointed teats, long teats, low vacuum fluctuation in the short milk tube and alternate pulsation make higher risk for hyperkeratosis level 3 and 4. Red or blue coloured teat skin and congestion of the teat tip after milking were significantly seen more often with lower collapse force of the liner. Furthermore the influences of pulsation phases A, B and D, duration of the pulsation cycle and machine-on time on congestion of the teat tip could be shown as significant. Also, working vacuum level, teat length and teat diameter influenced the appearance of congestion. The diameter of the mouthpiece lip showed influence on the appearance of oedema rings around the teat basis. Alternate pulsation and low vacuum fluctuation in the short milk tube caused red or blue teat skin more frequently. 
The make of the milking plant did not affect teat condition, but the use of certain clusters, liners and settings (pulsation, vacuum) and also the morphology of the teats did so. 


\section{Literaturverzeichnis}

Billon P, Gaudin V (2001): Influence of the duration of a and c phase of pulsation on the milking characteristics and on udder health of dairy cows. Conference on "Physiological and technical aspects of machine milking", Nitra, Slovak Republic. ICAR Technical Series No 7: 41-47.

Boast D, Bennett M, Hale M, Turner DM, Allcock J, Hillerton JE (2005): Details of some forces applied to the cow`s teat during milking. Proceedings of the 4th IDF International Mastitis Conference, Maastricht, The Netherlands, 12.-15.06.2005: 390-396.

Capuco AV, Wood DL, Quast JW (2000): Effects of teatcup liner tension on teat canal keratin and teat condition in cows. Journal of Dairy Research 67: 319-327.

DeLaval (2008): Milch und Melken. Arbeitsgruppe zur Förderung von Eutergesundheit und Milchhygiene in den Alpenländern AFEMA (Hrsg.)

DIN/ISO 3918 (1998), Melkanlagen: Begriffe, Beuth Verlag, Berlin

DIN/ISO 5707 (1998), Melkanlagen: Konstruktion und Leistung, Beuth Verlag, Berlin

DIN/ISO 6690 (1998), Melkanlagen: Mechanische Prüfungen, Beuth Verlag, Berlin

Ebendorff W, Ziesack J (1991): Untersuchungen zum Einfluss eines verminderten Melkvakuums (45 kPa) auf Zitzenbelastung und Eutergesundheit sowie Milchertrags- und Milchentzugsparameter. Mh. Vet. Med. 46: 827-831.

Franics, P. G. 1984. Teat skin lesions and mastitis. Br. Vet. J.: 430-436.

Geidel S, Graff K (2001): Morphologie der Zitze und melktechnische Parameter. 1. Jahrestagung der "Wissenschaftlichen Gesellschaft der Milcherzeugerberater e.V.". 12.-13.09.2001.

Gleeson DE, O'Callaghan E (2001): The effect of two milking systems on bovine teat condition. Conference on "Physiological and technical aspects of machine milking", Nitra, Slovak Republic. ICAR Technical Series No 7: 243246. 
Gleeson DE, Kilroy D, O'Callaghan E, Fitzpatrick E, Rath M (2003): Effect of machine milking on bovine teat sinus injury and teat canal keratin. Irish Veterinary Journal 56: 46-50.

Gleeson DE, O'Callaghan EJ, Rath MV (2002): Effect of milking on bovine teat tissue as measured by ultrasonography. Irish Veterinary Journal 55: 628632.

Graff K (2005): Untersuchungen von Zusammenhängen zwischen morphologischen Merkmalen des Euters, der Eutergesundheit und melktechnischen Parametern bei Tieren der Rasse Deutsche Holstein. Dissertation Martin Luther Universität Halle.

Graff K, Heidig K, Geidel S (2007): Wartung und Pflege von Melkanlagen. Milchpur: 48-53.

Grindal RJ (1988): II The Role of the Milking Machine in Mastitis. Br. Vet. J.: 524-533.

Grunert E (1990): Weiblicher Geschlechtsapparat, in: Dirksen G, Gründer HD, Stöber M: Die klinische Untersuchung des Rindes. Verlag Parey, Berlin und Hamburg: 472-548.

Hamann J (1988a): Zum Einfluss des maschinellen Milchentzuges auf die Infektionsgefahr für die bovine Milchdrüse. München, Univ., Veterinärmed. Fak., Habil.-Schr.

Hamann J (1988b): Zitzengewebereaktionen und maschineller Milchentzug ein Beitrag zum Infektionsrisiko in der Zwischenmelkzeit. Milchwissenschaft 43: 8-12.

Hamann J, Mein GA (1988): Responses of the bovine teat to machine milking: measurement of changes in thickness of the teat apex. Journal of Dairy Research 55: 331-338.

Hamann J, Mein GA (1990): Measurement of machine-induced changes in thickness of the bovine teat. Journal of Dairy Research 57: 495-505.

Hamann J, Mein GA (1995): Dynamic tests for reactions of the teat. Proc 3rd International Seminar, Tel Aviv, Israel S7: 24-29 
Hamann J, Mein GA (1996): Teat thickness changes may provide biological test for effective pulsation. Journal of dairy Research 63: 179-189.

Hamann J, Nipp B, Persson K (1994): Teat tissue reactions to milking: Changes in blood flow and thickness in the bovine teat. Milchwissenschaft 49: 243-247.

Hamann J, Mein GA, Wetzel S (1993): Teat Tissue Reactions to Milking: Effects of Vacuum Level. J Dairy Sci 76: 1040-1046.

Hansen S (2002): Influence of environmental and pulsation factors on teat skin condition and teat tissue with regard to mastitis. Hannover, Tierärztliche Hochschule, Dissertation: 102, Fig. 15.

Hillerton JE (2005): Do liners differ? NMC Annual Meeting Proceedings: 133-138.

Hillerton JE, Boast, D, Davies D, Ohnstad I, Middleton N (2003): Changes in milking liner performance with age. National Mastitis Council Annual Meeting Proceedings: 239- 250.

Hillerton JE, Ohnstad I, Baines JR, Leach KA (2000): Changes in cow teat tissue created by two types of milking cluster. Journal of Dairy Research 67: 309-317.

Hillerton JE, Pankey JW, Pankey P (2002): Effect of over-milking on teat condition. Journal of Dairy Research 69: 81-84.

Hubal M (2005): Technische Überwachung von Melkanlagen, in: Brade W und Flachowski G: Rinderzucht und Milcherzeugung, 2. Aufl., Hannover/Braunschweig 2005 ISBN 3-86576-012-0: 26-32.

Hubal M, Krömker V (2010): Melktechnische Einflüsse auf die Zitzenkondition von Milchkühen - Eine Literaturübersicht. Tierärztliche Praxis 4/2010: 225-232.

Kirk JH (2003): Risk Factors for Excessive Hyperkeratosis of Teat Ends. http://www.vetmed.ucdavis.edu/vetext/INF-DA/RiskFactorsPoorTeatEnd.pdf (angezeigt am 06.06.2008)

Krömker V (2006): Kurzes Lehrbuch der Milchkunde und Milchhygiene. MVS Medizinverlage, Parey, Stuttgart 2006 ISBN 3-8304-4155-X. 
Krömker V, Hamann J (1997): Diagnostik des Mastitisrisikos tierindividuelle Merkmale. Der praktische Tierarzt, Coll. Veterinarium XXVIII (1997) 70-75.

Lacy-Hulbert SJ, Hillerton JE, Woolford, MW (1996): Influence of pulsationsless milking on teat canal keratin growth and turnover. Journal of Dairy Research 63: 517-524.

Landwirtschaftskammer Niedersachsen (2006): Handbuch für die Überprüfung von Melkanlagen in der Milcherzeugerberatung, Selbstverlag Mein GA, Neijenhuis F, Morgan WF, Reinemann DJ, Hillerton JE, Baines JR, Ohnstad I, Rasmussen MD, Timms L, Britt JS, Farnsworth R, Cook N, Hemling T (2001): Evaluation of bovine teat condition in commercial dairy herds, 1. Non infectious factors; 2. Infectious factors and infections; 3. Getting the numbers right; 4. Relationship between teat-end callosity or hyperkeratosis and mastitis. Proceedings of the $2^{\text {nd }}$ International Symposium on Mastitis and Milk Quality 2001: 338-366.

Mein GA, Williams DMD, Reinemann DJ (2003b): Effects of milking on teat-end hyperkeratosis: 1. Mechanical forces applied by the teatcup liner and responses of the teat. 42nd annual meeting of the National Mastitis Council, Fort Worth Texas, 26.-29.01.2003.

Mein GA, Reinemann DJ, O'Callaghan E, Ohnstad I (2003a): Where the rubber meets the teat and what happens to milking characteristics. IDF symposium: 100 years with Liners and Pulsators. September 2003.

Mein GA, Reinemann DJ, Schuring N, Ohnstad I (2004): Milking machines and mastitis risk: A storm in a teatcup. Meeting of the National Mastitis Council. 2004.

Neijenhuis F, Klungel GH, Hogeveen H, Noordhuizen JPTM (2004): Machine milking risk factors for teat end callosity in dairy cows on herd level. In: F. Neijenhuis. Teat Condition in Dairy Cows. Utrecht University, Faculty of Veterinary Medicine, diss: 107-128. 
Neijenhuis F, Barkema HW, Hogeveen H, Noordhuizen JPTM (2000): Classification and longitudinal Examination of Callused Teat Ends in Dairy Cows. J Dairy Sci 83: 2795-2804.

Ohnstad I (1998): Machine milking and the well-being of the dairy cow. Proceedings of the British Mastitis Conference 1998: 62-67.

Ortega R, Pérez MA, Muniz R, Fernandez R (2008): Milking machine tuning to improve udder health and to reduce teat end hyperkeratosis in dairy cows. In: T. J. G. M. Lam (editor). Mastitis control. From science to practice. Proceedings of international conference. The Hague, Netherlands. 30 september - 2 october 2008: 333-340.

Østerås O, Rønningen O, Sandvik L, Waage S (1995): Field studies show associations between pulsator characteristics and udder health. Journal of Dairy Research 62: 1-13.

Paulrud CO, Clausen S, Andersen PE, Rasmussen MD (2005): Infrared thermography and ultrasonography to indirectly monitor the influence of liner type and overmilking on teat tissue recovery. Acta vet. scand. 46: 137-147.

Rasmussen MD (1993): Influence of switch level of automatic cluster removers on milking performance and udder health. Journal of Dairy Research 60: 287-297.

Rasmussen MD (2004): Overmilking and teat condition. NMC Annual Meeting Proceedings: 169-175.

Rasmussen MD, Madsen NP (2000): Effects of milkline Vacuum, pulsator airline vacuum, and cluster weight on milk yield, teat condition, and udder health. J. Dairy Sci 83: 77-84.

Rasmussen MD, Frimer ES, Decker EL (1994): Reverse pressure gradients across the teat canal related to machine milking. J. Dairy Sci 77: 984-993.

Rasmussen MD, Frimer ES, Kaartinen L, Jensen NE (1998): Milking performance and udder health of cows milked with two different liners. J. Dairy Res. 65: 353-363.

Reid DA, Johnson AP (2003): Trouble shooting herds with poor teat condition. National Mastitis Council Annual Meeting Proceedings: 124-127. 
Reinemann DJ, Bade R, Zucali M, Spanu C, Ruegg PL (2008): Understanding the influence of machine milking on teat defense mechanisms. In: T. J. G. M. Lam (editor). Mastitis control. From science to practice. Proceedings of international conference. The Hague, Netherlands. 30 september - 2 october 2008: 323-331.

Rønningen O, Reitan AD (1990): Influence of static and dynamic teat charactersitics and milking time on udder health in Norwegian Red Cattle. Journal of Dairy Research 57: 171-177.

Ryšánek D, Olejník P, Babák V (2001): Vacuum fluctuation in short milk tube during peak milk flow. Conference on "Physiological and technical aspects of machine milking", Nitra, Slovak Republic. ICAR Technical Series No 7: 125-130.

Schukken YH, Petersson LG, Rauch BJ (2006): Liners and teat end health. NMC Annual Meeting Proceedings: 183-196

Seykora AJ, McDaniel BT, (1985): Heritabilities of teat traits and their relationships with milk yield, somatic cell count, and percent two-minute milk. Journal of Dairy Science 68: 2670-2683.

Spencer SB, Rogers GW (2003): Optimization of a milking machine liner. NMC Annual Meeting Proceedings: 234-238.

Spohr M (2005): Milchgewinnung und Milchhygiene, in: Brade W und Flachowski G: Rinderzucht und Milcherzeugung, 2. Aufl., Hannover/Braunschweig 2005 ISBN 3-86576-012-0: 13-17.

Thompson PD, Sieber RL (1980): Milking machine effects on impacts and teat-end lesions. Proceedings of International Workshop on Machine Milking and Mastitis: 61-72.

Wehowsky G, Tröger F (1994): 4. Milchgewinnung, in: Wendt K, Bostedt H, Mielke H \& Fuchs HW 1994: Euter- und Gesäugekrankheiten. Jena und Stuttgart: Gustav Fischer Verlag: 202-203.

Wendt K (1994): 5.2. Veränderungen der Haut und Unterhaut, in: Wendt K, Bostedt H, Mielke H \& Fuchs HW 1994: Euter- und Gesäugekrankheiten. Jena und Stuttgart: Gustav Fischer Verlag: 301-310. 
Wendt K (2004): Beurteilung der Zitzenkondition und Einflüsse der Melktechnik auf die Zitze. Wissenschaftliche Gesellschaft der Milcherzeugerberater e.V.

Williams DM, Mein GA (1985): The role of machine milking in the invasion of mastitis organisms and implications for maintaining low infection rates. Kieler Milchwirtschaftliche Forschungsberichte 37: 415-425. 


\section{Anhang}

A1 DIN/ISO Protokoll Niedersachsen nach DIN/ISO 6690/1998

\section{Protokoll über die Milcherzeugerberatung in Niedersachsen - Qualitätssicherungsprogramm Milcherzeugung -}

Betrieb:
OT, Str., Nr.
Wohnort:

Wohnort:

Melkort: Stall(1) - Weide(2)

\section{Allgemeine Angaben}

Messpunkte vorhanden ("Leer"

1 A1

2 A2

$3 \mathrm{Vm}$

$4 \mathrm{vr}$

$5 \quad \mathrm{pp}$

$6 \mathrm{Pe}$

Messungen

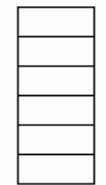

Ant $(1-4 ; T, F, S)$

System (1 - 5)

Bed. Personen Kuhzahl lakt. $n$ Melkzeuge

7 Anlagenvak

ME A1 Mp

8 Vakuumhöhe nahe Anlagenvakuummeter

9 Genauigkeit des Anlagenvakuummeters

10 V-Melksystem $N \quad N \quad V m$

11 Betriebsvak.

12 Empfindlichkeit der Regeleinheit

13 Betriebsvak RE J N $\mathrm{Vr}$

14 Betriebsvak. RE minus $2 \mathrm{kPa}$ (für $Z .21$ u. 24

15 Eetriebsvak. VP J N Vp

16 Meßvak an Vm J J Vm

17 Meßvak an RE $J$ J $\quad$ Vr

18 Meßvak an VP $J \quad J \quad V p$

19 Vakuumhöhe im Pulsraum

$\begin{array}{cccccc} & \text { ME } & \text { RE } & \text { Mp } & \text { LE } & \text { V-höhe } \\ 20 \text { Res durchfluss } & \mathbf{J} & \mathbf{J} & \text { Vm } & \text { A1 } & \text { Z 16 }\end{array}$

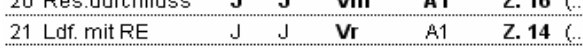

22 Manueller Rdf. J N Vm A1 Z. 16 (.........

23 Regelverlust $\leqslant 10 \%$ von Z. $220.35 \mathrm{l} / \mathrm{min} \quad(Z .22-Z .20)$

$\begin{array}{lllllllll}24 & \text { Ldf ohne RE } & J & N & V r & A 1 & Z .14\end{array}$

25 Leckluft RE $\quad \approx 5 \%$ von Z. $220.35 \mathrm{l}$ min $(Z .24-Z .21)$

26 Ldf. mit ME J N Vrod Vp A2 Z13oZ15

27 Ldf. ohne ME $N \quad N$ Vrod Vp A2 Z13oZ15 (

28 Luftverbrauch Melkeinheiten ( 35 limin je ME) (Z.27-Z.26)

29 Ldf. ohne ML N N Vrod Vp A2 Z13oZ15 C

30 Leckluft ML $10 \mathrm{limin}+2$ liminiAnschluss $(Z .29-Z .27)$

31 Ldf ohne Ls. $\quad N \quad N \quad V p \quad V P \quad Z .15 c$

32 Leckluft Ls. $\quad 55 \%$ von Zeile $31 \quad$ (Z.31-Z. 29)

33 Ldf Vakump $N$ max:

Melkeinheiten

34 Pulsatortyp(1-3,M-S) $\square, \square$ Pulsierung, Wechselt./Gleicht. $\square$ Pulszahl 35 Pulsverhältnis S:E $\quad$ Lufteinlass am MZ (1 bis 3 ) Prüfung

36 Pulsatoren Anzahl

37 Lufteinlass am MZ

38 Absperventil $(1 ; 2)$

39 Melkvakuum

40 Niedrigvakuum

41 Schaltpunkt

42 Verzögerungszeit

43 Ldf. langer Milchschlauch bei Absenkung um $5 \mathrm{kPa}$

44 Vakuumanschlüsse $(n=$ )

45 Milchhähne $(n=\ldots)$

46 Staudruck an $\mathrm{Pe}$

Betr.Schl:

Ber.Bez.Nr

Molkerei-Nr.:

Liefer-Nr.

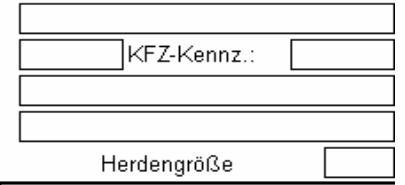

Material HLL(KU o. VZ

Material LL (KU o. VZ)

HLL $\emptyset \mathrm{mm}$ Soll

ftleit. Längeim

LLø $\mathrm{mm}$ Soll

Nenn-Betriebsvak. kPa

Ist

$M L \mathrm{~mm} \emptyset \quad$ Soll

ML Montage (1 bis 3)

ML Gefälle $\%$

Milcheinlauf (1 oder 2)

Brücke (1 oder 2)

Reinigungsvakuum

zulässig 1,0 kPa (Zeile 7 zu 8)

ulässig 1,0 kPa (Zeile 10 zu 11)

Zeile 11 - 2 kPa)

Vakuumabfall Milchabscheider/Regeleinheit $\quad \square$ zul. 1,0 (Z.17 zu 16] Vakuumabfall Milchabscheider Vakuumpumpe

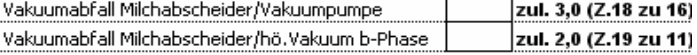

Luft I/min

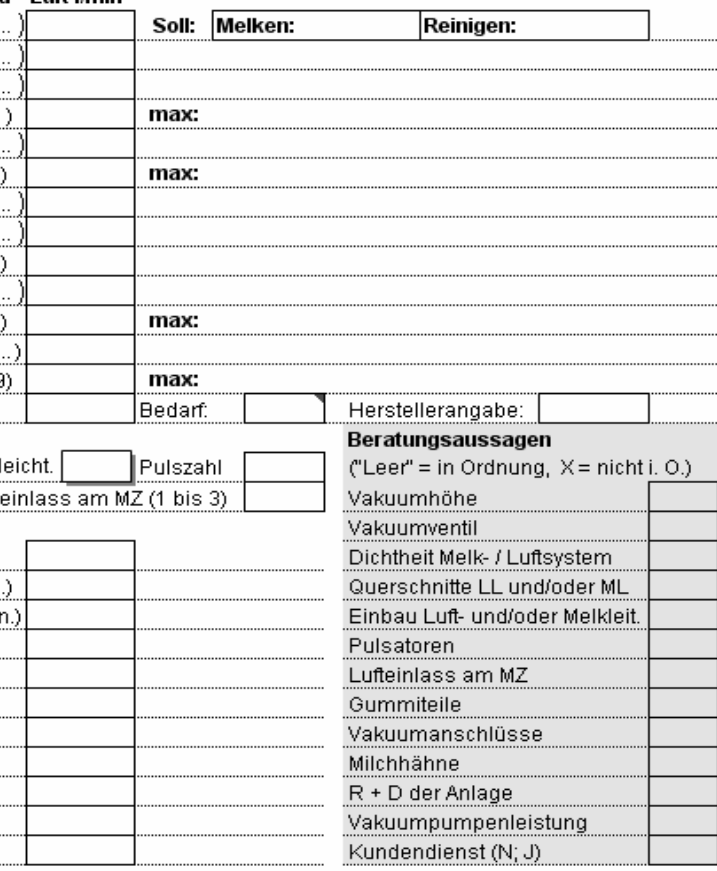


(Rückseite)

Markante Daten für die Messung, Prüfung und Beurteilung

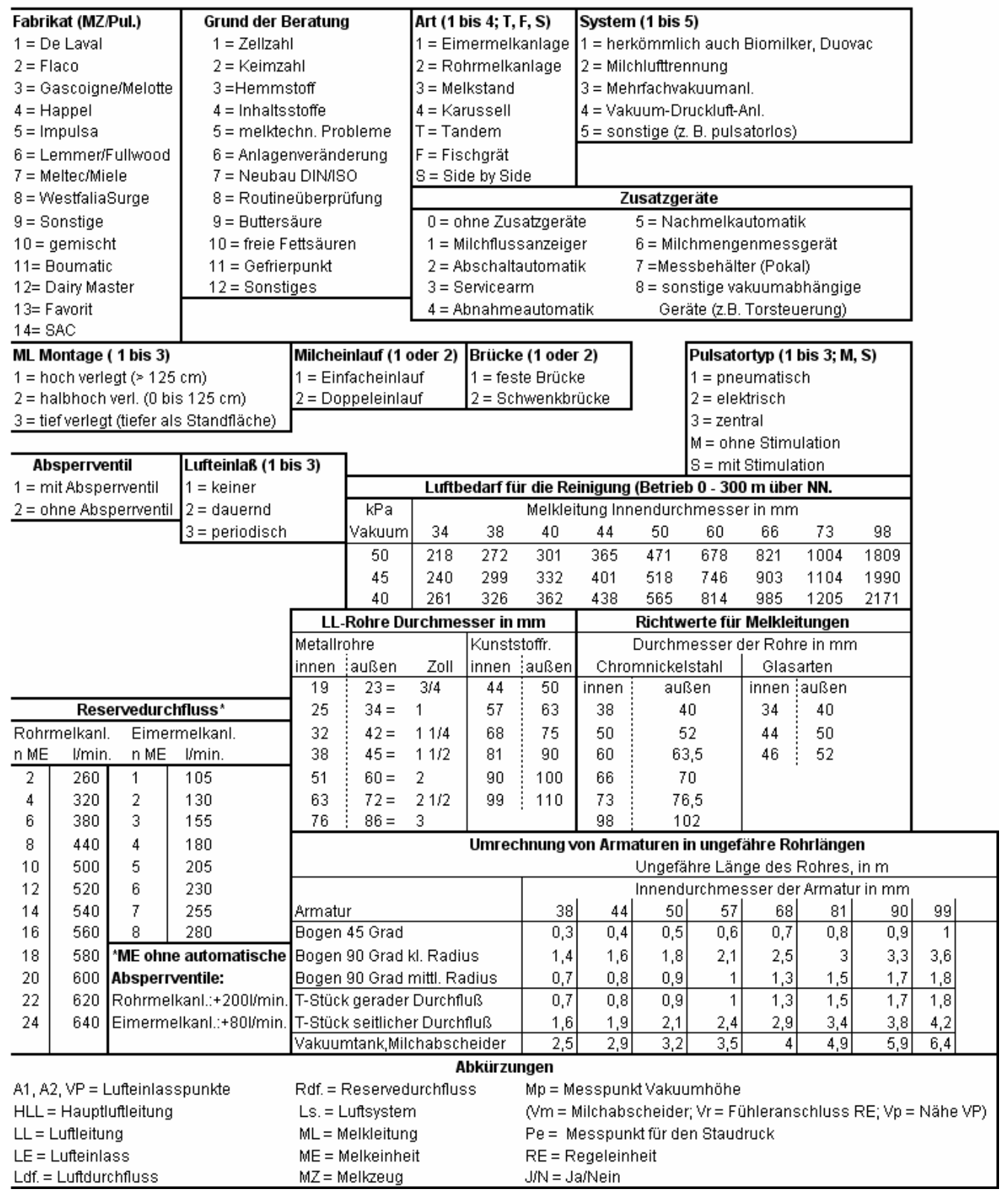




\section{MilkoTest MT52}

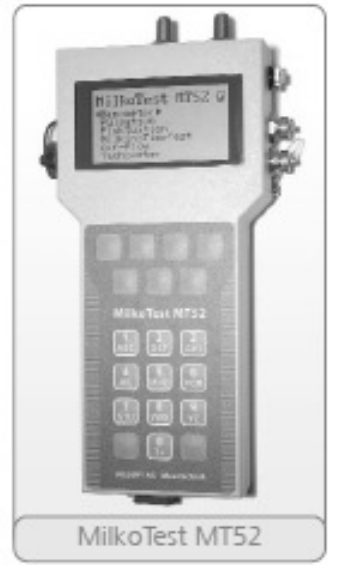

MilkoTest MT52 stammt, wie das bewāhrte Pulsotest-Gerāt, aus dem Hause Bilgery/Bepro AG, Messtechnik. Das Gerät ist die konsequente Weiterentwicklung unserer bewāhrten seit über 20 Jahren weltweit im Einsatz stehenden Messgeräte.

Das in die Zukunft gerichtete HighTec Gerät der neusten Generation zeichnet sich besonders durch den universellen Einsatz (zur Zeit 8 Messprogramme), die einfache Bedienung sowie die kompakte Bauform aus.

Insbesondere erleichtert MilkoTest MT52 durch die neue Protokollfunktion die Kontroll- und Service-Arbeiten an Melkanlagen erheblich.

Das Gerät ist für den Anschluss von zwei externen Vakuum- oder Temperatursensoren ausgerüstet. Die internen und externen Sensoren sind unempfindlich gegen Wasser oder Milch. Problemlose Messungen auch an milchführenden Stellen sind selbstverstāndlich. Es besteht die Möglichkeit zur Spülung der Sensoren mit Reinigungsflüssigkeit.
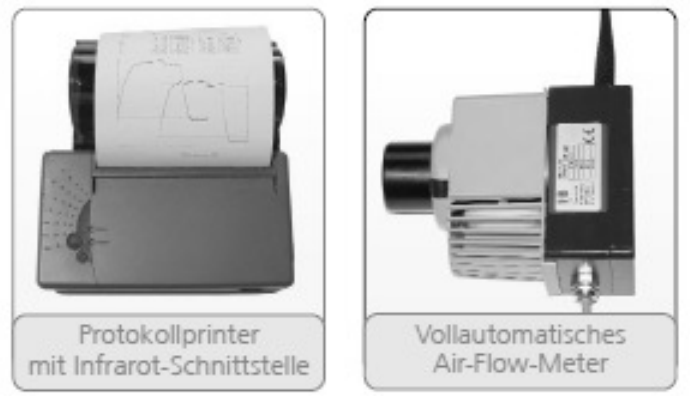

\begin{tabular}{|ll|}
\multicolumn{2}{|c|}{ Technische Daten } \\
\hline Vakuum-Sensoren: \\
Vakuum & $60 \mathrm{kPa}$ \\
Überdruck & $20 \mathrm{kPa}$ \\
Auflösung & $12 \mathrm{Bit}$ \\
Genauigkeit & Güteklasse 0.6 \\
Geräteintern & 2 Sensoren \\
Extern steckbar & 2 Sensoren Option \\
Anzeige: & \\
LCD-Modul & $128 \times 64$ Pixel Graphik \\
Anzeigefeld & $71 \times 39$ mm hinterleuchtet
\end{tabular}

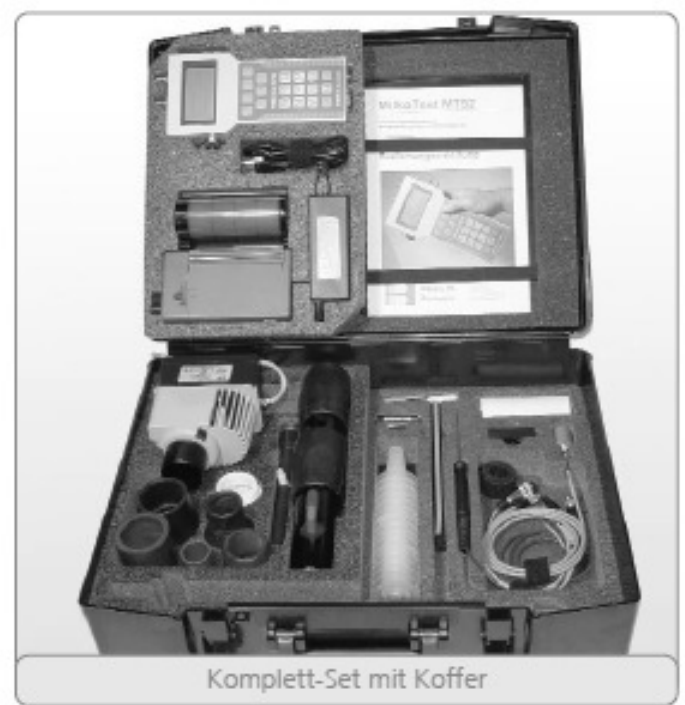

Memory:

Programmspeicher 512 kBytes Flash

Datenspeicher

1 MB RAM (1.5 MB)

Schnittstellen:

Zum PC

RS232

Zu Printer Seiko Infrarot (IrDa 1.0)

Eingangs-

spannung:

7,5 bis 15 VDC max. 1,3A

Akkus:

Ni-Metall-Hydrid

7.2V 1500 mAh

Ladedauer:

3 Std. für Voll-Ladung

Betriebsdauer:

10 bis 20 std.

abhängig von der

Beleuchtung und des AFM

Gehäuse:

$225 \times 107 \times 40 \mathrm{~mm}$ (LxBxH)

Gewicht:

$670 \mathrm{~g}$ 


\section{Blatt 1 Betriebs- und Melkanlagendaten}

Betrieb:

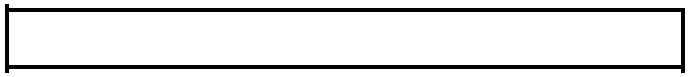

OT, Str., Nr::

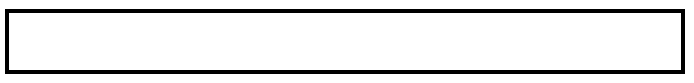

Wohnort:

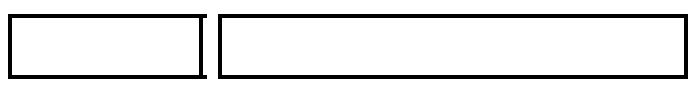

Datum

\begin{tabular}{|c|c|c|c|}
\hline Allgemeine Angaben & Melkzeug & \multicolumn{2}{|c|}{ Milchschlauch/Pulsation } \\
\hline Fabrikat (1 - 14) & \multirow{7}{*}{$\begin{array}{l}\text { MZ Typ } \\
\text { Gowicht g } \\
\text { Volumon ccm } \\
\text { Stutzon KMS mm }\end{array}$} & \multirow{2}{*}{$\begin{array}{l}\text { Lango Mlohschlauch } \\
\text { Matorial (1/2) }\end{array}$} & \\
\hline Art (1 - 4; T,F,S) & & & \\
\hline System (1 - 5) & & \multirow{2}{*}{$\begin{array}{l}\text { Durchmosser mm } \\
\text { Glaich_W ochsoltakt }\end{array}$} & \\
\hline Bad. Parsonan & & & \\
\hline Botriabsvakuum & & \multirow{3}{*}{\begin{tabular}{|l} 
Pulsrate \\
Sougphase \% \\
Saugphase ms \\
\end{tabular}} & \\
\hline & & & \\
\hline Molkzoit AM & & & \\
\hline Dynamische Messungen & Zitzengummi & \multirow{2}{*}{\multicolumn{2}{|c|}{ Chemikalien }} \\
\hline Fluktuationon: & \multirow{5}{*}{$\begin{array}{l}\text { Zitzongummityp } \\
\text { Schahdurchmesser } \\
\text { Kopflochdurchm. } \\
\text { Enfaltdruck KPa }\end{array}$} & & \\
\hline Kuzzor Milchschlauch & & \multirow[t]{3}{*}{ Vorreinigung } & \\
\hline bei Milchfluss Vmin. & & & \\
\hline Pula B-Phaso & & & \\
\hline Drucksummo ZG & & & \\
\hline
\end{tabular}




\section{Blatt 2 Kuhdaten}
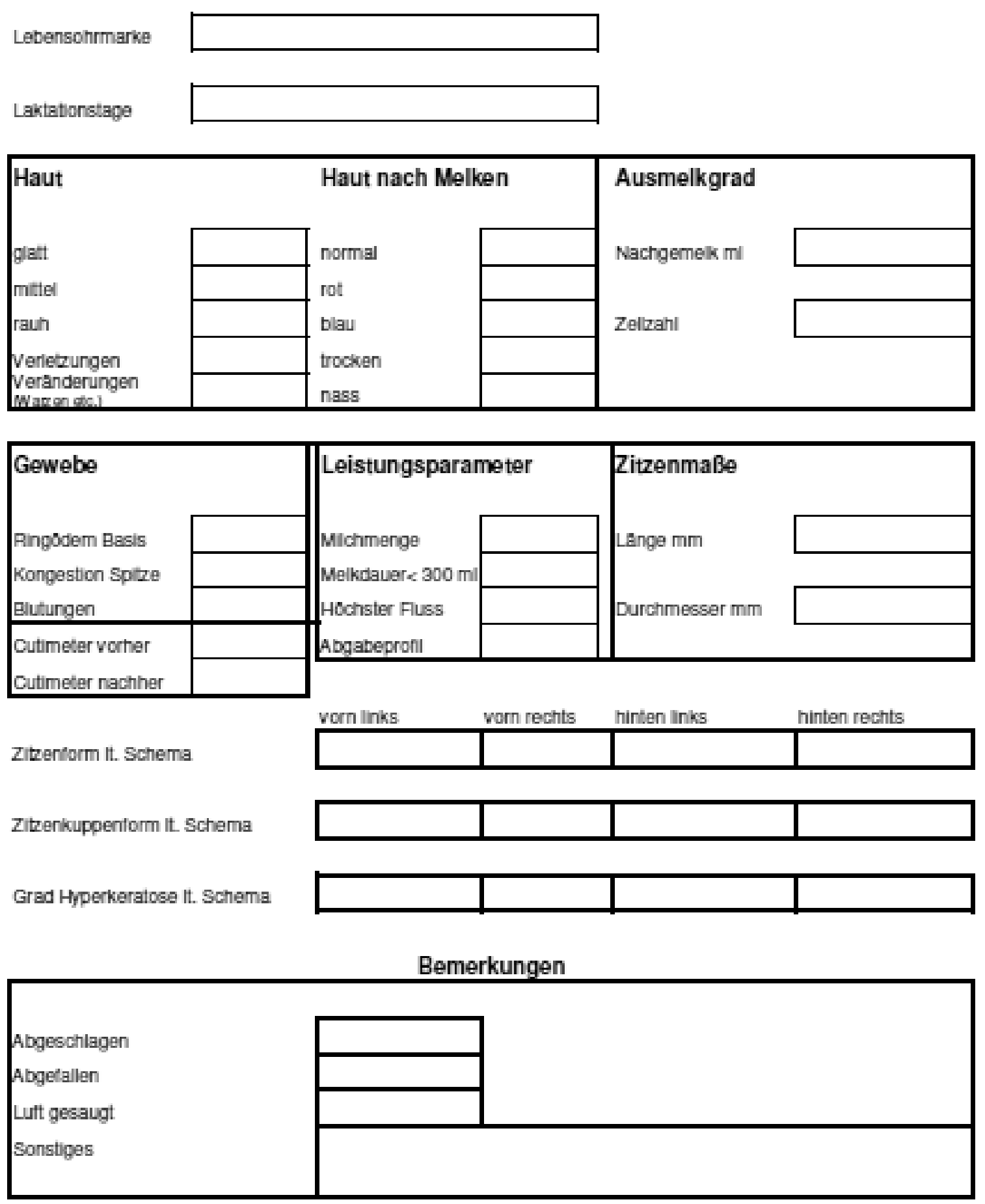


\section{Blatt 3 Bewertungsschemen}

Zitzenformen (schematisch) (GRUNERT 1990)

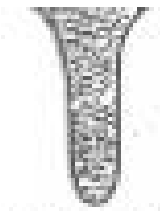

Normale

Form

1

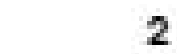

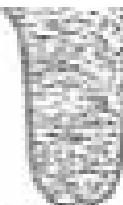

Fleiser Zitze

2

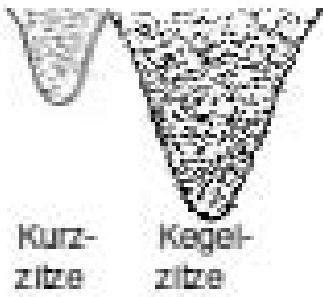

3

4

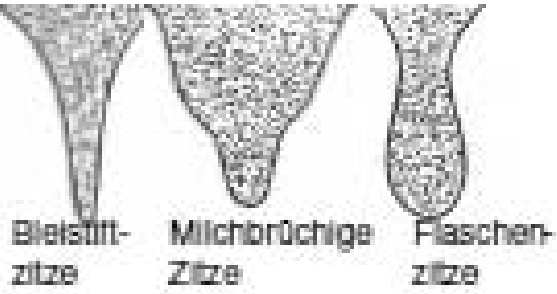

5

6

7

Zitzenkuppenformen (schematisch) (GRUNERT 1990)

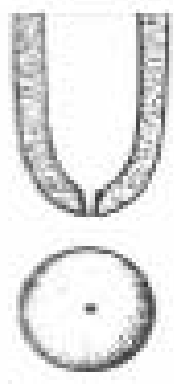

1

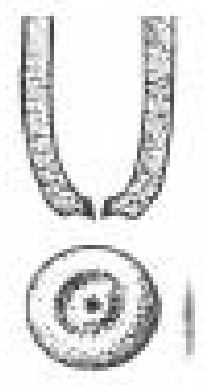

2

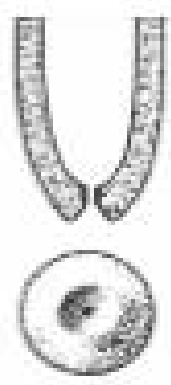

3

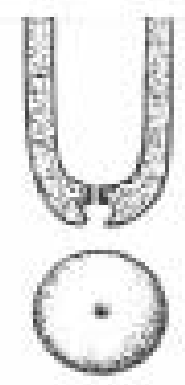

4
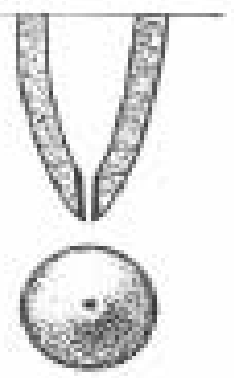

5

Hyperkeratosen

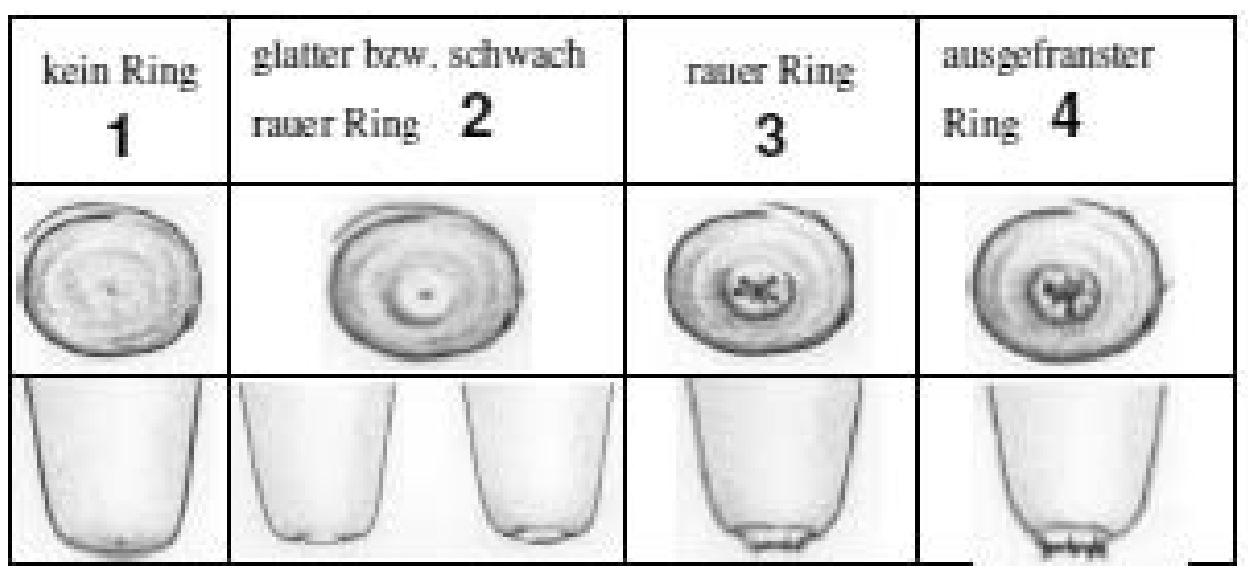




\section{Eidesstattliche Erklärung}

Hiermit erkläre ich an Eides statt, dass ich die vorliegende Arbeit selbständig und ohne Benutzung anderer als der angegebenen Hilfsmittel angefertigt habe. Alle Stellen, die wörtlich oder sinngemäß aus veröffentlichten oder nicht veröffentlichten Schriften entnommen sind, wurden als solche kenntlich gemacht. Die Arbeit hat in gleicher oder ähnlicher Form noch keiner anderen Prüfungsbehörde vorgelegen.

Ort, Datum

Unterschrift

Ich gebe meine Zustimmung, dass die vorliegende Arbeit in der Bibliothek aufgestellt werden kann.

Ort, Datum

Unterschrift 


\section{Danksagung}

An dieser Stelle möchte ich allen danken, die zum Gelingen dieser Arbeit beigetragen haben.

Herrn Prof. Dr. Dr. M. Gauly danke ich herzlich für die Überlassung des Themas und für das mir entgegengebrachte Vertrauen.

Herrn Prof. Dr. D. Ordolff danke ich für die Übernahme des Korreferats und die kritischen Anmerkungen bei der Erstellung dieser Arbeit.

Herrn Prof. Dr. V. Krömker danke ich herzlich für die stetige Bereitschaft zur Diskussion und für die geduldige Hilfe bei der Entwicklung des Studiendesigns sowie für die kritische Durchsicht der Arbeit.

Auch seinen Mitarbeitern Herrn J.-H. Paduch und Frau H. Haverkamp sei gedankt für die kritische Durchsicht der Arbeit.

Ohne das Verständnis und die Unterstützung durch meine Familie wäre die Anfertigung dieser Arbeit nicht möglich gewesen. Dafür Danke ich ihnen von ganzem Herzen. 


\section{Lebenslauf}

\section{Persönliche Daten}

Name, Vorname

Hubal, Michael

Geburtsdatum

24. Dezember 1964

Geburtsort

Bremen

Familienstand

verheiratet, 1 Kind

\section{Schulausbildung}

$1971-1975$

Grundschule Oyten

1975 - 1985

Gymnasium Achim

Abschluss: Allgemeine Hochschulreife

\section{Berufsausbildung}

$1985-1987$

Landwirtschaftliche Berufsausbildung

Osmers \& Osmers GbR, Oyten

J. Wüllmers, Uenzen

Abschluss: Landwirt

\section{Zivildienst}

$1987-1989$

Deutscher Paritätischer Wohlfahrtsverband

\section{Studium}

$1989-1993$

Gesamthochschule Kassel - Universität

Studium der Agrarwissenschaften

Abschluss: Diplom (Dipl. Ing. Agr.)

\section{Beruflicher Werdegang}

$1994-1997$

$1997-2000$

Seit 2001

\author{
Alfa Laval Agrar GmbH \\ Gebietsverkaufsleiter \\ Zuchtrinder Erzeugergemeinschaft Hannover \\ Zuchtinspektor \\ Landwirtschaftskammer Niedersachsen \\ Berater für Melktechnik und Eutergesundheit
}

